\title{
PLANT COMPOUND PEST CONTROL IN CALIFORNIA STRAWBERRY (FRAGARIA X ANANASSA) PRODUCTION
}

\author{
A Thesis \\ presented to \\ the Faculty of California Polytechnic State University, \\ San Luis Obispo
}

\author{
In Partial Fulfillment \\ of the Requirements for the Degree \\ Master of Science in Biology
}

by

Eli Mahanes Weissman

February 2017 
(C) 2017

Eli Mahanes Weissman

ALL RIGHTS RESERVED 
TITLE: Plant Compound Pest Control in California Strawberry (Fragaria x ananassa) Production

AUTHOR: Eli Mahanes Weissman

DATE SUBMITTED: February 2017

COMMITTEE CHAIR: Scott J. Steinmaus, Ph.D.

Professor of Plant Biology

COMMITTEE MEMBER: Kelly L. Ivors, Ph.D.

Associate Professor of Plant Pathology

COMMITTEE MEMBER: $\quad$ Matt Ritter, Ph.D.

Professor of Plant Biology

COMMITTEE MEMBER: Steven A. Fennimore, Ph.D.

University of California Extension Weed Specialist 


\begin{abstract}
Plant Compound Pest Control in California Strawberry (Fragaria x ananassa) Production

Eli Mahanes Weissman
\end{abstract}

Allelopathy occurs when one organism releases a compound into the environment that affects the functioning of another organism. Scientists have long suspected that alleopathic plant compounds could offer novel, softer chemistries to the ongoing battle of controlling pests in agricultural fields. Strawberry growers rely on toxic fumigants to kill soilborne fungal pests, weeds, nematodes, and insects. Increased regulations have reduced the use of fumigants (including methyl bromide), and strawberry growers need new sustainable pest control solutions. We selected four putative allelochemicals with known fungicidal and herbicidal activity (ferulic acid, gallic acid, juglone, and pCoumaric acid). We assessed the pesticidal activity of these plant compounds both in agar and in soil on two emerging soilborne fungal pathogens (Macrophomina phaseolina and Fusarium oxysporum f.sp. fragariae), and four annual weeds commonly found in strawberry production fields (Malva parviflora, Melilotus officinalis, Poa annua, and Senecio vulgaris). We also assayed lettuce (Lactuca sativa 'Inferno'), which served as a positive control plant species due to its sensitivity to phytotoxic compounds. Fitted sigmoidal dose-response curves predicted $\mathrm{EC}_{50}$ and $\mathrm{EC}_{75}$ values for each combination of plant compound and pest.

All plant compounds inhibited the in vitro radial mycelial growth of the two soilborne fungal pathogens in a dose-dependent manner. Fusarium oxysporum f.sp. fragariae was more sensitive to the plant compounds than Macrophomina phaseolina. Average $\mathrm{EC}_{50}$ values for the radial mycelial growth of two $F$. oxysporum f.sp. fragariae isolates were 75.1 parts per million by weight (ppmw) juglone, 469 ppmw p-Coumaric acid, and 687 ppmw ferulic acid. Average $\mathrm{EC}_{50}$ values for the radial mycelial growth of two M. phaseolina isolates were 196 ppmw juglone, 2869 ppmw p-Coumaric acid, and 5716 ppmw ferulic acid. The three compounds we assayed in vitro also reduced $M$. phaseolina colony forming unit counts in soil and the $\mathrm{EC}_{50}$ values were 476 ppmw ferulic acid, 612 ppmw juglone, and 827 ppmw p-Coumaric acid. Metconazole, the conventional fungicide control, did not inhibit $M$. phaseolina colony forming unit counts in soil at its label high rate. The plant compounds required similar or lower rates to inhibit colony forming units that grew from M. phaseolina overwintering structures (microsclerotia) in soil as to inhibit radial mycelial growth in vitro. Based on the $\mathrm{EC}_{50}$ value in soil assays, ferulic acid was the least expensive plant compound to apply on a per acre basis to inhibit $M$. phaseolina $(\$ 74,226)$. In F.oxysporum f.sp. fragariae soil assays, the compounds induced hormesis at lower rates and may be germination stimulant candidates. Metconazole and the high rates of every compound effectively or completely inhibited $F$. oxysporum f.sp. fragariae colony forming units in soil.

The plant compounds were more herbicidal than fungicidal in vitro. When combining the in vitro seedling length results for L. sativa, M. parviflora, P. annua, and $S$. vulgaris the $\mathrm{EC}_{50}$ values differed significantly $(\mathrm{p}<.0001)$ and were: 47 ppmw juglone, 120 ppmw p-Coumaric acid, 189 ppmw ferulic acid, and 297 ppmw gallic acid. At least one rate of ferulic acid, juglone, and p-Coumaric acid inhibited the germination of all 
plant species, while gallic acid only inhibited the germination of $P$. апnиa at $1000 \mathrm{ppmw}$ $(\mathrm{p}<.05)$. In soil, visible microbial contamination in individual wells of 24 -well plates and seed dormancy made it difficult to fit curves to weed seedling length data. The soil assay L. sativa seedling length $\mathrm{EC}_{50}$ values 11 days after initial treatment were slightly higher than in vitro, although plant compounds were in the same order of phytotoxicity: 129 ppmw juglone, 616 ppmw p-Coumaric acid, 644 ppmw ferulic acid, and 1584 ppmw gallic acid. Based on the $\mathrm{EC}_{50}$ value in soil assays, the least expensive compound to inhibit $L$. sativa seedling length on a per acre basis was gallic acid $(\$ 21,676)$.

Germination 26 days after initial soil treatment generally declined in a dose-dependent manner for each compound. There was a direct relationship between plant compound rate and seedling damage in soil with the higher rates of all compounds, except pCoumaric acid, inducing damage comparable to a conventional herbicide (pendimethalin or oxyfluorfen). Contaminated treatments appeared to be due to an interaction between plant compounds and microorganisms because herbicide and water controls had almost no microbial growth 11 days after initial treatment. Further, there was a significant positive linear relationship between level of contamination in phenolic acid-treated wells (ferulic acid, gallic acid, and p-Coumaric acid, $\mathrm{p}<.0001$ ) and the in-soil rate. This relationship was slightly negative in juglone soil treatments $(p=.0167)$, which may be due to its greater antimicrobial activity than the phenolic acids. We propose that herbicidal effects in soil were due to the joint effect of the plant compounds themselves, and the microbial growth in wells. Microbial growth was either antagonistic or additive to the inhibitory action of the plant compounds.

The plant compounds we assayed were inhibitory of emerging fungal pathogens in strawberry production and common annual strawberry field weeds. Evidence presented in this thesis correlates well with past research that not only found plant compounds to be herbicidal and fungicidal, but also described their modes-of-action (such as the production of reactive oxygen species that causes necrotic lesions on roots, and inhibition of glycolytic enzyme activity that prevents germination), and implicate plant compounds as carbon sources for a variety of microorganisms. Compound prices are currently exorbitant, but may decline as demand increases. Whether or not they provide effective pest control may depend on soil texture, organic matter, microbial diversity, and other edaphic factors.

Keywords: Allelopathy, allelochemical, ferulic acid, gallic acid, juglone, Fragaria $\mathrm{x}$ ananassa, Fusarium oxysporum f. sp. fragariae, Macrophomina phaseolina, Malva parviflora, Melilotus officinalis, metconazole, oxyfluorfen, p-Coumaric acid, pendimethalin, Poa annua, Senecio vulgaris, strawberry 


\section{ACKNOWLEDGMENTS}

My deepest gratitude goes out to the numerous undergraduates, family members, and friends who helped me complete this work. Their endless enthusiasm and good listening skills made navigating the challenges of scientific research possible. Specifically, thanks to the more than 40 botany students from Professor James Kelley's Winter 2016 class who helped setup and dismantle the in-soil weed seed assays. Special thanks to Hugo Alvarez, Christian Bejarano, Marlo Compton, Justin Dillard-Telm, Sarah Hepler, and Dawn Mones.

Doctors Frank Dayan, Steven Fennimore, and Dryw Jones all provided invaluable assistance and expertise. Doctor Andrew Schaffner offered crucial statistical consulting. Doctors Matt Ritter and Jenn Yost kindly invited me to their lab meetings, where I received excellent feedback.

I would like to extend my gratitude to the entire Strawberry Center Plant Pathology Lab including Dr. Gerald Holmes (the director of the Strawberry Center). Special thanks goes to graduate students Ryan Bitter, Mel Carter, Scott Cosseboom, and Jonathan Winslow who counseled me-emotionally and intellectually - and volunteered time during various components of my thesis. My deepest appreciation goes to Dr. Kelly Ivors who supported me financially, welcomed me into her lab, and helped me to become a scientist.

Most importantly, I would like to thank my advisor, Dr. Scott Steinmaus, whose willingness to take me on was the start of a great adventure, whose patience and suggestions helped me to learn and grow as a scientist and a person, and who introduced me to the wonderful world of weed science. I am happily forever indebted. Thank you.

And finally, thanks to the Baker/Koob Endowment, California Weed Science Society, and Cal Poly Graduate Education for financial support, and my parents, Laura Mahanes and Steve Weissman whose guidance, encouragement, and love have always provided me the strength to finish what I start. 


\section{TABLE OF CONTENTS}

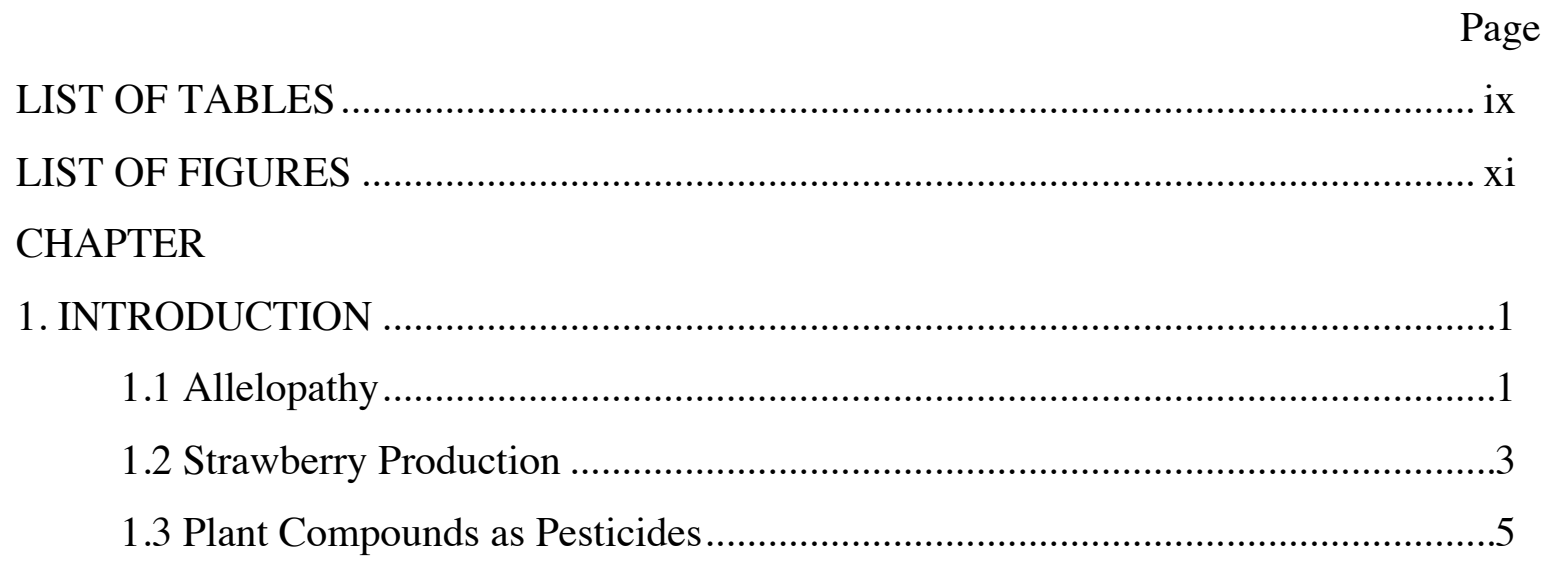

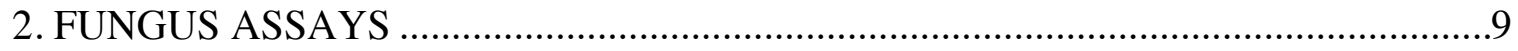

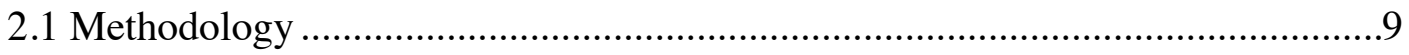

2.1.1 In Vitro Assays ................................................................................

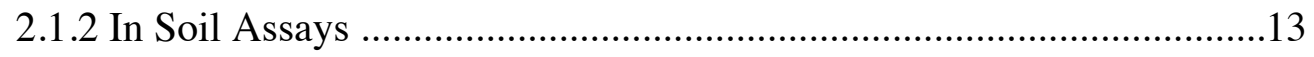

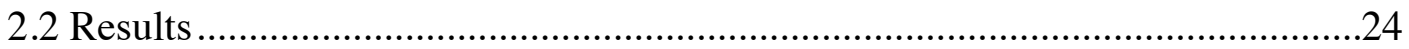

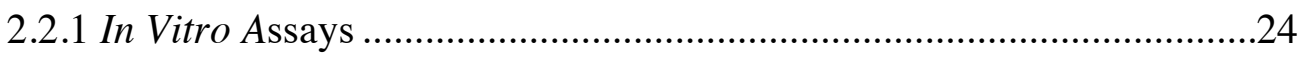

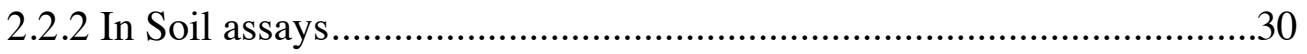

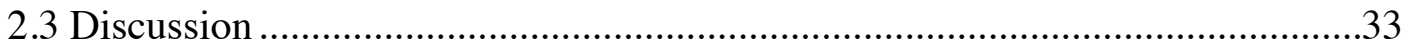

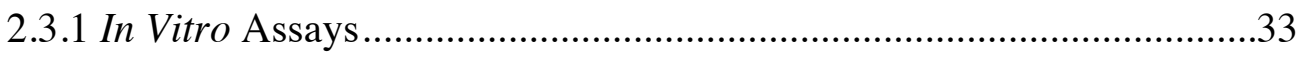

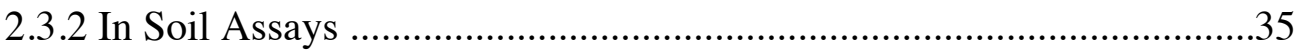

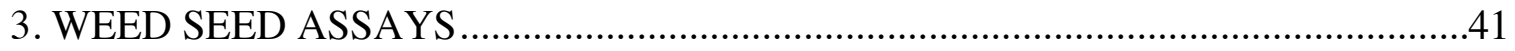

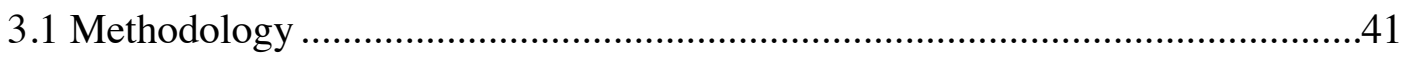

3.1.1 In Vitro Assays .................................................................................41

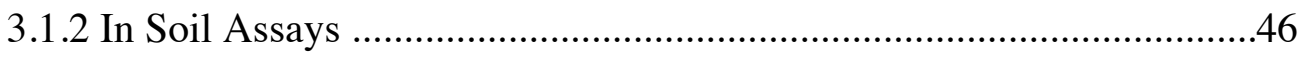

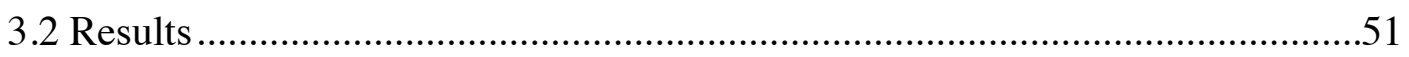

3.2.1 In Vitro Assays....................................................................................51

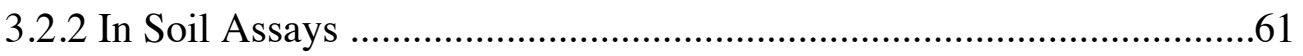

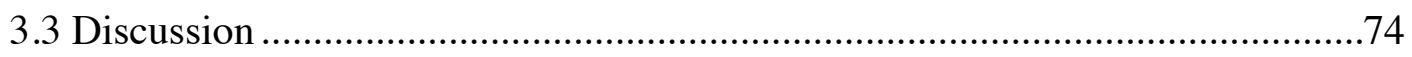

3.3.1 In Vitro Assays .................................................................................

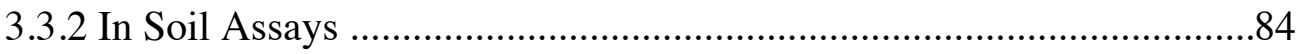

4. PLANT COMPOUNDS IN STRAWBERRY PRODUCTION …………………….....91 


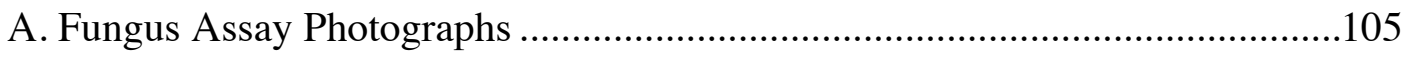

A.1 In Vitro Fungus Assays .................................................................105

A.2 In Soil Fungus Assays .....................................................................107

B. Macrophomina phaseolina Andersen Cascade Impactor Pilot Study ..............109

C. Strawberry Farm Locations and Weed Species Collected ...............................110

D. Seed Surface Sterilization Study .................................................................111

E. Weed Seed Assay Photographs .................................................................114

E.1 In Vitro Weed Seed Assays ..............................................................114

E.2 In Soil Weed Seed Assays ................................................................117

F. In Soil 11 Day Seedling Length Results for All Plant Species........................121

G. Description of Nonlinear Regression Parameters ........................................122 


\section{LIST OF TABLES}

Table

Page

2.1. Regression adjusted $\mathrm{R}^{2}$ values, hillslope parameters, and mean $\mathrm{EC}_{50}$ and $\mathrm{EC}_{75}$ values (parts per million by weight) for fungi growing in media amended with ferulic acid, juglone, or p-Coumaric acid

2.2. Cost (USD)/liter based on the averaged mean $\mathrm{EC}_{50}$ or $\mathrm{EC}_{75}$ values (parts per million by weight) of Macrophomina phaseolina 8 and 13 isolates, and current compound prices .

2.3. Cost (USD)/liter based on the averaged mean $\mathrm{EC}_{50}$ or $\mathrm{EC}_{75}$ values (parts per million by weight) of Fusarium oxysporum f.sp. fragariae 10.3 and 19 isolates, and current compound prices

2.4b. Plant compound per acre application rates (Kg/acre) and costs (USD) per acre to control Macrophomina phaseolina in soil

3.1. Generalized linear model (binomial distribution and logit function)

results for in vitro weed seed assays (probability of germination)

3.2. One-factor analysis of variance comparing the effect of treatments on seedling length

3.3. Hillslope, adjusted $\mathrm{R}^{2}$, and $\mathrm{EC}_{50}$ and $\mathrm{EC}_{75}$ values (parts per million by weight) when combining seedling length data from Lactuca sativa, Malva parviflora, Poa annua, and Senecio vulgaris

3.4. Regression adjusted $\mathrm{R}^{2}$, Hillslope, $\mathrm{EC}_{50}$, and $\mathrm{EC}_{75}$ values (parts per million by weight) for lettuce and weeds seeds growing on water agar amended with ferulic acid, gallic acid, juglone, or p-Coumaric acid.

3.5. Concentrations (parts per million by weight ( $\mathrm{ppmw})$ ) for each plant compound

3.6. Generalized linear model (binomial distribution and logit function) for the probability of germination in soil 26 days after initial treatment

3.7. Generalized linear model (binomial distribution and logit link function) main effect $\mathrm{p}$-values for the damage rating in wells 11 days after initial treatment .66 
3.8. Analysis of variance (response variable: seedling length) for Lactuca sativa 'Inferno', Malva parviflora, Poa annua, or Senecio vulgaris growing in soil amended with plant compounds

3.9. Regression hillslope, adjusted $\mathrm{R}^{2}$, and $\mathrm{EC}_{50}$ and $\mathrm{EC}_{75}$ values (parts per million by weight), application rate (Kg/acre), and cost (USD) for Lactuca sativa 'Inferno' growing in soil amended with ferulic acid, gallic acid, juglone, or p-Coumaric acid

3.10a. Regression hillslope, and $\mathrm{EC}_{50}$ and $\mathrm{EC}_{75}$ values (parts per million by weight) for several weed species (Malva parviflora, Poa annua, and Senecio vulgaris) growing in soil amended with ferulic acid, gallic acid, juglone, or p-Coumaric acid

3.10b. Plant compound application rates (Kg/acre) and costs (USD) to control weeds in strawberry field soil 


\section{LIST OF FIGURES}

Figure

Page

2.1. The effect of increasing plant compound concentrations $(10,100,500$, and 1000 parts per million by weight (ppmw)) on radial mycelial growth of Macropohomina phaseolina 8 (A), M. phaseolina 13 (B), Fusarium oxysporum f.sp. fragariae 10.3 (C), and F. oxysporum f.sp. fragariae 19 (D) in vitro.

2.2. The effect of increasing plant compound concentrations in soil on colony forming unit (CFU) counts of Macrophomina phaseolina plated with an Andersen Cascade Impactor on RB selective media

2.3. The effect of increasing plant compound concentrations in soil on colony forming unit (CFU) counts of Fusarium oxysporum $\mathrm{f}$. sp. fragariae plated directly on Komada selective media

3.1. The effect of increasing plant compound concentrations $(10,100,500$, and 1000 parts per million by weight (ppmw)) on the probability of Lactuca sativa 'Inferno' germination in vitro

3.2. The effect of increasing plant compound concentrations $(10,100$, 500 , and 1000 parts per million by weight (ppmw)) on the probability of Malva parviflora germination in vitro

3.3. The effect of increasing plant compound concentrations $(10,100$, 500 , and 1000 parts per million by weight (ppmw)) on the probability of Poa annua germination in vitro

3.4. The effect of increasing plant compound concentrations $(10,100$, 500 , and 1000 parts per million by weight (ppmw)) on the probability of Senecio vulgaris germination in vitro

3.5. The effect of increasing plant compound concentrations $(10,100$, 500 , and 1000 parts per million by weight (ppmw)) on the seedling length of Lactuca sativa, Malva parviflora, Poa annua, and Senecio vulgaris when combined .....58

3.6. The effect of increasing plant compound concentrations $(10,100,500$, and 1000 parts per million by weight (ppmw)) in vitro on the seedling length of Lactuca sativa 'Inferno' (A), Malva parviflora (B), Poa annua (C), and Senecio vulgaris (D)....60

3.7. Probability of Lactuca sativa 'Inferno' germination 11 days (A) and 26 days (B) after initial treatment 
3.8. Probability of Malva parviflora (A) and Melilotus officinalis (B) germination 26 days after initial treatment

3.9. Probability of Poa annua (A) and Senecio vulgaris (B) germination 26 days after initial treatment

3.10. Mean seedling damage rating for all plant species combined (Lactuca sativa 'Inferno', Malva parviflora, Melilotus officinalis, Poa annua, and Senecio vulgaris) in plant compound treated soil

3.11. Mean contamination rating for all plant species combined

(Lactuca sativa 'Inferno', Malva parviflora, Melilotus officinalis, Poa апnиa, and Senecio vulgaris) in plant compound treated soil

3.12. Lactuca sativa 'Inferno' seedling length 11 days after initial soil treatment in response to increasing rates of plant compounds

3.13. Seedling length 11 days after initial treatment of several weeds growing in plant compound treated soil in response to increasing rates of plant compounds (parts per million by weight (ppmw)) 


\section{INTRODUCTION}

\section{CHAPTER 1.}

\subsection{Allelopathy}

Over 2000 years ago, Theophrastus, Aristotle's disciple, described a mysterious phenomenon in which a plant releases a substance that affects neighboring plants. Early botanists, from medieval times and through the $19^{\text {th }}$ century, continued to observe that some plants were "mutually repulsive", noting the "antipathy" between cabbage and grape vines, and the "injurious" nature of the walnut tree (Willis, 2007). It was not until 1937 that Hans Molisch named this process “allelopathy” (Rice, 1984). Others expanded upon the original plant-centric definition, and allelopathy now describes any compound produced by a plant or microorganism that positively or negatively affects another plant or microorganism. These compounds, known as "allelochemicals", influence a target species' ability to grow, reproduce, or survive. Allelochemicals are usually secondary metabolites, products of metabolism not involved in the normal functioning of an organism (Heisey, 1990). They take the chemical form of phenolics, quinones, terpenoids, flavonoids, and N-containing compounds (Bandeira et al., 2011). Plant allelochemicals are released via root exudation, volatilization, plant residue decay, and rainwater mediated leaching (Bandeira et al., 2011).

The subject of allelopathy is controversial because of the difficulty in proving that allelopathic effects occur in complex natural systems. Putnam (1985) suggested using a Koch's postulates-like approach: observe and describe the suspected allelopathic interference, isolate the toxic compound(s) from suspected allelopathic plants, run assays at field-relevant rates, describe symptoms, and show that toxic levels of compound(s) move from a donor to a target plant. As Blum (2014) describes, due to numerous biotic 
and abiotic factors that affect the toxicity of plant compounds, even these extensive efforts may not prove that a single plant or compound that the plant produces is allelopathic in a given ecosystem. The complexity of soil ecosystems is astounding. Mendes et al. (2011), through 16S rDNA sequencing, found 33000 unique bacterial and archael species in the rhizosphere of sugar beets (Beta vulgaris L.). Each bacterial species can potentially produce thousands of secondary metabolites (Raaijmakers and Mazzola, 2012) that interact antagonistically, additively, or synergistically. Blum (1996) found that mixtures of phenolic compounds, which are ubiquitous in plants and major components of decaying plant material, additively produce herbicidal effects. Dayan (2002) showed that benzoquinones and naphthoquinones, (e.g. the suspected allelochemicals juglone, sorgoleone, lawsone, and plumbagin) are more soluble in soils with greater alkalinity. Fisher (1978) showed that juglone toxicity persists in soils with higher water content. Soil texture, organic matter, competitive sorption between secondary metabolites at negatively charged exchange sites, UV light, and the presence of arbuscular mycorrhizae can also reduce, enhance, or have no effect at all on the toxicity of plant compounds (Putnam, 1985; Dalton et al., 1989; Tharayil et al., 2006; Duhamel et al., 2013; Achatz et al., 2014). Currently there is no model complex enough to predict how one compound or several compounds might function within a given environment to promote or inhibit the success of another organism. Even so, the inability to prove allelopathy, does not preclude our ability to exploit suspected allelochemicals in cropping systems.

Researchers long suspected that plant compounds could make effective agricultural pesticides (Weston, 1996; Vyvyan, 2002; Heisey and Heisey, 2003; Macias et al., 2007; Shrestha, 2009; Ferreira and Reinhardt, 2010; Bandeira et al., 2011). Plant 
compounds may have fewer negative environmental impacts than many traditional pesticides (Macias, 1995; Céspedes et al., 2014), and so may be especially valuable synthetic pesticide replacements in agricultural systems - such as conventional strawberry production - that face intense pest pressures, and rely on especially toxic compounds to control pests.

\subsection{Strawberry Production}

In the 1960s, strawberry (Fragaria x ananassa Duchesne ex Rozier) growers began applying two soil fumigants, methyl bromide and chloropicrin, to control insects, nematodes, weeds, and fungal pathogens. Fumigants are highly mobile, volatile pesticides typically injected below polyethylene tarps. Combining methyl bromide and chloropicrin fumigants provided excellent soilborne pest control, and helped increase yields six-fold from about 10,000 to 60,000 pounds per acre (CropLife Foundation, 2011). In 2012, strawberries were the fourth-highest pesticide-demanding crop in California with 12 million pounds of pesticides applied to strawberry fields (California Department of Pesticide Regulation, 2012). This same year, pesticide use in strawberry production made up $6.7 \%$ of all non-ranching agricultural pesticide applications, yet accounted for just $0.5 \%$ of cropland in California (California Department of Pesticide Regulation, 2013; Johnson and Cody, 2015; United States Department of Agriculture, 2015).

Strawberry growers that do not fumigate and replant their fields each year will face a sharp decline in profit (Bolda et al., 2011). This decline is largely the result of pest pressures. Due to frequent pesticide applications, growing strawberries contributes 
heavily to externalities associated with pesticide use in the United States, such as destruction of beneficial organisms, chemical resistance, and human poisonings (Pimentel, 2005).

Wofsy et al. (1975) predicted in a worst-case scenario that there would be a 10\% reduction in stratospheric ozone before the year 2000 unless anthropogenic methyl bromide contributions declined. In 1987, the Montreal Protocol mandated the phase-out of methyl bromide from agriculture by 2005 (Ozone, 2017). Strawberry growers successfully obtained exemptions allowing the limited use of methyl bromide to control the numerous pests invading their fields. However, grower exemptions, except for transplant production, ceased at the end of 2016 (G. Holmes, personal communication). Negative publicity encouraged regulations that have reduced or eliminated the use of other fumigants as well (e.g. chloropicrin, metam sodium, methyl iodide, and 1,3Dichloropropene). The decline in fumigation has coincided with the emergence of new strawberry pests, increasing the need for innovative methods of pest control.

The most threatening of these emerging pests to strawberry yields are two soilborne fungal diseases, charcoal rot (caused by Macrophomina phaseolina (Tassi) Goid), hereon referred to as $M p$ ) and fusarium wilt (caused by Fusarium oxysporum f. sp. fragariae Winks \& Williams, hereon referred to as Fof). California strawberry growers first observed symptoms and signs of $M p$ in 2005 and Fof in 2006 (Koike, 2008; Koike, 2009). Growers using alternative fumigants to methyl bromide tended to have greater $M p$ and Fof problems (Koike, 2008). The two soilborne pathogens cause identical symptoms: wilting of strawberry plant foliage, necrotic vascular tissue, plant death, and reductions in strawberry fruit yields (Koike, 2008; Koike, 2009; Koike, 2013). During mycelial 
growth, each pathogen rapidly produces new over-wintering structures that can survive decades in the soil and then germinate to infect strawberry plants in future growing seasons ( $M p$ produces microsclerotia, and Fof produces chlamydospores).

Weed control is important in strawberry production due to the strawberry plant's lack of competitive ability associated with its shallow root system (Strand, 2008). Annual strawberry weed species such as little mallow (Malva parviflora L.), yellow sweet clover (Mellilotus officinalis (L.) Pall), annual bluegrass (Poa annua L.), and common groundsel (Senecio vulgaris L.) may increase in abundance with less fumigation. Even in fumigated fields, weeds grow below the polyethylene mulch commonly used in strawberry production and threaten yields if left unmanaged (Radosevich, 2007). This is especially true in organic production, and when conventional growers rely on translucent polyethylene mulch (Strand, 2008). Fumigants generally do not kill the hardened seed of M. officinalis and M. parviflora deep in the soil profile, and so they remain prominent members of strawberry field seedbanks. While fumigants often kill P. annua and $S$. vulgaris seeds, during the growing season these ruderal species invade from neighboring ecosystems.

\subsection{Plant Compounds as Pesticides}

We identified four plant compounds likely to inhibit growth of the two fungal pathogens and the four weed species previously mentioned. Plants in the Juglandaceae family produce hydrojuglone- $\beta$-D-glucopyranoside, a naphthoquinone, and store this conjugated juglone precursor in plant cell vacuoles. Hydrojuglone- $\beta$-D-glucopyranoside decomposes enzymatically to juglone (Duroux et al., 1998). Babula et al. (2009), 
assaying tobacco BY-2 cells, found that juglone affects multiple cellular processes by generating reactive oxygen species, disrupting the mitochondrial electron transport chain and photosynthetic pathways, and promoting programmed cell death. Bingwu et al. (2007) inhibited the mycelial growth of Fusarium oxysporum f. sp. niveum (E.F. Sm.) W.C. Snyder \& H.N. Hans) (the causal agent of fusarium wilt of watermelon) when testing both juglone and its derivative, 5,8-dihydroxy-1,4-naphthoquinone. Other researchers have also found juglone to be fungicidal (Clark et al., 1990; Curreli et al., 2001). Rietveld (1983) inhibited germination rate, radicle elongation, shoot elongation, and dry weight, of several herbaceous and woody plant species in juglone concentrations as low as 0.174 parts per million (ppm).

Phenolic acid plant compounds suspected of being allelopathic fall under two categories: hydroxycinnamic acids, and hydroxybenzoic acids (Heleno et al., 2015). Hydroxycinnamic acids appear to be more reactive in soils and phytotoxic than benzoic acids (Dalton et al., 1989). Ferulic acid and p-Coumaric acid are components of lignin in plant cell walls (Lam et al., 2001). The shikimic acid pathway produces ferulic and pCoumaric acids, both hydroxycinnamic acids, from the amino acids phenylalanine and tyrosine. Their modes of action include a reduction in hydraulic conductivity and net nutrient uptake in plant roots (Putnam, 1985; Blum, 1996), and glycolytic enzyme activity in seeds (Muscolo et al., 2001). All plants produce ferulic acid and p-Coumaric acid (Duke and Lydon, 1987), but some to a greater extent than others, notably: Eucalyptus spp., Brassicaceae family plants, Capsicum annum L., Celtis laevigata Willdenow, and Asparagus officinalis L. (Turner and Rice, 1975; Wacker et al., 1990; Reigosa et al., 1999; Chapuis-Lardy et al., 2002; Al-Sherif et al., 2013). Both ferulic acid 
and p-Coumaric acid reduce seed germination, seedling growth, leaf expansion, and mycelial growth in vitro (Chou and Patrick, 1976; Blum, 1996; Reigosa et al., 1999; McKeehen, 1999; Sarma and Singh, 2003; Golisz et al., 2007).

Gallic acid is a hydroxybenzoic acid and the water-soluble phenolic found in the highest quantities in Eucalyptus spp. hybrid leaf litter (Chapuis-Lardy et al., 2002). Many other plants produce gallic acid, including Calceolaria integrifolia s.1., Phragmites australis (Cav.) Trin. Ex Steudel, Fagopyrum esculentum, and Lawsonia inermis L. (Céspedes et al., 2014; Iqbal et al., 2003; Dhaouadi et al., 2015). Gallic acid and other phenolic acids generate reactive oxygen species possibly through oxidation to form a quinone, subsequent production of a semiquinone, reduction of oxygen by the semiquinone to a superoxide anion, superoxide dismutation to form hydrogen peroxide, and a final reaction that produces macromolecule-damaging hydroxyl radicals (Golisz et al., 2008; Rudrappa et al., 2007; Weir et al., 2004). Polyphenolic compounds can also produce phenoxyl radicals that result in the production of superoxide anions and hydrogen peroxide (Galati et al., 2002). Iqbal et al. (2003) found that gallic acid inhibited the root and shoot elongation of several plant species by $50 \%$ at concentrations ranging from 4 to 100 ppm. Céspedes et al. (2014) showed that gallic acid has fungicidal activity against plant pathogens, including two Fusarium species.

No study, to our knowledge, has specifically investigated the control of strawberry pests with plant-produced compounds. This thesis research determined if four putative allelochemicals (ferulic acid, gallic acid, juglone, and p-Coumaric acid) are able to inhibit the growth of common strawberry pests. We hypothesized that these plant compounds would inhibit the growth of two soilborne fungal pathogens, $M p$ and $F o f$, as 
well as four weed species, M. parviflora, M. officinalis, P. annua, and S. vulgaris. Assays in both plant compound-amended agar and in soil tested this hypothesis. Very few researchers have ever performed assays with these specific plant compounds in soil, and no reserach, to our knowledge, has assayed the compounds with these specific strawberry field pests. Successful inhibition of the growth of pathogenic fungi and weed species at an environmentally safe and economical rate would make plant compounds potential fumigant replacements in strawberry production. 


\section{CHAPTER 2.}

\section{FUNGUS ASSAYS}

\subsection{Methodology}

\subsubsection{In Vitro Assays}

Isolate Preparation - From April to August of 2014, we collected wilting strawberry (Fragaria x ananassa Duchesne ex Rozier) plants with necrotic leaves (both are symptoms of soilborne pathogen infection) from California production fields. To isolate Macrophomina phaseolina (Mp) and Fusarium oxysporum f. sp. fragariae (Fof), we surface sterilized small sections of necrotic strawberry crown vascular tissue. We then placed four of these sections in Petri plates with full-strength potato dextrose agar (PDA). Several days later, we identified $M p$ and Fof growing from some of the strawberry crown sections and - to produce a pure culture of $M p$ or Fof-transferred the mycelium to the center of a fresh Petri plate with PDA. After growing the pure culture, we used a cork borer to make plugs of the isolates and stored the plugs in glycerol-filled cryotubes at $70^{\circ} \mathrm{C}$.

We selected four study isolates for the plant compound assays: $M p 8$ (Irvine, CA, Fragaria x ananassa 'San Andreas' from a conventional field), Mp13 (Oxnard, CA, Fragaria x ananassa '1975' from an organic field), Fof10.3 (Guadalupe, CA, unknown cultivar, from a conventional field), and Fof19 (Watsonville, CA, Fragaria x ananassa ‘Albion' from a rice bran field trial). Using a sterile probe, we transferred stored-plugs in cryotubes to half-strength potato dextrose agar ( $1 / 2$ PDA) to produce actively growing mycelium. After allowing seven days for Fof to grow, and four days for $M P$, we transferred plugs from the unamended $1 / 2$ PDA plates to plant compound amended $1 / 2$ PDA plates. The transfer dates differed because $M p$ grows more quickly than Fof. 
Experimental Treatments - We prepared three plant compounds, ferulic acid (Alfa Aesar, USA), juglone (Alfa Aesar, USA), and p-Coumaric acid (MP Biomedicals, USA) at $10,100,500$, and 1000 parts per million by weight (ppmw). Past research demonstrated that these three plant compounds are fungicidal or fungistatic (Bingwu et al., 2007; Clark et al., 1990; Curreli et al., 2001; McKeehen et al., 1999; Sarma and Singh, 2003; Céspedes et al., 2014). Metconazole (Quash ${ }^{\mathrm{TM}}$ ), provided by Valent ${ }^{\circledR}$ (USA), served as a fungicide control.

We autoclaved $1 / 2$ PDA in a 2 liter Erlenmyer flask to $121^{\circ} \mathrm{C}$ and cooled the $1 / 2$ PDA in a $55^{\circ} \mathrm{C}$ water bath. We dissolved the technical grade (99\%+ purity) plant compounds and metconazole in dimethyl sulfoxide (DMSO). The volume of DMSO solvent varied from 0.9 to $1.3 \mathrm{~mL}$ depending on the mass of the treatment compound. We added plant compounds to DMSO in powdered form, at quantities sufficient to produce $100 \mathrm{ppmw}$ solutions in molten media, and then aliquoted this solution to produce the 10 ppm concentrations. We placed the larger masses of plant compounds necessary to produce 500 and 1000 ppmw concentrations in $25 \mathrm{~mL}$ beakers. We then added DMSO and used a magnetic stirrer and stir plate to dissolve the compounds before transferring these solutions to microcentrifuge tubes. We vortexed all treatments, completely dissolving the plant compounds in DMSO. We prepared $1 / 2$ PDA plates with metconazole at 5 ppmw, the rate which Carter (2016) found strongly inhibited $M p$ and Fof radial mycelial growth in vitro. We also prepared a $1 / 2$ PDA water control containing only DMSO.

After vortexing the DMSO/treatment compound solutions in microcentrifuge tubes, we pushed each solution through a $0.22 \mu \mathrm{m}$ Millipore filter (Nalgene, Rochester, 
NY, USA), attached to a $1 \mathrm{~mL}, 3 \mathrm{~mL}$, or $5 \mathrm{~mL}$ syringe (BD, Franklin Lakes, NJ, USA) depending on the volume of the treatment compound/DMSO solution, and into molten $1 / 2$ PDA (at approximately $55^{\circ} \mathrm{C}$ ). A magnetic stirrer mixed the treatment compounds with the $1 / 2$ PDA. Juglone formed a flaky precipitate when we added the 500 and $1000 \mathrm{ppmw}$ juglone/DMSO solutions to molten $1 / 2$ PDA. To dissolve the precipitate, we heated the $1 / 2$ PDA 500 and $1000 \mathrm{ppmw}$ juglone solutions to approximately $90^{\circ} \mathrm{C}$ while stirring with a magnetic stirrer for approximately one hour. Although Hejl et al. (1993) did not see a reduction in juglone bioassay activity after autoclaving, Vogel and Dawson (1985) noted that $10^{-4}$ and $10^{-5} \mathrm{M}$ concentrations of autoclaved juglone were "somewhat" less toxic than filter sterilized juglone. And so, our results may slightly underestimate juglone toxicity. We poured compound treatments and controls into 110 x $15 \mathrm{~mm}$ Petri plates (Thermo Fisher Scientific Inc. ${ }^{\oplus}$, Franklin, MA, USA) and allowed the solutions to solidify and cool overnight. Plates remained in a dark refrigerator at approximately $7^{\circ} \mathrm{C}$ until needed.

We center-inoculated treatment and control plates with $2 \mathrm{~mm}$ mycelial-plugs sourced from the unamended plates with actively growing mycelium. To reduce contamination and maintain moisture, we wrapped the plates in parafilm. We replicated each of the following treatments and controls four times: ferulic acid, p-Coumaric acid, and juglone solutions at 10,100,500, and $1000 \mathrm{ppmw}$, metconazole at $5 \mathrm{ppmw}$, and the water control with DMSO-only. Gallic acid was a late edition to this thesis work and we did not include it as a part of the in vitro or in soil fungus assays. Center-inoculated Petri plates were stored in the dark at roughly $21^{\circ} \mathrm{C}$. We repeated both $M p$ and Fof in vitro assay experiments. 
Data Collection and Analysis - In Petri plates, mycelium grows in a roughly circular manner with hyphae spreading outward from the center-inoculated plug. To record radial mycelial growth, we drew circular tracings of the radial mycelial growth front (score lines) every one to two days on the bottom of $M p$ plates, and every two to three days on the bottom of Fof plates. We continued scoring until individual plates were full. Data collection ceased after 45 days for Fof 10.3 , and 100 days for Fof 19 . Except for pCoumaric acid at $1000 \mathrm{ppmw}$ and metconazole, all treatment plates were full by these days.

Along a ruler-drawn diameter line (eighty-six millimeters in length) on the bottom of each plate, we measured and recorded the distance between scores. To calculate the radial mycelial growth rate (in $\mathrm{mm} /$ day), we divided the diameter length, from one side of the outside-most score to the other, by the number of days the mycelial front took to reach that outside score.

To determine if there were significant differences between radial mycelial growth in plant compound treatment plates and the water or fungicide controls at $5 \%$ overall significance, we performed a one-factor ANOVA and Dunnet's post-hoc tests for each pathogen ( $\alpha=.025$ to lower the type I error rate due to multiple Dunnet's tests) (JMP Pro 12.1.0, SAS Institute, Carey, NC, www.jmp.com). We transformed the data and removed outliers, when appropriate, to satisfy normality and equal variance assumptions.

To model the dose-response relationship between $\mathrm{mm} /$ day radial mycelial growth and plant compound concentration, we fit logistic or Gompertz curves to each compound (GraphPad Prism 7.0a, La Jolla, CA, www.graphpad.com). When necessary, we performed a weighted sum of squares analysis to satisfy model assumptions. The best 
curve fit satisfied both normality (D'Agostino \& Pearson Omnibus K2, Shapiro-Wilk, or Kolmogorov-Smirnov distance tests) and homoscedasticity assumptions, while having low parameter dependency, and the lowest AICc value among fits. We did not share parameters between compound functions because their dose-response relationships differed.

\subsubsection{In Soil Assays}

Soil - We collected soil from Rutiz Family Farms (Arroyo Grande, CA, 35.105290, 120.599102) on the $23^{\text {rd }}$ of November (2015). The soil is a mixed, thermic Alfic Xerosamments and the soil series is Oceano sand with 95\% sand, 4-7\% clay, and the remainder of the size class 0.002 to $0.1 \mathrm{~mm}$ (www.nrcs.usda.gov). In past years, farmers grew conventional strawberries at this location, applying methyl bromide and other fumigants. Since purchasing the land 13 years ago, the Rutiz Family has grown organic row crops (not certified), fertilizing with fish emulsion and chicken manure.

The Rutiz Family Farm soil we assayed to test the in soil response of strawberry pests to plant compounds was a loamy sand (1.9\% clay, $21.5 \%$ silt, $76.6 \%$ sand) with $1.7 \%$ organic matter, a $\mathrm{pH}$ of 7.2 , an ECe of $1.1 \mathrm{ds} / \mathrm{m}$, a CEC of $5.4 \mathrm{meq} / 100$ grams, and an N-P-K ratio of 53-380-240 (Soil Control Lab, Watsonville, CA, www.compostlab.com). These values correspond to other strawberry production field soils, which are typically low in organic matter, sandy, have electrical conductivity values around $1.5 \mathrm{ds} / \mathrm{m}$, and a $\mathrm{pH}$ between 5.5 and 6.5 or slightly above neutral (Haifa, 2016). The low cation exchange capacity of sandy soil with little organic matter allows plant compounds to remain free in the soil solution for longer than a soil with greater clay and organic matter content (Dalton et al., 1989; Tharayil et al., 2006). The soil's bulk 
density was $1.54( \pm 0.059) \mathrm{g} / \mathrm{cm}^{3}$, and the $24 \mathrm{hr}$ gravimetric water holding capacity was $0.35( \pm 0.011) \mathrm{g} / \mathrm{cm}^{3}$. Prior to assaying the fungal pathogens, we oven-dried the soil at $105^{\circ} \mathrm{C}$ for $24 \mathrm{hrs}$, sieved to breakup clods, and added soil to separate treatment beakers.

Macrophomina phaseolina Inoculum Production - We center inoculated cryogenically stored $M p 8$ and $M p 13$ (the same isolates we assayed in vitro) isolate plugs ( $2 \mathrm{~mm}$ ) on full strength PDA. After allowing $M p$ mycelium to grow for approximately one week, we transferred new plugs $(2 \mathrm{~mm})$ from these cultures to an autoclaved cornmeal-sand substrate. The cornmeal-sand substrate had a volumetric ratio of 2.75:1:1 of sand:cornmeal:deionized water (Singleton et al., 1992).

To allow for good airflow during incubation, we placed small quantities of cornmeal-sand substrate (approximately $125 \mathrm{~mL}$ ) in separate $250 \mathrm{~mL}$ Nalgene ${ }^{\circledR}$ autoclavable containers. We autoclaved the white aquarium sand (Petco®), San Diego, CA, USA), cornmeal, deionized water mix twice for one hour, and loosened the mix between autoclavings. Under a laminar flow hood, we added the $2 \mathrm{~mm}$ plugs aseptically at a ratio of $1 \mathrm{Mp}$ plug per 12.5 to $20 \mathrm{~mL}$ of cornmeal-sand substrate.

After placing the containers in an incubator at $30^{\circ} \mathrm{C}$, we loosened the caps partway to maintain aerobic conditions. Each day during the seven-day incubation, we shook the containers vigorously to breakup clods. When $M p$ microsclerotia darkened the cornmeal-sand substrate, and $M p$ metabolized the majority of the cornmeal, we removed the containers from the incubator and spread the inoculum on trays to dry. After a fiveday drying period, we ground the inoculum through a coarse sieve using a large pestle (Thermo Fisher Scientific Inc. ${ }^{\circledR}$, Franklin, MA, USA). We mixed the two isolates $(M p 8$ 
and 13), and stored the inoculum at approximately $22^{\circ} \mathrm{C}$ in $2 \mathrm{~L}$ mason jars. To allow for airflow during storage, we inverted the inside of the mason jar lids.

Fusarium oxysporum $f$. sp. fragariae Inoculum Production - We prepared Fof assay soil in an identical manner to the $M p$ assay soil. To prepare mycelium cultures for Fof inoculum, we first center inoculated cryogenically stored $\left(-70^{\circ}\right.$ C) Fof 19 and Fof 10.3 isolate plugs ( $2 \mathrm{~mm}$ ) (the same isolates assayed in vitro) on full-strength PDA. We allowed Fof mycelium to grow for three and a half weeks, flooded one of the plates grown from cryo-storage with sterile deionized water, aliquoted $250 \mu$ onto 20 new fullstrength PDA plates per isolate, and spread the aliquots with a sterile hockey stick. At three and a half weeks of fungal growth, to confirm the Fof isolates produced chlamydospores, we either aseptically flooded a cultured PDA plate and aliquoted the suspension onto a microscope slide, or removed an approximately $2 \mathrm{~mm}^{2}$ section of mycelium from the plate, minced this section with a scalpel, and placed the minced section on a slide. Under a microscope, we observed chlamydospores growing in the Fof 10.3 cultures. The chlamydospores had a thickened inner wall, were approximately 9 $\mu \mathrm{m}$ in diameter, and were positioned both terminally and intercalary along hyphae. The Fof 19 isolate did not produce chlamydospores. Additional experiments substantiated that Fof 19 rarely, if ever, produces chlamydospores in vitro. For this reason, we did not make inoculum with Fof 19 .

To prepare the Fof inoculum, we autoclaved white aquarium sand $(2.5 \mathrm{~L})$ twice for one hour, and broke up the sand after each autoclaving. We blended 20 Petri plates of Fof 10.3 PDA cultures in sterile deionized water $(250 \mathrm{~mL})$ using the pulse setting, and 
spread the inoculum on a large metal tray to dry for seven days at ambient temperature and humidity. Once dry, we used a coarse sieve to break up large clods. We allowed the inoculum to dry for an additional week covered in a plastic container, and then moved the inoculum to cold storage (approx. $40^{\circ} \mathrm{C}$ ) until needed.

\section{Selective Media Preparation and Colony Forming Unit Counts of Inoculum - Prior}

to inoculating soil, we quantified colony forming units (CFUs) of the inoculum for both fungal pathogens on selective media. We defined a colony forming unit as either a single microsclerotium, or a colony of mycelium and its associated structures (e.g. Fof chlamydospores and conidia). Plating inoculum on selective media reduces contaminant growth, allowing for more accurate CFU enumeration (personal observation).

To produce Mp selective RB media (Cloud and Rupe, 1991), we autoclaved fullstrength PDA in a $2 \mathrm{~L}$ Erlenmeyer flask for 20 mins at $121^{\circ} \mathrm{C}$ and placed the molten PDA on a stir plate $\left(300 \mathrm{rpm}\right.$, and $\left.60^{\circ} \mathrm{C}\right)$ in a laminar flow hood. We added $\mathrm{Na}$ carbonate $(1 \mathrm{~g})$, rifampicin $(0.1 \mathrm{~g})$ dissolved in methanol $(10 \mathrm{~mL})$, Subdue Maxx® $(1016 \mu \mathrm{l})$, and Tergitol $(1 \mathrm{~mL})$ to the molten PDA. The poured plates dried for approximately one hour before storage in a $7^{\circ} \mathrm{C}$ refrigerator.

To enumerate CFUs produced by $M p$, we both direct plated and used an Andersen Cascade Impactor (Thermo Fisher Scientific Inc. ${ }^{\circledR}$, Franklin, MA, USA) to plate $M p$ inoculum on the RB media. We found that there was less variability between replicate plates when using the Andersen Cascade Impactor than when direct plating a dilution, and chose this method to plate $M p$ inoculated soil in future experiments (See Appendix B.). To dilute the inoculum for direct plating, we added mortar-and-pestle crushed 
inoculum $(1 \mathrm{~g})$ to sterile deionized water $(10 \mathrm{~mL})$ in a $15 \mathrm{~mL}$ conical tube. Immediately following vortexing, we aliquoted $(1 \mathrm{~mL})$ of solution into a $15 \mathrm{~mL}$ conical tube with deionized water $(9 \mathrm{~mL})$. Again, immediately after vortexing, we pipetted the solution $(250 \mu \mathrm{l})$ onto plates with RB media. We spread the aliquot with a sterile hockey stick and allowed the colonies to germinate for nine days. Under a dissecting microscope, we counted the number of colonies, defining an $M p$ colony as one with radial mycelial growth, hyphal branching at right or acute angles to parent hyphae, septations near hyphal branching, often including aerial hyphae, and containing black microsclerotia (Kaur et al., 2012). We counted CFUs approximately 1 week after plating. The number of units varied, but were approximately $20000 \mathrm{CFUs/g} \mathrm{inoculum.}$

To produce Fof selective Komada media (Komada, 1975), we combined deionized water (1 L), D-galactose (20 g), L-asparagine (2 g), magnesium sulfate heptahydrate $(0.5 \mathrm{~g})$, di-potassium phosphate $(1 \mathrm{~g})$, potassium chloride $(0.5 \mathrm{~g})$, ferric salt (10 mg), and bacto agar (15 g) in a 2 L Erlenmeyer flask. After mixing, we autoclaved the solution for 25 mins at $121^{\circ} \mathrm{C}$, and then placed the solution in a $55^{\circ} \mathrm{C}$ water bath to cool. To a $15 \mathrm{~mL}$ conical tube, we added an antibiotic solution of $95 \%$ ethanol $(10 \mathrm{~mL})$, Oxgall (0.5 g), PCNB 75\% WP (1 g), Borax (1 g), and streptomycin sulfate $(0.3 \mathrm{~g})$. We placed the antibiotic solution on its side on a shaker at room temperature for approximately 45 mins. After equilibrating in the water bath, we moved the media to the laminar flow hood and added Tergitol ${ }^{\mathrm{TM}}(1 \mathrm{~mL})$ to the solution while stirring. Once the media had cooled to $50^{\circ} \mathrm{C}$, we shook the antibiotic solution to mix and added it to the media. We used $10 \%$ phosphoric acid $(5 \mathrm{~mL})$ two times to rinse out the antibiotic solution from the $15 \mathrm{~mL}$ conical tube and added the acid to the media. Before pouring the 
plates, we assured the media $\mathrm{pH}$ was between 3.4 and 4.0 using a $\mathrm{pH}$ meter. We added hydrochloric acid or sodium hydroxide to adjust the $\mathrm{pH}$, when necessary (Komada recipe from Doctor Thomas Gordon, UC Davis).

To enumerate Fof inoculum, we autoclaved bacto agar $(0.1 \mathrm{~g})$ in deionized water $(100 \mathrm{~mL})$ in a $250 \mathrm{~mL}$ Erlenmeyer flask for $10 \mathrm{mins}$. To a second $250 \mathrm{~mL}$ Erlenmeyer flask, we added deionized water $(198 \mathrm{~mL})$, sodium hexametaphosphate $(2 \mathrm{~g})$, and Fof inoculum (6 g), and stirred with a magnetic stir bar at $300 \mathrm{rpm}$ for five mins. After cooling the autoclaved media to $55^{\circ} \mathrm{C}$ in a water bath, and moving it to a laminar flow hood, we aliquoted solution $(3 \mathrm{~mL})$ and replaced this with inoculum solution from the second Erlenmeyer flask ( $3 \mathrm{~mL})$. We mixed the final solution for five mins on a stir plate, and then transferred $250 \mu \mathrm{l}$ to several plates with Komada media and spread with a sterile glass hockey stick. We counted CFUs approximately 1 week after plating.

Both Fof isolates (10.3 and 19) that we assayed in vitro produced few colonies when we plated inoculum of these isolates on selective Komada media. Thomas Gordon (UC Davis) provided Fof plates that we used to produce inoculum with a higher CFU count (approximately $20000 \mathrm{CFUs/g)} \mathrm{for} \mathrm{all} \mathrm{soil} \mathrm{experiments.}$

Plant Compound Integration in Soil -We performed aseptic techniques throughout the experiment to reduce contamination - a potential confounding factor. After $24 \mathrm{hrs}$ of drying in an oven at $105^{\circ} \mathrm{C}$, we sieved Rutiz Family Farm field soil through a coarse sieve to break apart clods and remove large organic matter. We autoclaved the dried soil in a $2 \mathrm{~L}$ mason jar with inverted lid for $1 \mathrm{hr}$, and stored the soil at room temperature (approximately $24^{\circ} \mathrm{C}$ ). The day before integrating plant compounds, working in a laminar 
flow hood, we added autoclaved soil ( $24 \mathrm{~g})$, to 19 separate $150 \mathrm{~mL}$ beakers (16 treatments, and 3 controls).

Under a chemical fume hood, we prepared stock plant compound solutions in vials with Teflon ${ }^{\mathrm{TM}}$-lined tops (to prevent acetone loss due to volatilization) by adding 0.5 $\mathrm{g}$ of ferulic acid to $13.34 \mathrm{~mL}$ acetone, $1.5 \mathrm{~g}$ gallic acid to $12.65 \mathrm{~mL}$ acetone, $0.3 \mathrm{~g}$ juglone to $14.23 \mathrm{~mL}$ acetone, and $0.3 \mathrm{~g}$ p-Coumaric acid to $14.23 \mathrm{~mL}$ acetone. We stirred all stock solutions with a magnetic stir bar until no precipitate was visible. To fully dissolve juglone in acetone, we heated the solution to $35^{\circ} \mathrm{C}$ on a stir plate for 30 mins at 1200 rpm. We used micropipettes and glass pipettes to aliquot stock solutions to additional vials. The acetone in these vials diluted the compounds to the desired treatment concentrations.

All treatment and control solutions had final acetone volumes of $3.6 \mathrm{~mL}$. We found that stirring $150 \mu \mathrm{l}$ acetone/g soil fully integrated the plant compound solutions in soil. The amount of plant compound in each dilution vial was sufficient to produce the final ppmw needed in $24 \mathrm{~g}$ of soil on a ug compound/g soil basis. We vortexed each treatment, and then treated the soil by drawing the acetone/compound solutions into separate syringes ( $5 \mathrm{cc}$, BD, Franklin Lakes, NJ, USA) and pushing the solutions through Millipore filters $(0.22 \mu \mathrm{m}$, Nalgene, Rochester, NY, USA). After acetone/compound addition to soil, we immediately mixed the treatments with a sterile spatula (sprayed with $70 \% \mathrm{EtOH})$ to fully integrate the plant compounds. We allowed the acetone to volatize for at least one hour under the fume hood, and then moved the soil treatments into a $4.4^{\circ} \mathrm{C}$ fridge, allowing for additional volatilization overnight. After removing the treatments from the fridge the following morning, we noted a distinct acetone odor, and 
placed the soil treatments in a fume hood for an additional four hours before returning the treatments to a $4.4^{\circ} \mathrm{C}$ fridge.

Inoculum Integration in Soil - In a laminar flow hood, two days after treating the soil with plant compounds, we mixed $M p$ inoculum (1.6 g, crushed with a mortar and pestle) in treatment soil ( $8 \mathrm{~g})$, and Fof inoculum ( $1 \mathrm{~g}$, uncrushed) in treatment soil $(5 \mathrm{~g})$ in separate $100 \mathrm{~mL}$ beakers $(0.2 \mathrm{~g}$ inoculum/g soil $)$. We used separate clean, flamed spatulas for each treatment to mix inoculum into the soil.

24-Well Plate Setup - We transferred treated soil (1.2 g) from treatment beakers to 24well plate wells. To measure soil for each well, we poured treated soil into a microcentrifuge tube with a line drawn just below the $1 \mathrm{~mL}$ measurement on the microcentrifuge tube's side. We weighed $1.2 \mathrm{~g}$ of soil in microcentrifuge tubes several times to determine that this was the correct volume. While pouring treatments with Fof inoculum into microcentrifuge tube measurers, we continuously stirred the treatments to assure an even distribution of inoculum. This was not necessary for the crushed $M p$ inoculum, as it remained evenly distributed in the soil while pouring.

After filling the wells with randomly assigned soil treatments, we irrigated all treatment and negative control wells with sterile deionized water $(425 \mu \mathrm{l})$, and positive control wells with fungicide (425 $\mu$ l metconazole). We prepared metconazole (Quash $\left.{ }^{\circledR}\right)$ at its high label rate by vigoursly shaking Quash ${ }^{\circledR}(0.102 \mathrm{~g})$ in sterile deionized water (680 $\mathrm{mL})$. 
Before placing the 24-well plates in random order in a low temperature incubator (Fisher Scientific 3724, Thermo Fisher Scientific Inc. ${ }^{\oplus}$, Franklin, MA, USA) at $24^{\circ} \mathrm{C}$, we wrapped the plates in parafilm.

Soil and Inoculum Plating on Selective Media - After 48 hrs of incubation, we removed the lid of each 24-well plate, and placed the plates in a laminar flow hood to dry (approximately $60 \mathrm{hrs).} \mathrm{Once} \mathrm{the} \mathrm{soil} \mathrm{in} \mathrm{wells} \mathrm{had} \mathrm{dried,} \mathrm{we} \mathrm{used} \mathrm{clean} \mathrm{(washed} \mathrm{with}$ soap and water) and sterile ( $70 \% \mathrm{EtOH})$ spatulas to break up and mix the treatments in each well. We then weighed small quantities of soil with inoculum from each well.

Macrophomina phaseolina - After grinding each soil/inoculum treatment with a clean mortar and pestle to a fine powder, we added $M p$ inoculum and soil mixture ( 0.05 g) to microcentrifuge tubes (two subsamples per treatment replicate). Pilot studies determined that $0.05 \mathrm{~g}$ of material allowed for greater colony detection than larger masses (see APPENDIX B.). This mass was also large enough to minimize error when using a Mettler Toledo ME103E Precision Balance (Mettler-Toledo Ltd., Beaumont Leys, Leicester, United Kingdom). To plate treatments, we used an Andersen Cascade Impactor with components and selective media placed in the following order from the top to the bottom of the impactor: funnel drop, scatter plate, $\# 1$ stage (1.81 mm orifice), $\mathrm{RB} M p$ selective media treatment plate, \#6 stage ( $0.25 \mathrm{~mm}$ orifice), $\mathrm{RB}$ media excess material catch plate, base, and hose connected to a Welch-llmvac pump (Welch ${ }^{\circledR}$, Niles, IL, USA). Pilot studies revealed that this setup achieved an even material spread and high readability. We cleaned all components of the Andersen Cascade Impactor between each treatment with alcohol $(70 \% \mathrm{EtOH})$. We placed the plates randomly on a single shelf in a 
growth chamber (CONVIRON ${ }^{\circledR}$ CMP 5090, Winnipeg, Manitoba, Canada) at $24^{\circ} \mathrm{C}$ and ambient humidity (approximately 65\%, www.timeanddate.com).

Fusarium oxysporum f. sp. fragariae - To prepare Fof inoculum for direct plating of two subsamples from each microcentrifuge tube, we added soil with inoculum from each treatment replicate to microcentrifuge tubes $(0.07 \mathrm{~g})$. We aliquoted an actively stirring sodium hexametaphosphate (NHMP) solution (502 $\mu \mathrm{l})$ and added the aliquot to the microcentrifuge tube to produce a $1 \%(\mathrm{w} / \mathrm{w})$ NHMP solution. After vortexing this solution for 20 secs, we aliquoted an actively stirring $\left(55^{\circ} \mathrm{C}\right)$ bacto agar solution $(702 \mu \mathrm{l})$ and added this aliquot to the microcentrifuge tube to produce a final solution consisting of $0.1 \%(\mathrm{w} / \mathrm{w})$ water agar, $1 \%(\mathrm{w} / \mathrm{w})$ NHMP, and $0.07 \mathrm{~g}$ of inoculated soil. We vortexed this final solution for 10 secs. To plate the treatments on selective media, we aliquoted $600 \mu \mathrm{l}$ of final solution twice-using $1 \mathrm{~mL}$ cut micropipette tips, to allow for pipetting of larger material-onto Komada media (plates dried in a laminar flow hood overnight), and spread the aliquot with a sterile hockey stick. We placed the plates randomly on a single shelf in a growth chamber (CONVIRON ${ }^{\circledR}$ CMP 5090, Winnipeg, Manitoba, Canada) at $24^{\circ} \mathrm{C}$ and ambient room humidity (approximately 65\%, www.timeanddate.com).

Experimental Treatments - The fungus assay soil experiment was a completely randomized factorial design with water and fungicide controls. We randomly assigned treatments to 152 wells over six and one-third, 24-well plates. There were four replicate wells per treatment. The treatments either had Fof or $M p$ inoculum that we integrated in soil containing the following plant compound rates ( $\mu \mathrm{g}$ compound/g soil): 113, 468, 1479, 4664 ppmw ferulic acid; 83, 263, 832, 2628 ppmw juglone, and 83, 263, 832, 2628 
ppmw p-Coumaric acid. There was a half-log difference between each plant compound concentration, as recommended by Duke (2015). We treated the soil in control wells with only acetone solvent. The experiment included water control replicates with and without inoculum. We applied metconazole (Quash $®)$ to soil in fungicide control wells (which included inoculum) at the label high rate. After producing soil treatments and incubating, we measured two subsamples from each well in the 24-well plates and plated the subsamples on individual selective agar plates.

Data Collection and Analysis - After 62 hrs of incubation, we refrigerated all Fof selective plates at $4.4^{\circ} \mathrm{C}$ to arrest growth. To confirm Fof identification, we transferred a portion of a colony from one plate, for each plant compound treatment and control, to acidified cornmeal agar (APDA). Several days later, we observed the purple/red pigmentation characteristic of Fof colonies. We also made slides from Fof colonies growing on plates and saw the terminal and intercalary chlamydospores, and micro- and macroconidia typical of Fusarium spp.. Over the course of five days, we enumerated Fof colonies while leaving plates still requiring enumeration in a $4.4^{\circ} \mathrm{C}$ refrigerator.

After approximately four and a half days, we removed $M p$ plates from the growth chamber and placed them in a $4.4^{\circ} \mathrm{C}$ refrigerator. We counted $M p$ CFUs during the following five days. Colony enumeration occurred under a dissecting microscope. In a minority of cases, we plated unknown colonies to assure they were not $M p$. Macrophomina phaseolina colonies had at least one microsclerotia (50-150 $\mu \mathrm{m}$ in diameter), and often septate, branching hyphae (Kaur et al., 2012). 
We excluded the Fof data from statistical analysis due to an experimental error, and because of hormesis, whereby low concentrations stimulated and high concentrations inhibited CFU production. There were over 1000 Fof CFUs per plate in some low-rate treatments, a number of CFUs we considered too numerous to count.

We used a Box-Cox transformation to meet the assumptions of an analysis of variance (ANOVA). After subjecting the transformed $M p$ data to an ANOVA $(\alpha=0.05)$, a Dunnet's post-hoc test compared treatment means to the three controls $(\alpha=0.0167$ to reduce the type I error rate) (JMP Pro 12.1.0, SAS Institute, Carey, NC, www.jmp.com).

To model the dose-response relationship of CFUs/plate to plant compound concentration, we fitted logistic or Gompertz curves to each compound (GraphPad Prism 7.0a, La Jolla, CA, www.graphpad.com). These procedures satisfied model assumptions.

\subsection{Results}

\subsubsection{In Vitro Assays}

All in vitro curve fits satisfied normality, homogenous variance, and dependency assumptions, although several curves failed replicate tests of goodness-of-fit. The adjusted $\mathrm{R}^{2}$ values were between 0.83 and 0.99 for 11 of 12 curve fits (Table 2.1.). The ferulic acid curve for $M p 13$ had an adjusted $\mathrm{R}^{2}$ value of 0.53 . This lesser fit was due to a biphasic relationship (500 ppmw inhibited radial mycelial growth to a lesser degree than 100 ppmw) (Figure 2.1.).

The in vitro radial mycelial growth of $M p$ and Fof isolates declined in a dosedependent manner (Figures 2.1.). We interpreted non-overlapping $\mathrm{EC}_{50}$ or $\mathrm{EC}_{75} 95 \%$ confidence intervals as strong evidence of a statistical difference in the strength of mycelial growth inhibition between compounds, or between fungal isolates. Generally, 
Fof 19 was the most sensitive isolate to plant compounds. The most fungicidal plant compound was juglone, which had significantly lower $\mathrm{EC}_{50}$ values for each isolate, and significantly lower $\mathrm{EC}_{75}$ values for three out of four isolates (Table 2.1.). The one exception to this was the Fof 10.3 assay in which p-Coumaric acid (798 ppmw) had a lower $\mathrm{EC}_{75}$ than juglone (1378 ppmw).

Ferulic acid and p-Coumaric acid inhibited the radial mycelial growth of $M p 8$ and Mp13 isolates equally. In Fof 10.3 assays, p-Coumaric acid inhibited radial mycelial growth at significantly lower concentrations than ferulic acid (Table 2.1.). And in Fof 19 assays, p-Coumaric acid had a significantly lower $\mathrm{EC}_{50}$ value than ferulic acid, but the two compounds had equivalent $\mathrm{EC}_{75}$ values. The Fof 19 isolate did not grow in the 1000 ppmw p-Coumaric acid treatment (see APPENDIX A.1). After 70 days, we re-plated plugs from this treatment on fresh $1 / 2$ PDA plates. Without the inhibitory effects of 1000 ppmw p-Coumaric acid, the mycelium grew at a nearly identical rate $(8.22 \mathrm{~mm} /$ day on average) to that of the water control $(8.34 \mathrm{~mm} /$ day on average $)$.

One-factor ANOVAs, followed by Dunnet's post hoc tests, compared controls to treatments for each isolate we assayed (all omnibus F-tests: $\mathrm{p}<.0001$ ). The fungicide control (metconazole) inhibited radial mycelial growth more than all plant compounds ( $\mathrm{p}$ $<\alpha<.025)$, with one exception: the 1000 ppmw p-Coumaric acid treatment inhibited Fof $10.3(\mathrm{p}=.737)$ and Fof $19(\mathrm{p}=.313)$ radial mycelial growth equivalently to the fungicide control. Compared to most plant compound treatments, the DMSO water control had significantly faster radial mycelial growth $(\mathrm{p}<\alpha<.025)$. The exceptions to this rule were all the $10 \mathrm{ppmw}$ plant compound treatments for both $M p$ isolates, $100 \mathrm{ppmw}$ p-Coumaric 
acid for $M p 13,10 \mathrm{ppm}$ ferulic and p-Coumaric acid for Fof 10.3 , and $10 \mathrm{ppm}$ p-Coumaric acid for Fof 19 (Figures 2.1.). 
Table 2.1. Regression adjusted $R^{2}$ values, hillslope parameters, and mean $\mathrm{EC}_{50}$ and $\mathrm{EC}_{75}$ values (parts per million by weight) for fungi growing in media amended with ferulic acid, juglone, or p-Coumaric acid. LCL: lower 95\% confidence limit. UCL: upper 95\% confidence limit.

\begin{tabular}{|c|c|c|c|c|c|c|c|c|c|c|}
\hline \multirow{2}{*}{$\begin{array}{l}\text { Species } \\
\text { (Isolate) }\end{array}$} & \multirow{2}{*}{$\begin{array}{c}\text { Plant } \\
\text { Compound }\end{array}$} & \multirow[b]{2}{*}{ Regression } & \multirow[b]{2}{*}{$\mathbf{R}^{2}$} & \multirow[b]{2}{*}{ Hillslope } & \multicolumn{3}{|c|}{$\mathbf{E C}_{50}$} & \multicolumn{3}{|c|}{$\mathbf{E C}_{75}$} \\
\hline & & & & & LCL & Mean & UCL & $\mathrm{LCL}$ & Mean & UCL \\
\hline \multirow{3}{*}{$\begin{array}{c}\text { Macrophomina } \\
\text { phaseolina } 8\end{array}$} & Ferulic Acid & Logistic $2 \mathrm{P}$ & 0.83 & -0.46 & 1267 & 2065 & 5134 & 7119 & 22618 & 113852 \\
\hline & Juglone & Logistic 3P & 0.97 & -0.51 & 109 & 142 & 180 & 882 & 1235 & 1886 \\
\hline & p-Coumaric Acid & Logistic $2 \mathrm{P}$ & 0.89 & -0.55 & 1868 & 2978 & 6544 & 8310 & 21843 & 74075 \\
\hline \multirow{3}{*}{$\begin{array}{c}\text { Macrophomina } \\
\text { phaseolina } 13\end{array}$} & Ferulic Acid & Gompertz 1P & 0.58 & -0.68 & 4567 & 9368 & 20147 & 46173 & 99312 & 200876 \\
\hline & Juglone & Logistic 3P & 0.97 & -0.50 & 204 & 250 & 295 & 1799 & 2239 & 2989 \\
\hline & p-Coumaric Acid & Logistic 3P & 0.85 & -0.72 & 1734 & 2759 & 9299 & 4406 & 12757 & 63241 \\
\hline \multirow{3}{*}{$\begin{array}{l}\text { Fusarium } \\
\text { oxysporum f. sp. } \\
\text { fragariae } 10.3\end{array}$} & Ferulic Acid & Gompertz 2P & 0.93 & -1.28 & 730 & 851 & 1024 & 2146 & 2971 & 4706 \\
\hline & Juglone & Logistic $2 \mathrm{P}$ & 0.87 & -0.48 & 76.7 & 136 & 202 & 901 & 1378 & 2403 \\
\hline & p-Coumaric Acid & Logistic $2 \mathrm{P}$ & 0.98 & -6.19 & 570 & 617 & 657 & 767 & 798 & 823 \\
\hline \multirow{3}{*}{$\begin{array}{l}\text { Fusarium } \\
\text { oxysporum f. sp. } \\
\text { fragariae } 19\end{array}$} & Ferulic Acid & Logistic 3P & 0.89 & -2.17 & 368 & 522 & 627 & 746 & 866 & 982 \\
\hline & Juglone & Logistic 3P & 0.99 & -0.45 & 11 & 14 & 17 & 132 & 158 & 191 \\
\hline & p-Coumaric Acid & Gompertz 2P & 0.97 & -1.98 & 275 & 321 & 361 & 630 & 719 & 862 \\
\hline
\end{tabular}


Table 2.2.* Cost (USD)/liter based on the averaged mean $\mathrm{EC}_{50}$ or $\mathrm{EC}_{75}$ values (parts per million by weight) of Macrophomina phaseolina 8 and 13 isolates, and current compound prices. LCL: lower 95\% confidence limit. UCL: upper 95\% confidence limit.

\begin{tabular}{|c|c|c|c|c|c|c|c|c|}
\hline \multirow[b]{2}{*}{ Compound } & \multicolumn{3}{|c|}{$\mathrm{EC}_{50}$} & \multirow{2}{*}{$\begin{array}{l}\text { Cost* } \\
\text { (\$/liter) }\end{array}$} & \multicolumn{3}{|c|}{$\mathbf{E C}_{75}$} & \multirow{2}{*}{$\begin{array}{l}\text { Cost* } \\
\text { (\$/liter) }\end{array}$} \\
\hline & UCL & Mean & LCL & & UCL & Mean & LCL & \\
\hline Ferulic Acid & 2917 & 5716 & 12641 & 47.10 & 26646 & 60965 & 157364 & 502 \\
\hline Juglone & 156 & 196 & 237 & 3.92 & 1340 & 1737 & 2437 & 34.74 \\
\hline p-Coumaric Acid & 1801 & 2869 & 7921 & 17.21 & 6358 & 17300 & 68658 & 104 \\
\hline
\end{tabular}

Table 2.3.* Cost (USD)/liter based on the averaged mean $\mathrm{EC}_{50}$ and $\mathrm{EC}_{75}$ values (parts per million by weight) of Fusarium oxysporum f.sp. fragariae 10.3 and 19 isolates, and current compound prices. LCL: lower 95\% confidence limit. UCL: upper $95 \%$ confidence limit.

\begin{tabular}{|c|c|c|c|c|c|c|c|c|}
\hline \multirow[b]{2}{*}{ Compound } & \multicolumn{3}{|c|}{$\mathbf{E C}_{50}$} & \multirow{2}{*}{$\begin{array}{l}\text { Cost* } \\
\text { (\$/liter) }\end{array}$} & \multicolumn{3}{|c|}{$\mathbf{E C}_{75}$} & \multirow{2}{*}{$\begin{array}{l}\text { Cost* } \\
\text { (\$/liter) }\end{array}$} \\
\hline & UCL & Mean & LCL & & UCL & Mean & LCL & \\
\hline Ferulic Acid & 549 & 687 & 825 & 5.66 & 1446 & 1919 & 2844 & 15.81 \\
\hline Juglone & 44 & 75 & 110 & 1.50 & 517 & 768 & 1297 & 15.37 \\
\hline p-Coumaric Acid & 422 & 469 & 509 & 2.81 & 698 & 759 & 843 & 4.55 \\
\hline
\end{tabular}

*current compound costs (ferulic acid: $\$ 8.24 / \mathrm{g}$, juglone: $\$ 20.00 / \mathrm{g}$, and p-Coumaric acid: $\$ 6.00 / \mathrm{g}$ ) are estimates based on several sources: sigmaaldrich.com, mpbiomedicals.com, and/or alfa.com. Prices will vary. 

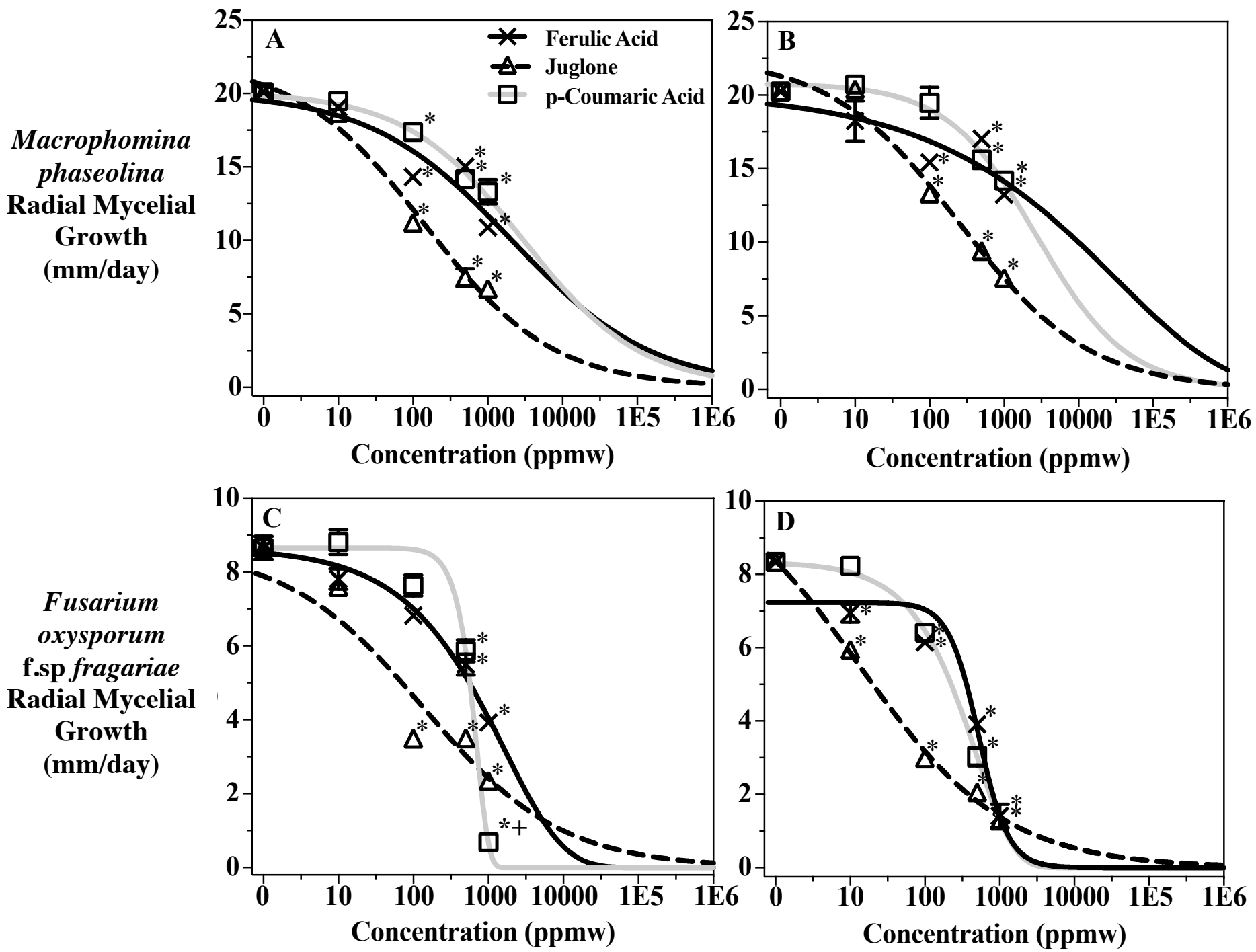

Figure 2.1. The effect of increasing plant compound concentrations $(10,100,500$, and 1000 parts per million by weight (ppmw)) on radial mycelial growth of Macropohomina phaseolina 8 (A), M. phaseolina 13 (B), F usarium oxysporum f.sp.fragariae $10.3(\mathrm{C})$, and $F$. oxysporum f.sp. fragariae 19 (D) in vitro. Concentration is on a logarithmic scale. *Significantly slower radial mycelial growth than the water control with DMSO $(\mathrm{p}<.025)$. +Not significantly different radial mycelial growth than the fungicide control $(\mathrm{p}>.025)$. There was no radial mycelial growth in 1000 ppm p-Coumaric acid F. oxysporum f.sp. fragariae 19 assays. Error bars are \pm 1 SEM. 

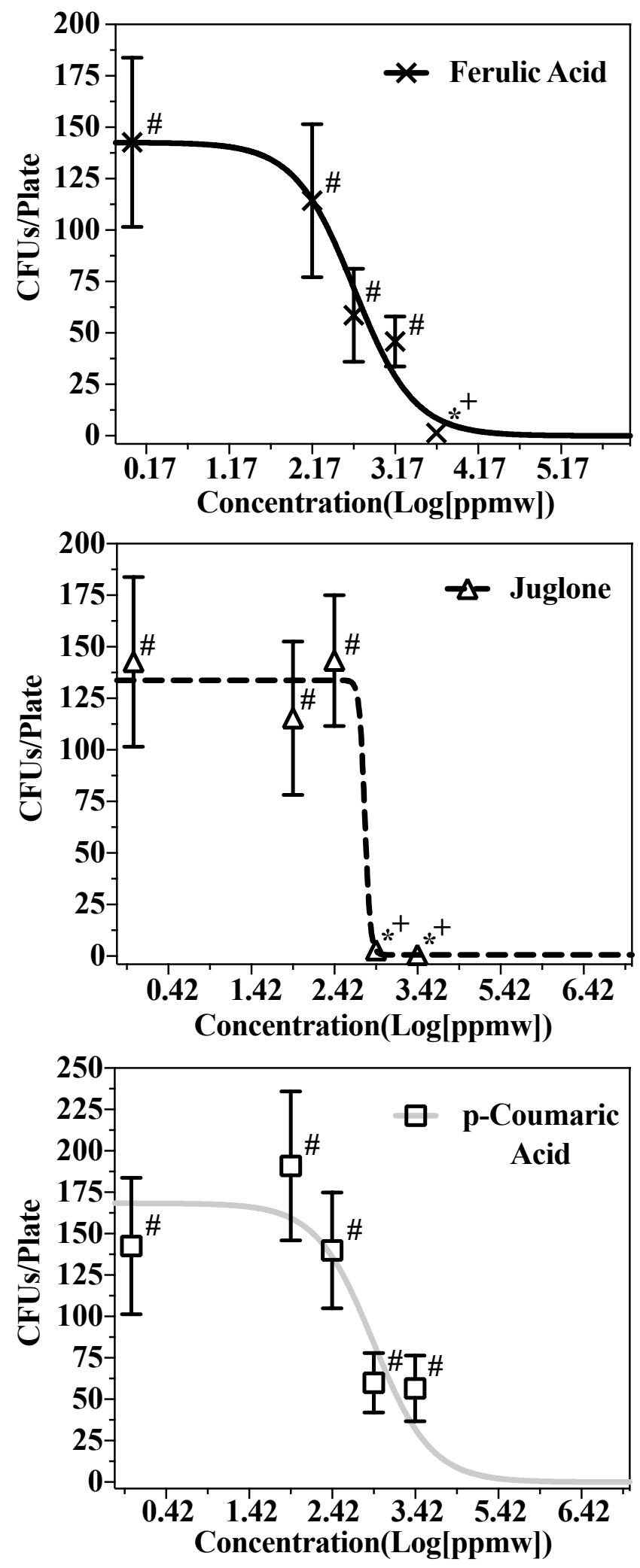

All curve fits for $M p$ soil assays satisfied

normality, homogenous variance, and dependency

assumptions, and passed replicates tests of

goodness-of-fit. In soil assays, the number of $M p$

colony forming units (CFUs) decreased in

response to increasing concentrations of all plant

compounds (Figure 2.2.). The second-highest rate

of juglone, and the high rates of juglone and ferulic

acid, had fewer colony forming units than the

water control with pathogen $(\mathrm{p}<.0001)$, and a not

statistically different number of colony forming

units than the no pathogen water control. All other

treatments had significantly more CFUs than the

Figure 2.2. The effect of increasing plant compound concentrations in soil on colony forming unit (CFU) counts of Macrophomina phaseolina plated with an Andersen Cascade Impactor on RB selective media. \#: the treatment had significantly more CFUs than the no pathogen water control, $\mathrm{p}<.0001$; *: the treatment had significantly fewer CFUs than the water control with pathogen, $\mathrm{p}<.0001 ;+$ : the treatment had significantly fewer CFUs than the fungicide control (metconazole), $\mathrm{p}<.0001)$. Metconazole treatments and the water control with pathogen had significantly more CFUs/plate than the water control without pathogen $(\mathrm{p}<.0001)$. 
no pathogen water control $(\mathrm{p}<.0001)$, and were not statistically different than the water control with pathogen $(\mathrm{p}>.0167)$.

Ferulic acid had the lowest $\mathrm{EC}_{50}$ value and juglone had the lowest $\mathrm{EC}_{75}$ value in $M p$ soil assays (Table 2.4.). However, all $\mathrm{EC}_{50}$ and $\mathrm{EC}_{75}$ confidence intervals overlapped between plant compounds. Based on $\mathrm{EC}_{50}$ and $\mathrm{EC}_{75}$ values, and current compound costs (ferulic acid: $\$ 8.24 / \mathrm{g}$, juglone: $\$ 20.00 / \mathrm{g}$, and p-Coumaric acid: $\$ 6.00 / \mathrm{g}$ ), per acre costs were lowest for ferulic acid and greatest for juglone (Table 2.4b.).

Table 2.4a. Macrophomina phaseolina in soil. Regression, adjusted $\mathrm{R}^{2}$, Hillslope, $\mathrm{EC}_{50}$ and $\mathrm{EC}_{75}$ values (parts per million by weight) for each plant compound.

\begin{tabular}{|cccc|ccc|ccc|}
\hline & \multirow{2}{*}{$\begin{array}{c}\text { Regre- } \\
\text { Compound }\end{array}$} & Adj. & Hill- & \multicolumn{3}{|c|}{ EC $_{\mathbf{5 0}}$} & \multicolumn{3}{|c|}{ EC $_{\mathbf{7 5}}$} \\
\cline { 5 - 10 } & $\mathbf{R}^{\mathbf{2}}$ & slope & UCL & Mean & LCL & UCL & Mean & LCL \\
\hline Ferulic Acid & Log 1P & 0.66 & -1.21 & 262 & 476 & 864 & 576 & 1184 & 2004 \\
Juglone & Log 3P & 0.78 & -13.17 & 514 & 612 & 719 & 539 & 666 & 763 \\
p-Coumaric Acid & Log 1P & 0.35 & -1.25 & 369 & 827 & 1857 & 713 & 1988 & 3999 \\
\hline
\end{tabular}

Table 2.4b. Plant compound per acre application rates (Kg/acre) and costs (USD) per acre to control Macrophomina phaseolina in soil.

\begin{tabular}{|c|c|c|c|c|}
\hline \multirow[b]{2}{*}{ Compound } & \multicolumn{2}{|c|}{$\mathbf{E C}_{50}$} & \multicolumn{2}{|c|}{$\mathbf{E C}_{75}$} \\
\hline & Kg/acre & $\begin{array}{c}\text { Cost } \\
\text { (\$/acre) }\end{array}$ & Kg/acre & $\begin{array}{c}\text { Cost } \\
\text { (\$/acre) }\end{array}$ \\
\hline Ferulic Acid & 9.01 & 74,226 & 22.42 & 184,718 \\
\hline Juglone & 11.58 & 231,631 & 12.60 & 251,964 \\
\hline p-Coumaric Acid & 15.66 & 93,961 & 37.63 & 225,804 \\
\hline
\end{tabular}

In Fof soil assays, all high rate wells for ferulic acid, juglone, and p-Coumaric acid had fewer average CFUs than the water control with pathogen (Figure 2.3.). There were no CFUs on selective media plates with soil from juglone high rate wells (see APPENDIX A.2). Compared to the water control with pathogen, ferulic acid high rate wells had an average of $98.7 \%$ fewer CFUs, p-Coumaric acid had an average of $60.4 \%$ 
fewer CFUs, and the fungicide control had an average of $97.1 \%$ fewer CFUs. Many treatments showed a hormetic response; an amplification, at low rates, of the number of CFUs in comparison to the water control with pathogen (see APPENDIX A.2). All plant compound rates for the Fof assays displayed hormesis except for the previously mentioned high rates.

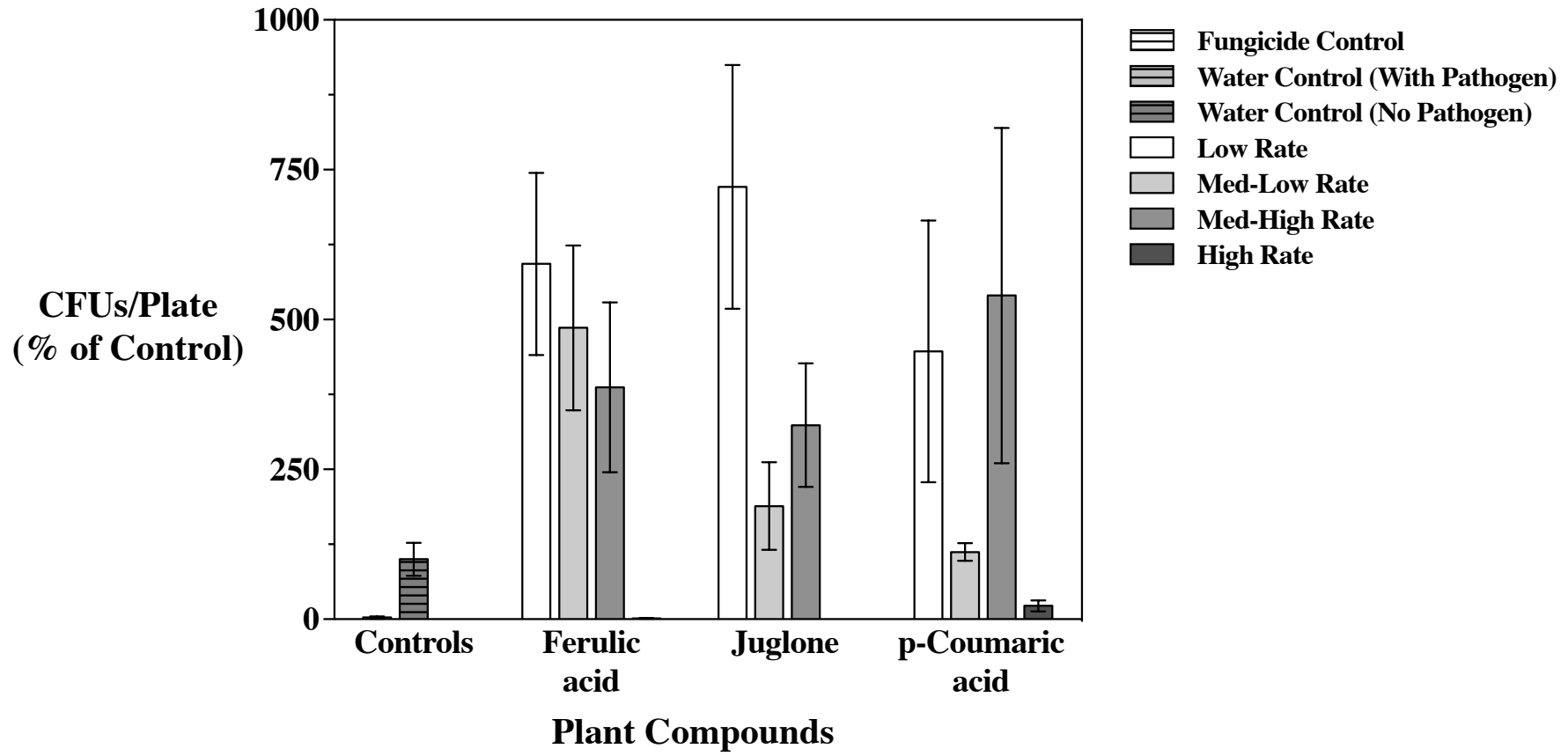

Figure 2.3. The effect of increasing plant compound concentrations in soil on colony forming unit (CFU) counts of F usarium oxysporum f. sp. fragariae plated directly on Komada selective media. Plates contained too many CFUs to count accurately, and we did not use an analysis of variance to compare simple effects. To produce this figure, we treated each of two subsamples from a replicate well in a 24-well plate as a separate replicate $(\mathrm{N}=8)$. Several bars representing treatment averages are not visible: high rates of ferulic acid (1.31\% of water control with pathogen) and juglone ( $0 \%$ of water control with pathogen), and the water control without pathogen ( $0 \%$ of water control with pathogen). Error bars are \pm 1 SEM. For numerical rate values (parts per million by weight) see page 23 . 


\subsection{Discussion}

In a paper on herbicide dose-response relationships, Seefeldt et al. (1995) recommends including at least five rates in assays to assure that the range of doses covers the half-maximal response concentration $\left(\mathrm{EC}_{50}\right)$. However, including so few rates requires an a priori approximation of the $\mathrm{EC}_{50}$ value, which is not always easy to obtain through a literature review or pilot study. Additional doses, beyond the five we included in our research, would have better characterized the dose-response relationship, and improved $\mathrm{EC}_{50}$ and $\mathrm{EC}_{75}$ predictions. Even so, we satisfied model assumptions and carefully fit curves to minimize Aikaike Information Criteria with correction (AICc) values, and so we are confident in the predictive capacity of the best-fit functions.

\subsubsection{In Vitro Assays}

Our research confirms past studies that have found ferulic acid, juglone, and pCoumaric acid to exhibit broad-spectrum fungicidal activity. In our assays, 1000 ppmw juglone inhibited the average radial mycelial growth of the fungal pathogens by between 62.7 and 84.5\%. Curreli et al. (2001) assayed Lentinus sajor-caju (Fr.) Fries., on 2\% juglone-amended malt extract agar. Juglone inhibited L. sajor-caju radial mycelial growth in a dose-dependent manner, and by $91.5 \%$ at $1000 \mathrm{ppm}$. We expected juglone to inhibit L. sajor-caju, a saprophytic fungus that decays lignin, to a greater extent than $M p$ or Fof because the compound may benefit Juglandaceae family species by slowing lignin degradation in natural settings.

Although juglone was the most fungicidal compound in our research, it may be too expensive to be economically viable. Juglone's cost fluctuated from around $\$ 1.00$ (USD)/gram to over $\$ 40$ (USD)/gram in just a two-year period. Lawsone is an isomer of 
juglone, with similar pesticidal activity and costs around \$2.00 (USD)/gram. Lawsone completely inhibited $L$. sajor-caju radial mycelial growth at just 500 ppm (Curreli et al., 2001). Lawsone and juglone both also inhibited velvetleaf (Abutilon theophrasti L.) on Whatman No. 1 filter paper (Spencer et al., 1986). Lawsone could serve as a cheaper alternative to juglone in strawberry production (\$0.392 (USD)/liter when calculating costs in the same manner as in Tables 2.2. and 2.3. and assuming similar fungicidal activity).

Ferulic acid plays a prominent role in plant disease resistance (Wacker, 1990; McKeehen et al. 1999; Hukkanen, 2007; Ponts et al., 2011; Al-Wakeel et al., 2013; Sarma and Singh, 2013). McKeehen et al. (1999) found an association between wheat (Triticum aestivum L.) cultivar resistance to Fusarium graminearum and F. culmorum (causal agents of Fusarium head blight) and the production of ferulic acid in wheat kernels. They assayed Fusarium spp. in vitro and found that ferulic acid $\mathrm{EC}_{50 \mathrm{~s}}$ ranged from 329 to $668 \mathrm{ppm}$, and p-Coumaric acid $\mathrm{EC}_{50 \mathrm{~s}}$ ranged from 316 to $793 \mathrm{ppm}$. Ponts et al. (2011) found similar $\mathrm{EC}_{50}$ values for ferulic and p-Coumaric acid on PDA plates. The in vitro Fof $\mathrm{EC}_{50}$ values from our research were similar, as well: 522 and $851 \mathrm{ppm}$ for ferulic acid, and 321 and 617 ppm for p-Coumaric acid.

Fungus sensitivity to ferulic acid and p-Coumaric acid depended on the isolate McKeehen et al. (1999) and Ponts et al. (2011) assayed. This was also true for Fof 10.3 and Fof 19. Fusarium oxysporum f.sp. fragariae 19 was more sensitive to plant compounds than Fof 10.3 (we also did not find the Fof 19 isolate to produce chlamydospores), suggesting that it would be easier to control in a strawberry field than 
Fof 10.3. The ability of plant compounds to inhibit soilborne pathogens in the field will depend on the particular strains of the soilborne pathogen present.

Our research is the only - that we are aware of - that includes assays of $M p$ with ferulic acid, p-Coumaric acid, or juglone in vitro. Macrophomina phaseolina and Sclerotinia sclerotiorum (Lib.) de Bary, the causal agent of white mold, are similar ascomycetes in that both species produce melanized overwintering sclerotial spores. Loffredo and Traversa (2014) found that ferulic acid at 100 ppm in PDA inhibited the radial mycelial growth of $S$. sclerotiorum by approximately $10 \%$ after 80 hours of growth. In our assays, $100 \mathrm{ppm}$ ferulic acid inhibited radial mycelial growth by an average of $29 \%(M p 8)$ and $24 \%(M p 13)$.

In conclusion, ferulic acid, juglone, and p-Coumaric acid consistently inhibit radial mycelial growth in vitro. Their antifungal properties affect a variety of fungal organisms spanning multiple phyla (Ascomycota, Basidiomycota, and Glomeromycota). While past in vitro studies, and those we presented in this paper, are promising, they do not include the countless interactions that can mediate the antifungal activity of plant compounds in actual soil. They also do not consider the economic feasibility of applying the compounds on a per acre basis.

\subsubsection{In Soil Assays}

Abiotic and biotic factors in soil systems modify the antifungal properties of plant compounds. Humic acid is a major component of soil. Loffredo and Traversa (2014), assayed S. sclerotiorum in PDA with a mixture of humic acid fractions from soil or compost and ferulic acid and found that, compared to plates with just ferulic acid, there was less in vitro inhibition of radial mycelial growth. Phenolic acids sorb reversibly and 
irreversibly to inorganic and-especially_organic soil colloids (Dalton et al., 1989; Tharayil et al., 2006; Tharayil et al. 2008). This can modify the activity of compounds because when plant compounds exit the soil solution, they are less bioavailable to promote or antagonize organismal growth (Ito et al., 1998).

Several soil microorganisms use ferulic acid, juglone, or p-Coumaric acid as sources of carbon and degrade these compounds into more or less toxic forms (Turner and Rice, 1975; Schmidt, 1988; Blum and Shafer, 1988). Oxidation-reduction reactions, hydrolysis, $\mathrm{pH}$, and polymerization can also affect the activity of plant compounds in the soil solution (Lehmann, 1987; Duroux et al., 1998; Dayan, 2002; Tharayil et al., 2008). We performed soil assays under aseptic conditions, and so any reduction in plant compound effectiveness, compared to in vitro, was primarily due to sorption and not microbial decomposition. Since we used a loamy sand soil with little organic matter, minimal microbial activity (because we autoclaved the soil), and no drainage, the in soil fungus assays were in conditions that would tend to make plant compounds more bioavailable.

Ito et al. (1998) assayed rice (Oryza sativa L.) seedlings in vitro and in soil. Compared to in vitro, soil assays required 10 to 20 times more dehydromatricaria ester, a compound produced by Solidago altissima L., to produce a half-maximal response. Due to sorption, we hypothesized that $\mathrm{EC}_{50}$ values would increase in $M p$ soil assays compared to in vitro soil assays. In 24-well plate wells with ferulic acid and p-Coumaric acid, we found the opposite to be true. A greater than one ratio of soil to in vitro $\mathrm{EC}_{50}$ or $\mathrm{EC}_{75}$ values designates a compound that was more inhibitory in soil than in vitro. The ratio of soil to in vitro ferulic acid (0.92) and p-Coumaric acid (0.29) $\mathrm{EC}_{50 \mathrm{~s}}$, were both less than 
one indicating enhanced inhibition in soils. Juglone was the only compound that required a higher concentration (three times greater) in soil than in vitro to reduce $M p$ growth by $50 \%$. Even so, the best-fitted curve for juglone had a steeper hillslope than the other compound curve fits, and this led to a much lower $\mathrm{EC}_{75}$ in soil than in vitro (ratio of in soil to in vitro $\mathrm{EC}_{755}: 0.38$ ). Thus, overall the plant compounds in soil required lower rates to achieve the same level of inhibition as in vitro. This also suggests that $M p$ microsclerotia are more sensitive to plant compounds than $M p$ actively growing mycelium. This is an especially promising result, as $M p$ competes poorly as a saprophyte in strawberry fields (Singleton et al., 1992), and without a host plant will mostly survive as microsclerotia, which we found were easier to inhibit than mycelium.

Traditional fungicides with a variety of modes-of-action did not inhibit $M p$ or Fof at twice the label rate in soil (Carter, 2016). In our assays, interactions between the soil and metconazole greatly reduced the effectiveness of the fungicide control. We applied $150 \mathrm{ppmw}$, the label high rate of metconazole, to fungicide control wells in the 24-well plates. This was a 30 -fold increase in metconazole dose compared to the 5 ppmw used in vitro. Metconazole in vitro inhibited $M p$ radial mycelial growth more than any plant compound at any dose. Yet in soil, metconazole did not inhibit CFU counts compared to the water control with pathogen treatments.

We did not expect enhanced plant compound antifungal activity in soil. Several factors could explain these results:

1. Although unlikely, due to the thickend cell walls of microsclerotia, it is possible that $M p$ microsclerotia are more sensitive to the plant compounds than the $M p$ mycelium. 
2. We do not have direct evidence of this, however we can not exclude the possibility that the plant compounds we applied competitively bound to cation exchange sites, releasing other antifungal compounds into the soil solution.

3. Preexisting compounds in the soil were additive or synergistic with the compounds we applied.

4. We may have simply observed inhibition of spore germination rather than cytotoxicity.

5. The compounds stimulated microsclerotia germination, and the mycelium died before producing pycnidia or microsclerotia.

Juglone and ferulic acid had lower $\mathrm{EC}_{75}$ values in soil assays than p-Coumaric acid (Table 2.4.). We attribute this to their polarity. Non-polar compounds, such as juglone, bind readily to soil colloids, which, at first, might reduce their activity. However, non-polar compounds follow a concentration gradient, moving from soil colloids, to soil solution, and then to cell membranes and other nonpolar plant parts (Blum, 2011; Duke, 2015). Nonpolar plant compounds also more easily pass the nonpolar tails of a cell's lipid bilayer, do not readily leach due to their poor water solubility, and are generally toxic at lower concentrations than polar plant compounds (Duke, 2015). Although ferulic acid is much more water-soluble than juglone, it is less water-soluble than p-Coumaric acid (Tharayil et al., 2006), and has a methoxy moiety that enhances its sorption to colloids (Dalton et al., 1989). The chemical nature of ferulic acid and juglone modifies their interaction with soil, enhances their ability to cross membrane-bound structures, and increases their antifungal activity. 
Our main conclusions for the in soil $M p$ assays are:

1. The plant compounds either inhibited the germination of $M p$ microsclerotia, or were cytotoxic to the pathogen.

2. In a loamy sand soil, sorption had little influence on the toxicity of these compounds.

3. Juglone, due to its nonpolarity, was the most antifungal of the plant compounds we tested. The steep logistic fit hillslope of juglone's doseresponse curve and low $\mathrm{EC}_{75}$ value are evidence of greater toxicity.

Hormesis is the stimulation of organismal growth or function at a low rate, by the same compound that is toxic at a higher rate. In the Fof soil assays, there was substantial hormesis at low rates, and this prevented statistical analysis of the data (see APPENDIX A.2). Future research should include additional doses over the range between the medium-high rates and the high rates that we applied in these assays. This will limit hormesis, and better elucidate the nature of the dose-response relationship.

We hypothesized that the hormetic response was due to a stimulation of chlamydospore germination, mycelial growth, and the subsequent production of macroand microconidia in the soil. Hormesis commonly occurs in pesticide and allelochemical assays (Rice, 1984; Seefeldt et al., 1995; Belz et al., 2005). Loffredo and Traversa (2014) saw a hormetic response where $S$. sclerotinia produced more sclerotia in PDA plates with $100 \mathrm{ppm}$ ferulic acid than a control. They also observed a hormetic response to a humic acid soil fraction and when they combined humic acid and phenolic acids in vitro. Additionally, sulphides from garlic and onion, and root exudate flavonoids from Fabaceae family plants are fungal spore germination stimulants (Coley-Smith and King, 1969; Ruan et al., 1995). Future research should explore applying low rates of ferulic acid, gallic acid, juglone, or p-Coumaric acid to stimulate chlamydospore germination, 
followed by a second application with a traditional fungicide or plant compound at a higher rate to control the fungus.

The plant compounds in this study inhibited both $M p$ and Fof growth in vitro and in soil. They are currently not economically viable options (Table 2.4), but with strawberry per capita consumption increasing (Wu et al., 2012), and if there existed a greater demand for the synthetic or extracted sourcing of these chemistries, this could change. If economically viable and registered as a fungicide, ferulic acid, juglone, or pCoumaric acid may prove useful to conventional and organic strawberry growers who currently have few cost-effective methods of controlling these destructive emerging soilborne fungal pathogens. 


\section{CHAPTER 3.}

\section{WEED SEED ASSAYS}

\subsection{Methodology}

\subsubsection{In Vitro Assays}

Seed Preparation - We collected Senecio vulgaris (common groundsel), Malva parviflora (little mallow), and Poa annua (annual blue grass) seed in July and August of 2014 from randomly selected Watsonville and Santa Maria, CA organic and conventional strawberry farms (see APPENDIX C.). Steven Fennimore (University of California Extension Weed Specialist) donated Melilotus officinalis (yellow sweet clover) seed, and we purchased additional M. officinalis seed from Johnny's Selected Seeds (www.johnnyseeds.com). Syngenta ${ }^{\circledR}$ provided romaine lettuce (Lactuca sativa 'Inferno’ L.) which served as a positive seed control.

We mixed weed seed of the same species from all source farms to randomize assay seeds, and spread small amounts of seed of each species on separate plastic trays. We then selected seed appearing viable based on normal shape, size, and color. We stored, and refrigerated all seed at approximately $7^{\circ} \mathrm{C}$ in paper bags.

We scarified the hard, hydrophobic seed coats of M. parviflora, and M. officinalis with a sand paper block (100-grit) in a box lined with sand paper (100-grit) prior to surface sterilization. Scarification continued until there was visible seed coat damage (Tarawali et al., 1995). We surface sterilized M.parviflora, M. officinalis, L. sativa, and P. annua seed in separate $10 \mathrm{~mL}$ conical tubes with $3 \%$ sodium hypochlorite and $1 \%$ Triton $^{\mathrm{TM}} \mathrm{X}-100$ solutions for approximately 10 mins while vortexing and inverting the solutions several times. Using sterile deionized water, we rinsed the seed five times. We vortexed and inverted the conical tubes while rinsing to assure adequate removal of the 
bleach and Triton ${ }^{\mathrm{TM}} \mathrm{X}-100$. To sterilize $S$. vulgaris seed, we placed the small seedwhich was difficult to sterilize without significant seed loss using the method previously described -in tea bags and submerged the tea bags in $100 \mathrm{~mL}$ of $6 \%$ sodium hypochlorite and $1 \%$ Triton $^{\mathrm{TM}} \mathrm{X}-100$ for 10 mins. We used a sterile spatula to place the seed on a sterile paper towel to dry. We stored the sterile seed overnight at room temperature (approx. $23^{\circ} \mathrm{C}$ ).

Experimental Treatments - In the weed seed assays, we used identical allelochemicals (with the addition of gallic acid) and concentrations to those prepared in the fungus assays (ferulic acid, gallic acid, juglone, and p-Coumaric acid at 10, 100, 500, 1000 ppmw). We prepared all media and amendments in the same manner as described for the fungus assays except mixed bacto agar $(14 \mathrm{~g})\left(\right.$ Thermo Fisher Scientific Inc. ${ }^{\circledR}$, Franklin, MA, USA) with deionized water (1 L, instead of using PDA). To serve as an herbicide control for P. annua, we amended media with unsterilized pendimethalin (Pendulum ${ }^{\circledR}$ Aquacap $^{\mathrm{TM}}$, BASF, USA) and DMSO. To serve as an herbicide control for M. parviflora, S. vulgaris, M. officinalis, and L. sativa we amended media with unsterilized oxyfluorfen (GoalTender ${ }^{\circledR}$, Dow AgroSciences, USA) and DMSO.

We determined the density of the individual herbicides by placing each herbicide in a specimen container and on a balance (Ohaus Adventure SL, Pine Brook, NJ, USA), drawing $1 \mathrm{~mL}$ of product into a micropipette, and recording the change in mass. For both pendimethalin (Pendulum ${ }^{\circledR}$ Aquacap ${ }^{\mathrm{TM}}$ ) and oxyfluorfen (GoalTender $®$ ), we replicated the density measurements four times. We needed accurate herbicide density measurements to calculate the strawberry-specific label high rate for each herbicide in 
ppmw (Pendulum ${ }^{\circledR}$ Aquacap $^{\text {TM }}$ density $( \pm 1 \mathrm{SD}): 1.19 \pm 0.004 \mathrm{~g} / \mathrm{mL}$; GoalTender ${ }^{\circledR}$ density ( $\pm 1 \mathrm{SD}): 1.14 \pm 0.005 \mathrm{~g} / \mathrm{mL})$. We produced herbicide-amended media at concentrations that were approximately $90 \%$ of the labeled in-field high rate. These rates equated to 2.7 pints per acre in 10 gallons of water for pendimethalin (Pendulum® Aquacap $\left.^{\mathrm{TM}}\right)($ http://www.cdms.net/ldat/ld3BO003.pdf), and 0.91 pints per acre in 20 gallons of water for oxyfluorfen (GoalTender®) (https://s3-us-west2.amazonaws.com/greenbook-assets/L75863.pdf).

After storing compound amended plates at $7^{\circ} \mathrm{C}$ between one and five weeks, depending on when the media was prepared, we placed the plates in a laminar flow hood for 24 hours to encourage evaporation of condensation from Petri plate lids. Drying plates overnight reduces contamination (see APPENDIX D.). We plated, with relatively even spacing, approximately 20 seeds per 110 x $15 \mathrm{~mm}$ Petri plate. We used a flamed, and then cooled, sterile spatula to spread the seed on plates. We placed six replicate parafilmed plates per treatment in a dark growth chamber (CONVIRON ${ }^{\circ}$ CMP 5090, Winnipeg, Manitoba, Canada), at ambient humidity (approximately 70\%, www.timeanddate.com) and temperature. Temperatures fluctuated between 21 and $28^{\circ} \mathrm{C}$ over the course of the experiment (the average temperature was approximately $25^{\circ} \mathrm{C}$ ). Twenty-one ${ }^{\circ} \mathrm{C}$ is likely well above the base temperature for germination of any of the winter annuals we tested (Steinmaus et al., 2000). Analysis of variance found a significant difference between shelf temperatures $(\mathrm{F}=195.0236, \mathrm{p}<.0001)$. The greatest difference between average shelf temperatures was just $0.9^{\circ} \mathrm{C}$ over the course of the experiment. Each day, we monitored plates for fungal and bacterial growth, and 
attempted to remove portions of contaminated media when possible to prevent further spread.

Data Collection and Analysis - In the growth chamber, we randomly blocked Petri plates by placing the six replicates for each treatment on six different shelves. We randomly arranged the treatments on trays and rotated the trays daily.

Pilot studies determined that the majority of the seed of all five species germinated after 10 days (data not included). There was minimal-if any-in vitro germination between days 10 and 15 . We removed $S$. vulgaris from the growth chamber at 10 days and M. officinalis seed at 12 days. Senecio vulgaris seedlings germinated rapidly and became limp and difficult to measure beyond 10 days. Melilotus officinalis seed displayed poor germination and growth in this experiment and we chose to discard these results. We incubated all other seedlings for 15 days. After removing seed assays from the growth chamber, we counted the number of germinated seeds on each Petri plate and measured the seedling length from the tip of the root radicle to the tip of the plumule (root-to-shoot growth, in $\mathrm{mm}$ ). We stored several replicates overnight in a $4^{\circ} \mathrm{C}$ fridge to prevent further growth, and collected data from these replicates on the following day.

The factors (levels in parentheses) were concentration $(10,100,500,1000$ ppmw), and treatment compound (ferulic acid, gallic acid, juglone, p-Coumaric acid, pendimethalin (Pendulum ${ }^{\circledR}$ Aquacap ${ }^{\mathrm{TM}}$ ), and oxyfluorfen $\left(\right.$ GoalTender $\left.{ }^{\circledR}\right)$ ). The response variables were $\%$ germination and seedling length $(\mathrm{mm})$. 
A generalized linear model assessed the effect of increasing plant compound concentrations on seed germination, and contrasts compared simple effects (JMP Pro 12.1.0, SAS Institute, Carey, NC, www.jmp.com).

To represent the dose-response relationship of seedling length to plant compound concentration, we fit logistic or Gompertz curves to each compound in the same manner as the fungus assays (GraphPad Prism 7.0a, La Jolla, CA, www.graphpad.com).

To assess compound potency, we combined all seedling length data from the four plant species, and fit logistic 2 parameter curves to each compound. We then compared a simpler global fit model in which two plant compound curves shared the $\operatorname{LogEC}_{50}$ parameter (logarithm of the concentration inhibiting the response by $50 \%$ ), to a more complex model in which the two plant compound curves had unique $\operatorname{LogEC}_{50}$ values (Motulsky and Christopoulos, 2003). We used the following F ratio to compare the models: $\frac{\text { Relative Difference in Sum of Squares }(S S) \text { Between Models }}{\text { Relative Difference in Degrees of Freedom }(D F) \text { Between Models }}=\frac{\frac{\text { SSsimple-SScomplex }}{\text { SScomplex }}}{\frac{\text { DFsimple-DFcomplex }}{\text { DFcomplex }}}$

When $\mathrm{p}<.0125$, we rejected the simpler model and concluded that the two $\mathrm{LogEC}_{50}$ values being compared were significantly different. We used a significance level of .0125 to control the type I error rate.

One-factor ANOVAs with Dunnet's tests compared seedling length means from plant compound treatments or from the water control, to the fungicide control $(\alpha=.05)$. 


\subsubsection{In Soil Assays}

Seed Preparation - Seeds remained in a fridge, stratified at $7^{\circ} \mathrm{C}$ until needed. We used a 100-grit sandpaper block and a box, lined with 100-grit sandpaper, to scarify $M$. parviflora and M. officinalis seed coats.

The seed assay surface sterilization procedure was similar to that for the in vitro seed assays but with slight modifications. We placed seeds in $50 \mathrm{~mL}$ conical tubes $\left(\right.$ Falcon $^{\mathrm{TM}}$, Thermo Fisher Scientific Inc. ${ }^{\circledR}$, Franklin, MA, USA) with sodium hypochlorite (3\%) and Triton ${ }^{\mathrm{TM}} \mathrm{X}-100(1 \%)$. We vortexed the seeds in solution twice for approximately 10 secs, and inverted the conical tubes several times. After 14 mins, we rinsed the seeds in the conical tubes five times with sterile deionized water. Two layers of cheesecloth prevented seed loss when pouring the rinse water. We allowed seeds to dry in a laminar flow hood on autoclaved aluminum foil for approximately $1 \mathrm{hr}$. We stored the seeds in aluminum foil-lined weigh boats (to prevent static cling) for two days.

Integrating Plant Compounds in Soil - Under a fume hood, prior to soil integration, we prepared stock solutions in vials with Teflon ${ }^{\mathrm{TM}}$-lined tops with $1.6 \mathrm{~g}$ of ferulic acid in 40 $\mathrm{mL}$ of acetone, $5.2 \mathrm{~g}$ gallic acid in $40 \mathrm{~mL}$ acetone, $0.75 \mathrm{~g}$ juglone in $30 \mathrm{~mL}$ acetone, and $0.75 \mathrm{~g} \mathrm{p}$-Coumaric acid in $30 \mathrm{~mL}$ acetone. To dilute the compounds and produce desired treatment concentrations, we used micropipettes and glass pipettes to transfer stock solution aliquots to glass test tubes with acetone. Each treatment solution and control had a total acetone volume of $15 \mathrm{~mL}$. We found that $150 \mu$ acetone/g soil was ideal to fully integrate the plant compound solution. The amount of plant compound in each treatment test tube was based on the final ppmw required in soil on a $\mu \mathrm{g}$ compound/g soil basis. We transferred each treatment solution from glass test tubes to $100 \mathrm{~g}$ of sieved, oven-dried 
soil $\left(105^{\circ} \mathrm{C}\right.$ for $\left.24 \mathrm{hrs}\right)$, and immediately mixed with a spatula to fully integrate the plant compounds. We allowed the acetone to volatize for at least an hour under a fume hood, and then placed the plant compound treated soil in a $4.4^{\circ} \mathrm{C}$ walk-in fridge to allow for additional volatilization overnight.

24-Well Plate Setup - We transferred approximately $1.2 \mathrm{~g}$ of soil from beakers with treatments to 24 -well plate wells. We measured the soil for each well by pouring treated soil into a microcentrifuge tube with a line drawn just below the $1 \mathrm{~mL}$ measurement on the microcentrifuge tube's side (we weighed $1.2 \mathrm{~g}$ of soil several times to determine that this was the correct volume). For L. sativa, M. officinalis, P. annua, and S. vulgaris, we placed four surface-sterilized seeds into individual wells (one species per well). We placed six seeds of M.parviflora in each well because pilot studies revealed that its germination rate in 24-well plate wells with soil was substantially lower than that of the other plant species. After seed addition to the wells with treated and untreated soil, we irrigated each well containing soil and plant compounds and water control well with sterile deionized water (500 $\mu \mathrm{l})$ and each herbicide control well with herbicide (500 $\mu \mathrm{l})$ using $1 \mathrm{~mL}$ micropipettes. To prepare herbicides at their high rates (1 pint GoalTender ${ }^{\circledR}$ and 3 pints Pendulum ${ }^{\circledR}$ AquaCap ${ }^{\mathrm{TM}}$ per acre) we added oxyfluorfen (GoalTender ${ }^{\circledR}$ ) (31 $\mu \mathrm{l})$ to sterile deionized water $(625 \mathrm{~mL})$, and pendimethalin $\left(\right.$ Pendulum ${ }^{\circledR}$ Aquacap $\left.{ }^{\mathrm{TM}}\right)(31$ $\mu l)$ to sterile deionized water $(208 \mathrm{~mL})$ in $1 \mathrm{~L}$ glass jars and shook vigorously to mix. We parafilmed the 24-well plates and placed them randomly on metal racks with grow lights at ambient temperature (approximately $26^{\circ} \mathrm{C}$ ) and humidity (approximately $60 \%$, www.timeanddate.com). We rotated plates on the metal racks every other day. 
On day four, we removed parafilm and all 24-well plate tops to prevent anaerobic conditions. We also noted that some of the wells appeared contaminated, and so collected “contamination" data (a covariate). We defined contamination as any well with visible microbial growth (most likely fungal). The levels of this factor were: not contaminated (0), half of well or less contaminated (1), and more than half of the well contaminated (2) (see APPENDIX E.2). We irrigated wells as needed throughout the experiment.

Experimental Treatments - The design was a randomized complete block with water and herbicide controls. We randomly assigned treatments to 1440 wells in 60,24 -well plates, and blocked by inside versus outside wells. During pilot studies, we observed that wells at the plate's exterior (16 wells) dried more quickly than wells at the plate's interior ( 8 wells). There were 12 replicates per treatment. The positive controls were the same as those from the in vitro assays, pendimethalin (Pendulum ${ }^{\circledR}$ AquaCap ${ }^{\mathrm{TM}}$ ) for Poa annua, and oxyfluorfen (GoalTender@) for Lactuca sativa 'Inferno', Melilotus officinalis, Malva parviflora, and Senecio vulgaris. We separated the plant compound concentrations by a half-log or quarter-log and used in vitro results from our research, pilot studies, and past results in the literature to determine the concentrations to apply to soil. The treatments for all five plant species, on a $\mu \mathrm{g}$ compound/g soil basis were: 1000, 1778, 3162, 5623 ppmw ferulic acid; 3162, 5623, 10000, 17783 ppmw gallic acid; 562, 1000, 1778, 3162 ppmw juglone; and, 100, 316, 1000, 3162 ppmw p-Coumaric acid.

Data Collection and Analysis - We removed all seedlings from wells on day 11 by carefully grasping seedlings at the soil line with bent-nosed metal forceps, rinsing the 
seedlings in deionized water to detach soil clods, and placing seedlings on a dampened paper 24-well plate template that corresponded to the 24-well plate the seedling came from. Due to a substantial number of individual measurements, we stored the moistened 24-well plate templates in individual 1-gallon ziplock bags and placed the bags in a $4^{\circ} \mathrm{C}$ refrigerator (to arrest growth). We collected data over the following two days.

We recorded root and shoot length for each seedling (with a ruler), number of seeds germinated per well, and level of contamination observed in each well. We also rated seedling damage in each well by assessing 24-well plate photographs from day 11 . The damage rating levels were: no damage (0), slight damage (1), and major damage (2). This rating system is similar to one used by Heisey and Heisey (2003). We defined "slight damage" as wells with seedlings that display at least one symptom of herbicide damage, and "major damage" as wells with seedlings showing multiple symptoms of herbicide damage (see APPENDIX E.2). These symptoms included: necrosis, chlorosis, epinasty, bleaching, stunted shoot or root growth, burned roots, necrotic speckling, and collapsed or discolored stems.

To represent the dose-response relationship of seedling length to plant compound concentration, we fit logistic or Gompertz curves to each compound in the same manner as the fungus assays (GraphPad Prism 7.0a, La Jolla, CA, www.graphpad.com). Analysis of variance-with appropriate Box-Cox transformations to satisfy normality and equal variance assumptions - followed by Dunnet's tests, compared seedling length in plant compound treatments to the water and herbicide controls $(\mathrm{p}<.025$, to control the type I error rate). 
Generalized linear models (binomial distribution and logit link function) followed by contrasts compared means between treatments and controls (water and herbicide) for each of the following response variables ( $p<.025$ to control the type I error rate):

damage rating, germination at 11 days, and germination at 26 days. Linear regressions assessed the relationship between mean contamination rating and increasing plant compound rates (JMP Pro 12.1.0, SAS Institute, Carey, NC, www.jmp.com). 


\subsection{Results}

\subsubsection{In Vitro Assays}

Germination - Generalized linear models compared treatments with non-zero germination probabilities. We checked that there was a non-significant Pearson coefficient to assure the data fit the binomial probability distribution, and was not overdispersed. We only removed moderate or extreme outliers if there was a clear recording error or confounding factor related to the replicate.

The blocking factor (shelf) affected the germination of L. sativa $(\mathrm{p}<.0001)$ but not the three weed species $(\mathrm{p}>$.05) (Table 3.1.). The effect of concentration nested in compound, and the effect of compound were significant for all plant species $(\mathrm{p}<.0001)$.

Table 3.1. Generalized linear model (binomial distribution and logit function) results for in vitro weed seed assays (probability of germination). We nested concentration in compound. The blocking factor was incubator shelf (6 levels).

\begin{tabular}{|c|c|c|}
\hline $\begin{array}{l}\text { Lactuca } \\
\text { sativa }\end{array}$ & $\begin{array}{c}\text { Malva } \\
\text { parviflora }\end{array}$ & Роа аппиа \\
\hline
\end{tabular}

\begin{tabular}{lllll} 
& \multicolumn{4}{c}{ p-values } \\
\cline { 3 - 5 } Generalized Linear Model & .0001 & .0001 & .0001 & .0001 \\
\cline { 3 - 5 } Block & .0001 & .5304 & .5040 & .1188 \\
Compound & .0001 & .0001 & .0001 & .0001 \\
Concentration[Compound] & .0001 & .0001 & .0001 & .0001 \\
\hline
\end{tabular}

The compound that inhibited germination to the greatest extent across all plant species was juglone (Figures 3.1-3.4.). Gallic acid inhibited germination the least. Generally, M. parviflora germination was the least sensitive, and P. annua germination was the most sensitive to plant compounds. 
At least one rate of juglone completely inhibited germination of L. sativa, $M$. parviflora, and $P$. annua $(\mathrm{p}<.001)$. Poa апnиa was particularly sensitive to juglone phytotoxicity and 100 ppmw inhibited its germination by approximately $97 \%(\mathrm{p}<.0001)$.

At the other extreme, gallic acid inhibited $P$. annua germination at $1000 \mathrm{ppmw}(\mathrm{p}$ $<.0001)$, but no other gallic acid treatment of any other plant species significantly inhibited germination $(\mathrm{p}>.05)$.

Malva parviflora was the least sensitive plant species to the inhibitory effects of phenolic acid plant compounds (Figure 3.2.). Although ferulic acid did significantly inhibit $M$. parviflora germination, its greatest inhibitory concentration, $500 \mathrm{ppmw}$, only inhibited germination by approximately $34 \%$. One hundred ppmw was the only pCoumaric acid concentration to significantly inhibit M. parviflora germination (by approximately $35 \%)$.

The herbicide control, oxyfluorfen (GoalTender®), significantly inhibited $S$. vulgaris germination $(\mathrm{p}<.05)$, but only by approximately $16 \%$ (Figure 3.4.), and did not significantly inhibit the germination of L. sativa, or M. parviflora (Figures 3.1., 3.2.). Pendimethalin (Pendulum ${ }^{\circledR}$ AquaCap ${ }^{\mathrm{TM}}$ ) completely inhibited the germination of $P$. annua in these assays (Figure 3.3.). 


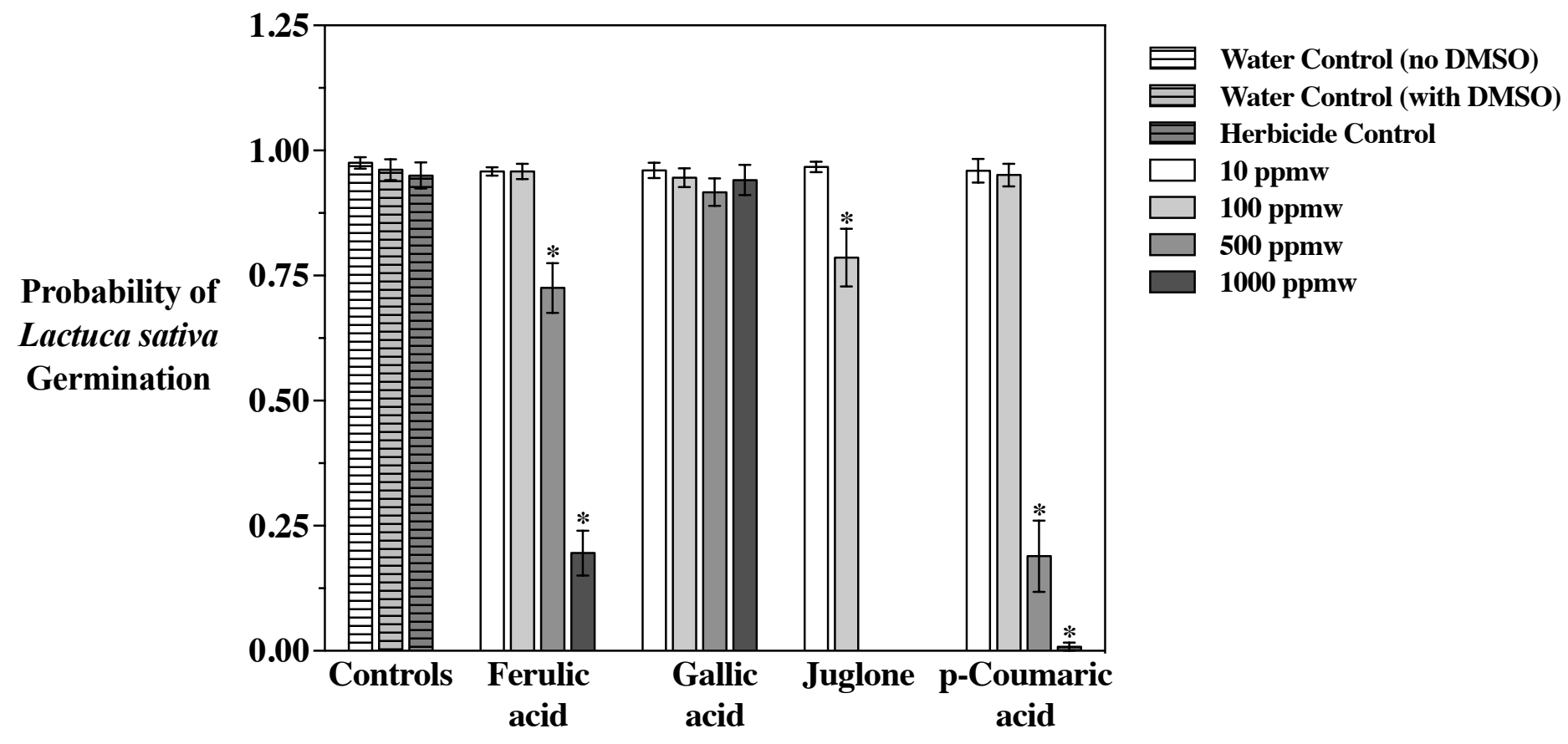

Figure 3.1. The effect of increasing plant compound concentrations $(10,100,500$, and 1000 parts per million by weight (ppmw)) on the probability of Lactuca sativa 'Inferno' germination in vitro. *The treatment was significantly different than the water control with DMSO $(\mathrm{p}<.0001)$. Error bars are \pm 1 SEM.

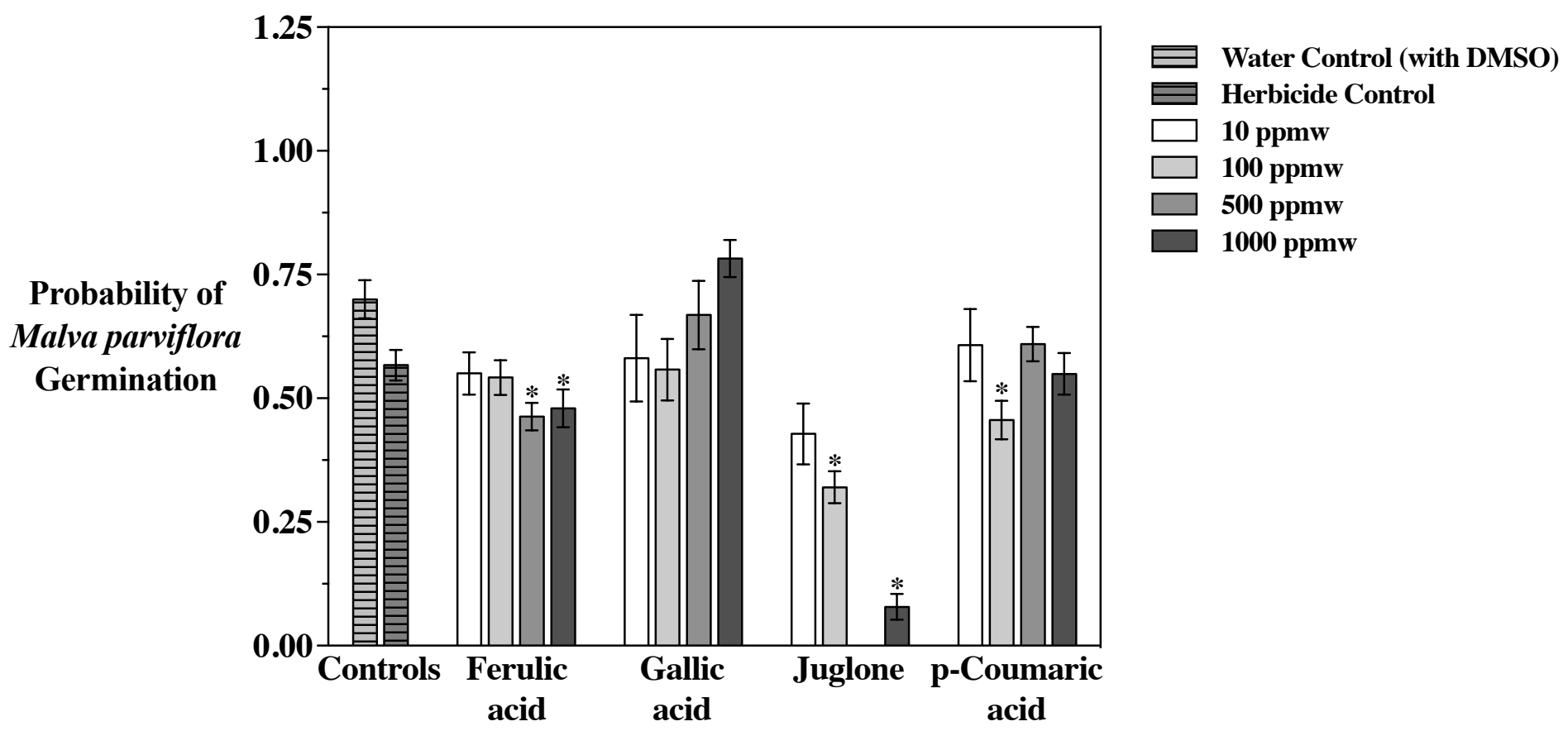

Figure 3.2. The effect of increasing plant compound concentrations $(10,100,500$, and 1000 parts per million by weight (ppmw)) on the probability of Malva parviflora germination in vitro. *The treatment was significantly different than the water control with DMSO. $\mathrm{p}<.001$ for all compounds except 1000 ppmw ferulic acid $(\mathrm{p}=.002)$. Error bars are \pm 1 SEM. 


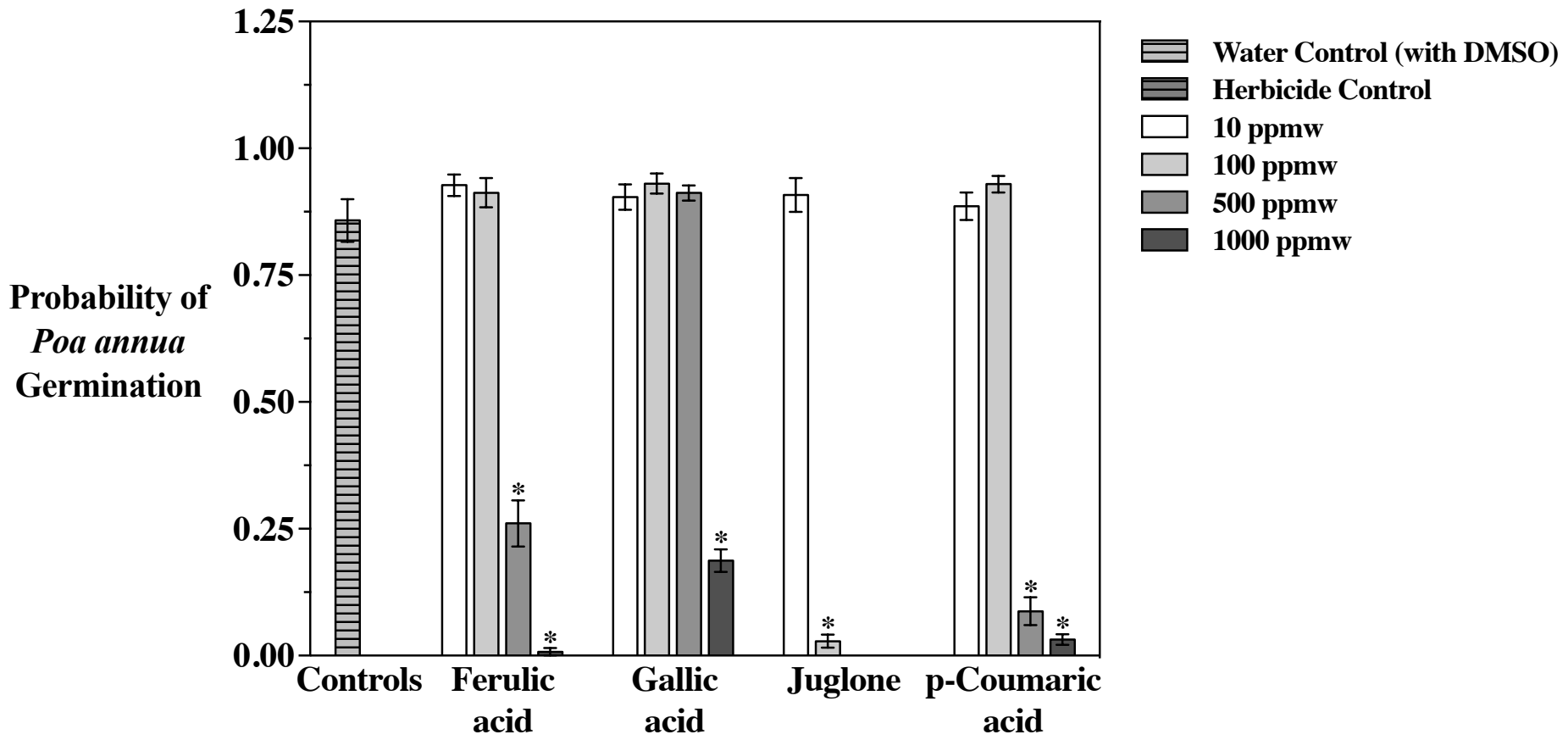

Figure 3.3. The effect of increasing plant compound concentrations $(10,100,500$, and 1000 parts per million by weight (ppmw)) on the probability of Poa annua germination in vitro. *The treatment was significantly different than the water control with DMSO $(\mathrm{p}<.0001)$. There was no germination in the herbicide controls. Error bars are \pm 1 SEM.

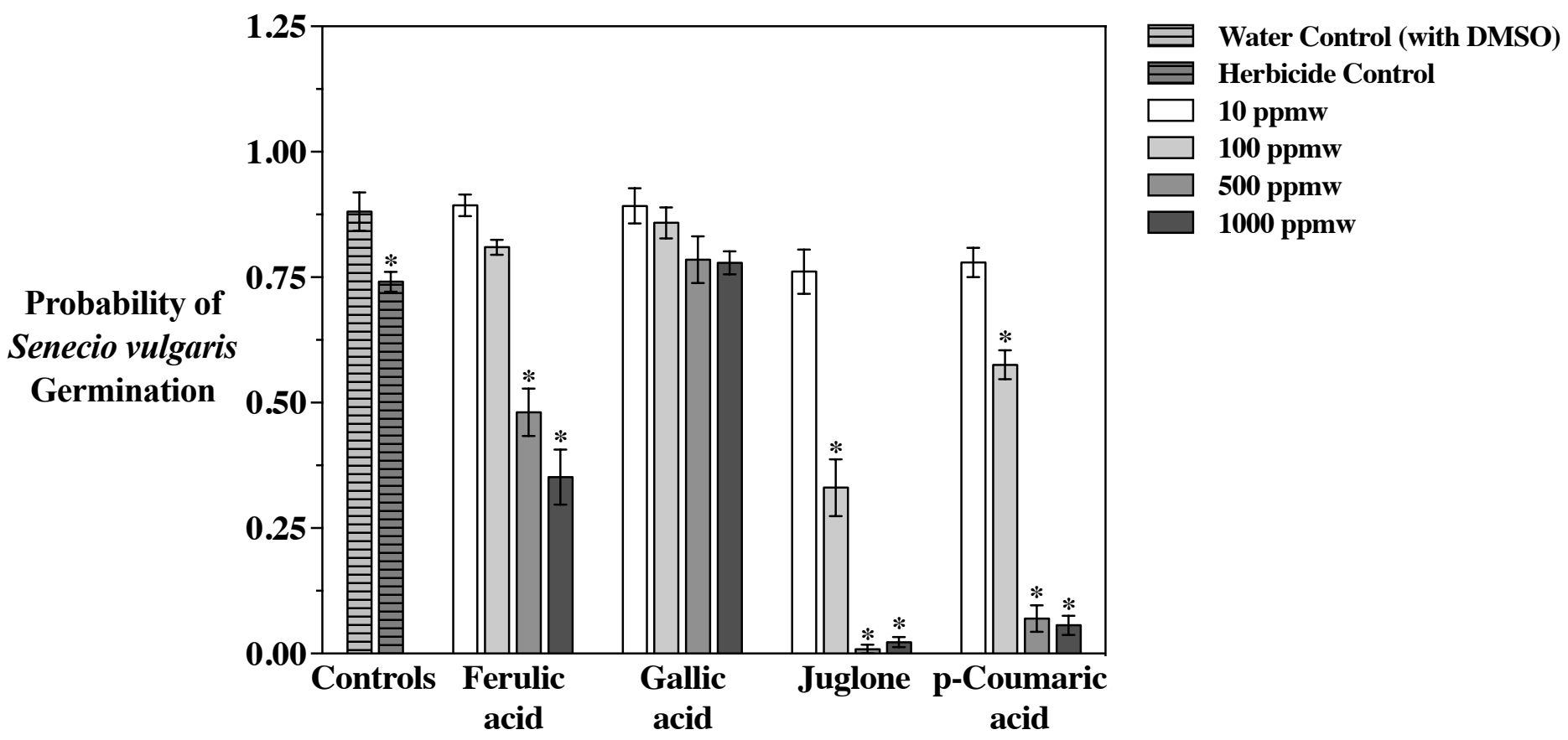

Figure 3.4. The effect of increasing plant compound concentrations $(10,100,500$, and 1000 parts per million by weight (ppmw)) on the probability of Senecio vulgaris germination in vitro. *The treatment was significantly different than the water control with DMSO $(\mathrm{p}<.0001$ for all except the herbicide control: $\mathrm{p}=.004)$. Error bars are \pm 1 SEM. 
Seedling Length - All in vitro curve fits satisfied normality, equal variance, and dependency assumptions. Juglone's logistic curve fit for Lactuca sativa 'Inferno' was the only curve to not pass the replicate's test for goodness-of-fit. Adjusted $\mathrm{R}^{2}$ values for curves modeling each combination of plant species and plant compound were between 0.80 and 0.99. Eleven out of 16 fits had adjusted $\mathrm{R}^{2}$ values of 0.95 or above (Table 3.4.).

To assess compound potency, we considered overlapping EC confidence intervals to surround EC values that were not significantly different, and non-overlapping EC confidence intervals to surround significantly different $\mathrm{EC}$ values. The most sensitive weed seed depended on the compound and if considering the $\mathrm{EC}_{50}$ or the $\mathrm{EC}_{75}$ values. Overall, Senecio vulgaris had the lowest $\mathrm{EC}_{50}$ and $\mathrm{EC}_{75}$ values of all plant species (Table 3.4.). However, these values did not always significantly different than the EC values of the other plant species we assayed.

Generally, EC confidence intervals overlapped when comparing plant compound EC values between plant species. This suggests that the plant compounds had minimal species-dependent herbicidal activity. There were a few exceptions. Gallic acid had significantly greater seedling length $\mathrm{EC}_{50}$ values for P. annua and L. sativa, than for $M$. parviflora and S. vulgaris (Table 3.4.). The gallic acid seedling length $\mathrm{EC}_{50}$ and $\mathrm{EC}_{75}$ values for $P$. апnи acid is a slightly species selective herbicidal chemistry, requiring more than two times the concentration to reach the half-maximal response for $P$. апnиа, than the half-maximal response for M. parviflora.

Juglone exhibited some selectivity, inhibiting S. vulgaris growth by $50 \%$ at a significantly lower concentration than was required to inhibit $L$. sativa by $50 \%$ (Table 
3.4.). There was no significant difference between the juglone concentrations needed to inhibit S. vulgaris and L. sativa by $75 \%$.

Juglone was the most phytotoxic plant compound in vitro. All juglone seedling length $\mathrm{EC}_{50}$ values were significantly lower than the $\mathrm{EC}_{50}$ values of every other compound, regardless of the plant species we assayed. For two of the four plant species, the juglone seedling length $\mathrm{EC}_{75}$ values were also significantly lower than the other plant compound $\mathrm{EC}_{75}$ values. The seedling length $\mathrm{EC}_{75}$ for $\mathrm{p}$-Coumaric acid in the L. sativa assays was lower than the juglone $\mathrm{EC}_{75}$, but these concentrations were not significantly different. The seedling length $\mathrm{EC}_{75}$ for juglone in the $M$. parviflora assays was the lowest among plant compounds, but also was not significantly different than p-Coumaric acid's $\mathrm{EC}_{75}$ (Table 3.4.).

Comparing the effect of ferulic acid or p-Coumaric acid across species, their $\mathrm{EC}_{50}$ values were not significantly different. However, within assays for each plant species, the $\mathrm{EC}_{50}$ values were significantly lower for p-Coumaric acid than ferulic acid for three of four species (Table 3.4.). The exception was that ferulic acid and p-Coumaric acid did not have significantly different $\mathrm{EC}_{50}$ values in $P$. annua assays.

Analyses of variance for each plant species, followed by Dunnet's post-hoc tests, compared plant compound treatments or the water control to the herbicide control. All ANOVAs and the treatment factors for each species were significant $(\mathrm{p}<.0001)$. The blocking factor (shelf) was only significant for P. annua $(\mathrm{p}=.0228)$ (Table 3.2.). The herbicide control significantly inhibited the seedling length of $P$. annua (100\% inhibition) and S. vulgaris (12.2\% inhibition) compared to the water control, but not L. sativa (18.3\% inhibition, not significantly different than the water control) or M. parviflora 
(18.7\% inhibition, not significantly different than the water control). Generally, treatments higher than 10 ppmw significantly inhibited seedling length $(\mathrm{p}<.05)$ compared to the herbicide control (Figure 3.6.).

Table 3.2. One-factor analysis of variance comparing the effect of treatments on seedling length. The treatment factor levels were plant compounds at each of the four rates, the water control, and the fungicide control. The blocking factor was the growth chamber shelf.

\begin{tabular}{lcccc}
\cline { 3 - 5 } & $\begin{array}{c}\text { Lactuca sativa } \\
\text { 'Inferno' }\end{array}$ & Malva parviflora & Poa annua & Senecio vulgaris \\
& \multicolumn{4}{c}{$\mathrm{p}$-values } \\
\hline ANOVA (omnibus) & .0001 & .0001 & .0001 & .0001 \\
Block & .8874 & .2870 & .0228 & .9367 \\
Treatment & .0001 & .0001 & .0001 & .0001 \\
\hline
\end{tabular}

We fit additional curves to the plant compound assay data by combining the response, seedling length as a $\%$ of the control, for each plant species, and fitting logistic functions to each of the compounds. This made it possible to perform F-tests between a simpler model (logistic one parameter functions) with shared $\mathrm{EC}_{50}$ values among compounds, and more complex model (logistic two parameter functions) where the $\mathrm{EC}_{50}$ values were not shared. The null hypothesis was that the complex model did not fit the data any better than the simple model. When comparing any two plant compound functions, we found that there was a significant difference between the simple and complex models, indicating that the complex model was a better fit, and therefore, there was a difference between the $\mathrm{EC}_{50}$ values of the compounds $(\mathrm{p}<.0001$, Table 3.3.). Plant compound phytotoxicity was as follows: juglone $>$ p-Coumaric acid $>$ ferulic acid $>$ gallic acid. The order of least to most expensive plant compound was: gallic acid $<$ pCoumaric acid $<$ juglone $<$ ferulic acid. 


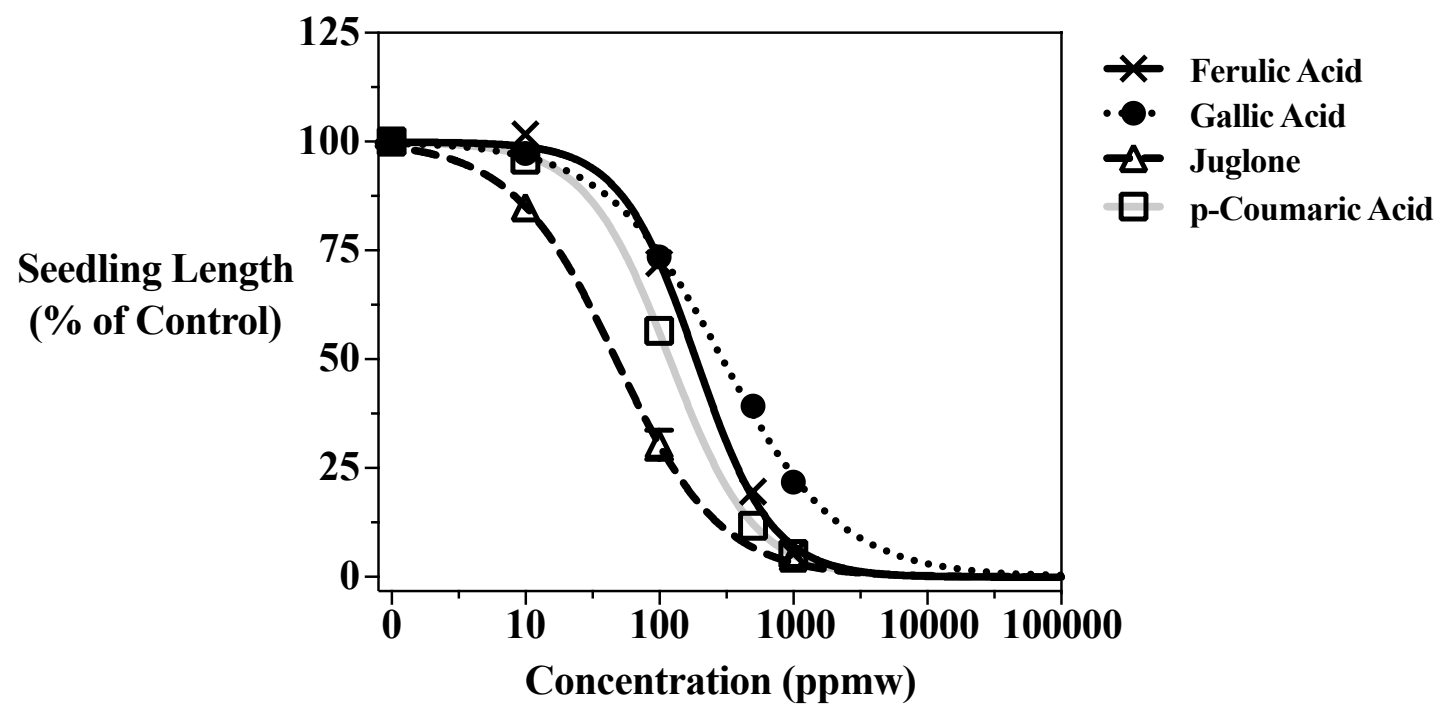

Figure 3.5. The effect of increasing plant compound concentrations $(10,100,500$, and 1000 parts per million by weight (ppmw)) on the seedling length of Lactuca sativa, Malva parviflora, Poa annua, and Senecio vulgaris when combined. Logistic two-parameter functions fit the data for each compound. Error bars are \pm 1 SEM.

Table 3.3. Hillslope, adjusted $\mathrm{R}^{2}$, and $\mathrm{EC}_{50}$ and $\mathrm{EC}_{75}$ values (parts per million by weight) when combining seedling length data from Lactuca sativa, Malva parviflora, Poa annua, and Senecio vulgaris. All $\mathrm{EC}_{50}$ values are significantly different $(\mathrm{p}<.0001)$. Cost (USD) is based on a liter of solution at the $\mathrm{EC}_{50}$ or $\mathrm{EC}_{75}$ of each compound. LCL: lower $95 \%$ confidence limit. UCL: upper 95\% confidence limit.

\begin{tabular}{|c|c|c|c|c|c|c|c|c|c|c|}
\hline \multirow{2}{*}{\multicolumn{2}{|c|}{$\begin{array}{c}\text { Adj. } \\
\mathbf{R}^{2}\end{array}$}} & \multirow[b]{2}{*}{ Hillslope } & \multicolumn{3}{|c|}{$\mathbf{E C}_{50}$} & \multirow{2}{*}{$\begin{array}{c}\text { Cost } \\
\text { (\$/liter) }\end{array}$} & \multicolumn{3}{|c|}{$\mathbf{E C}_{75}$} & \multirow{2}{*}{$\begin{array}{c}\text { Cost } \\
\text { (\$/liter) }\end{array}$} \\
\hline & & & UCL & Mean & LCL & & UCL & Mean & $\mathrm{LCL}$ & \\
\hline Ferulic Acid & 0.94 & -1.54 & 170 & 189 & 209 & 1.56 & 339 & 386 & 442 & 3.18 \\
\hline Gallic Acid & 0.92 & -0.98 & 263 & 297 & 332 & 0.21 & 782 & 908 & 1067 & 0.66 \\
\hline Juglone & 0.91 & -1.12 & 40 & 47 & 56 & 0.95 & 103 & 127 & 160 & 2.54 \\
\hline p-Coumaric Acid & 0.95 & -1.38 & 109 & 120 & 132 & 0.72 & 233 & 266 & 309 & 1.60 \\
\hline
\end{tabular}


Table 3.4. Regression adjusted $\mathbf{R}^{2}$, Hillslope, $\mathrm{EC}_{50}$, and $\mathrm{EC}_{75}$ values (parts per million by weight) for lettuce and weed seeds growing on water agar amended with ferulic acid, gallic acid, juglone, or p-Coumaric acid. LCL: lower 95\% confidence limit. UCL: upper 95\% confidence limit.

\begin{tabular}{|c|c|c|c|c|c|c|c|c|c|c|}
\hline \multirow[b]{2}{*}{ Species } & \multirow[b]{2}{*}{ Compound } & \multicolumn{3}{|c|}{ Adj. } & \multicolumn{3}{|c|}{$\mathbf{E C}_{50}$} & \multicolumn{3}{|c|}{$\mathbf{E C}_{75}$} \\
\hline & & Regression & $\mathbf{R}^{2}$ & Hillslope & LCL & Mean & UCL & LCL & Mean & UCL \\
\hline \multirow{4}{*}{$\begin{array}{l}\text { Lactuca sativa } \\
\text { 'Inferno' }\end{array}$} & Ferulic Acid & Gompertz 2P & 0.99 & -2.02 & 172 & 191 & 210 & 381 & 420 & 465 \\
\hline & Gallic Acid & Gompertz 2P & 0.99 & -1.74 & 324 & 354 & 385 & 807 & 885 & 977 \\
\hline & Juglone & Logistic 2P & 0.98 & -0.70 & 56 & 64 & 72 & 243 & 305 & 400 \\
\hline & p-Coumaric Acid & Logistic $2 \mathrm{P}$ & 0.98 & -1.38 & 107 & 119 & 132 & 225 & 263 & 316 \\
\hline \multirow{4}{*}{$\begin{array}{c}\text { Malva } \\
\text { parviflora }\end{array}$} & Ferulic Acid & Logistic $2 \mathrm{P}$ & 0.94 & -1.81 & 180 & 226 & 279 & 323 & 413 & 531 \\
\hline & Gallic Acid & Logistic 2P & 0.90 & -0.85 & 135 & 193 & 264 & 484 & 705 & 1096 \\
\hline & Juglone & Logistic 2P & 0.92 & -1.10 & 33 & 48 & 68 & 87 & 131 & 210 \\
\hline & p-Coumaric Acid & Gompertz 2P & 0.95 & -1.55 & 72 & 96 & 126 & 208 & 270 & 359 \\
\hline \multirow{4}{*}{ Роа аппиа } & Ferulic Acid & Logistic 3P & 0.95 & -0.91 & 125 & 157 & 187 & 469 & 526 & 599 \\
\hline & Gallic Acid & Logistic 3P & 0.95 & -0.83 & 409 & 478 & 541 & 1468 & 1799 & 2352 \\
\hline & Juglone & Logistic 3P & 0.89 & -1.59 & 39 & 55 & 79 & 73 & 110 & 152 \\
\hline & p-Coumaric Acid & Gompertz 3P & 0.80 & -1.22 & 104 & 125 & 150 & 202 & 247 & 293 \\
\hline \multirow{4}{*}{$\begin{array}{l}\text { Senecio } \\
\text { vulgaris }\end{array}$} & Ferulic Acid & Logistic $2 \mathrm{P}$ & 0.95 & -2.05 & 150 & 184 & 229 & 242 & 314 & 416 \\
\hline & Gallic Acid & Logistic $2 \mathrm{P}$ & 0.96 & -1.45 & 220 & 262 & 306 & 468 & 560 & 676 \\
\hline & Juglone & Logistic $2 \mathrm{P}$ & 0.96 & -1.42 & 25 & 33 & 43 & 52 & 71 & 97 \\
\hline & p-Coumaric Acid & Logistic 1P & 0.96 & -1.97 & 107 & 123 & 142 & 185 & 216 & 247 \\
\hline
\end{tabular}



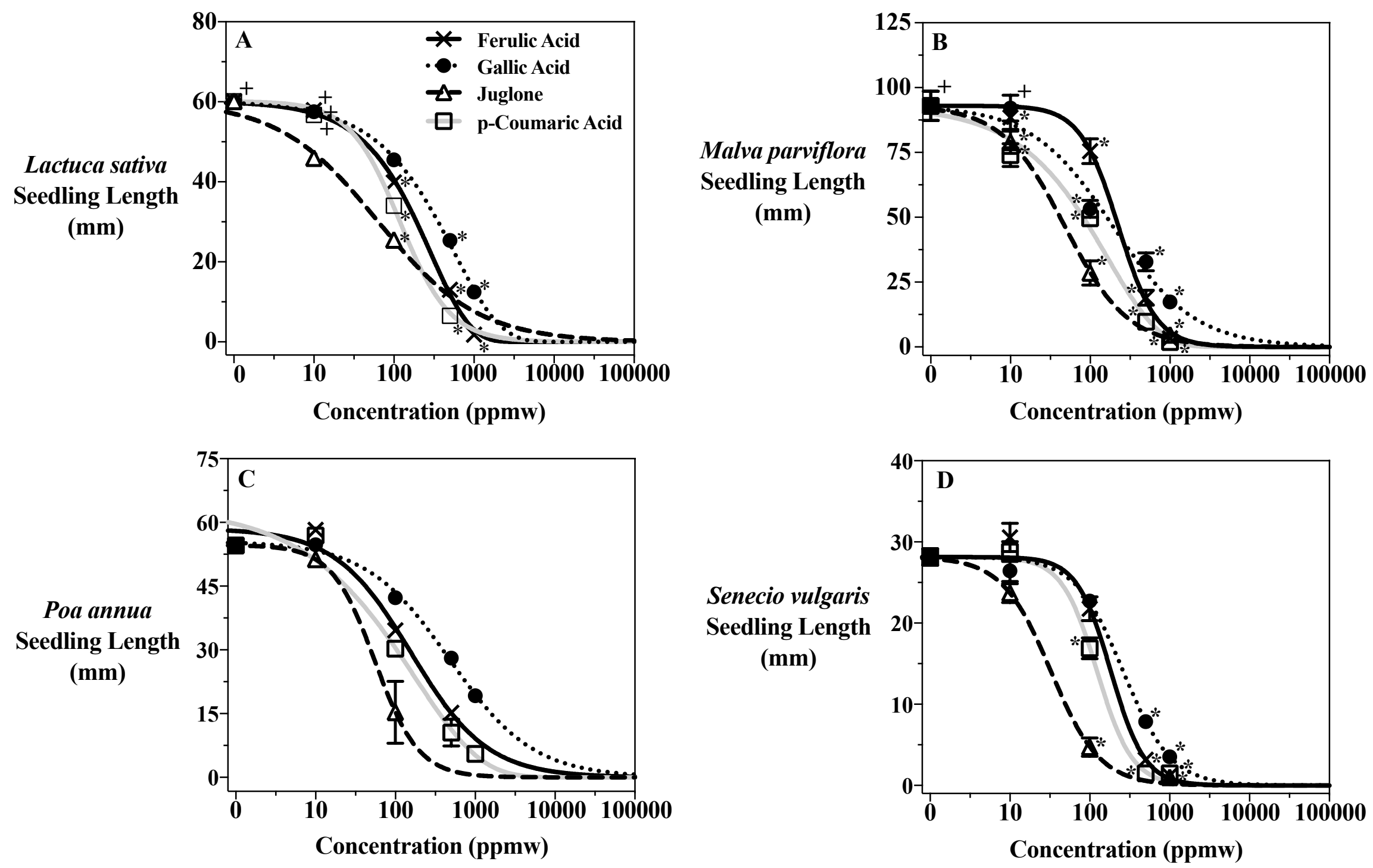

Figure 3.6. The effect of increasing plant compound concentrations $(10,100,500$, and 1000 parts per million by weight (ppmw)) in vitro on the seedling length of Lactuca sativa 'Inferno' (A), Malva parviflora (B), Poa annua (C), and Senecio vulgaris (D). +Seedling length was significantly greater than the herbicide control $(\mathrm{p}<.05)$. *Seedling length was significantly less than the herbicide control $(\mathrm{p}<.05)$. There was no growth in the $P$. annua herbicide control plates. Error bars are \pm 1 SEM. 


\subsubsection{In Soil Assays}

Table 3.5. Concentrations (parts per million by weight (ppmw)) for each plant compound. We separated concentrations by a quarter-log or half-log. Concentrations were based on in vitro assays, pilot studies, and past research.

\begin{tabular}{ccccc}
\cline { 2 - 4 } & Ferulic Acid & Gallic Acid & Juglone & $\begin{array}{c}\text { p-Coumaric } \\
\text { Acid }\end{array}$ \\
Rate & & Concentration (ppmw) & \\
\hline Low & 1000 & 3162 & 562 & 100 \\
Medium Low & 1778 & 5623 & 1000 & 316 \\
Medium High & 3162 & 10000 & 1778 & 1000 \\
High & 5623 & 17783 & 3162 & 3162 \\
\hline
\end{tabular}

Germination - The generalized linear models for 26 day germination data for each species were highly significant ( $\mathrm{p}<.0001$; Table 3.6.). The effects of compound and concentration nested in compound were also highly significant for all plant species $(\mathrm{p}<$ .0001). Contamination (day 11) did not affect the germination of any plant species ( $\mathrm{p}>$ .05). The blocking factor (inside versus outside well) was significant in M. officinalis assays $(\mathrm{p}=.0397)$, but did not significantly affect the germination of the other plant species.

Table 3.6. Generalized linear model (binomial distribution and logit function) for the probability of germination in soil 26 days after initial treatment. We nested concentration in compound. Contamination (day 11) was a covariate. The blocking factor levels were inside and outside wells of 24-well plates.

$\begin{array}{ccccc}\text { Lactuca } & \text { Malva } & \text { Melilotus } & \text { Poa } & \text { Senecio } \\ \text { sativa } & \text { parviflora } & \text { officinalis } & \text { annua } & \text { vulgaris } \\ \text { 'Inferno' } & & & \end{array}$

\begin{tabular}{llllll} 
& \multicolumn{5}{c}{ p-values } \\
\cline { 3 - 6 } Generalized Linear Model & .0001 & .0001 & .0001 & .0001 & .0001 \\
\cline { 3 - 6 } Block & .2546 & .5930 & .0397 & .0805 & .7505 \\
Contamination (day 11) & .1975 & .2671 & .9098 & .5339 & .1033 \\
Compound & .0001 & .0001 & .0001 & .0001 & .0001 \\
Concentration[Compound] & .0001 & .0001 & .0001 & .0001 & .0001 \\
\hline
\end{tabular}


There were only minor differences between Lactuca sativa 'Inferno' germination on day 11 and day 26 (Figure 3.7.). Gallic acid's medium-low rate had significantly less germination than the water control on day $11(\mathrm{p}<.025)$, but this significant difference no longer existed by day $26(\mathrm{p}>.025)$. There was no germination in gallic acid mediumhigh rate treatments on day 11 , but there was germination on day 26 and this level of germination was significantly less than both the herbicide and water controls $(\mathrm{p}<.025)$.

The dose-dependent inhibition of germination varied according to the plant compound we assayed. Ferulic acid, at the rates we used, did not inhibit the germination of any plant species in a clear dose-dependent manner. In gallic acid, juglone, and pCoumaric acid treatments, however, germination decreased with increasing plant compound rates (Figures 3.7.-3.9.). The dose-dependency was especially apparent in gallic acid and p-Coumaric acid assays. For all plant species, except for M. officinalis where the medium-low rate of gallic acid was also inhibitory, the two low rates of gallic acid and p-Coumaric acid did not inhibit germination, while the two higher rates did inhibit germination. Juglone inhibited the germination of all plant species at all rates. In M. parviflora and M. officinalis juglone assays, seeds did not germinate in wells above the lowest rate. 

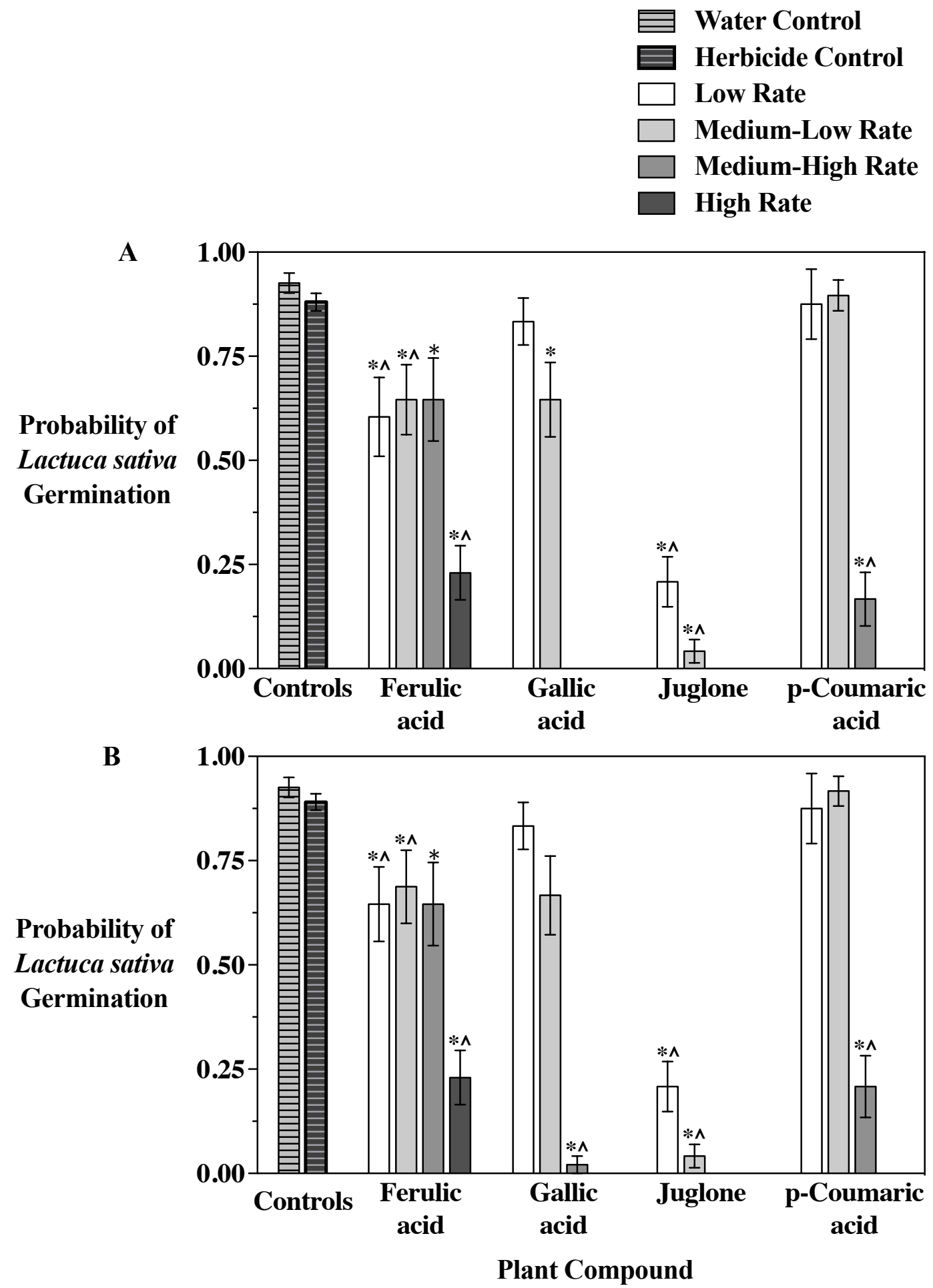

Figure 3.7. Probability of Lactuca sativa 'Inferno' germination 11 days (A) and 26 days (B) after initial treatment. *The treatment was significantly different than the water control $(\mathrm{p}<.025)$. $\wedge$ The treatment was significantly different than the herbicide control $(\mathrm{p}<.025)$. Error bars are \pm 1 SEM. 


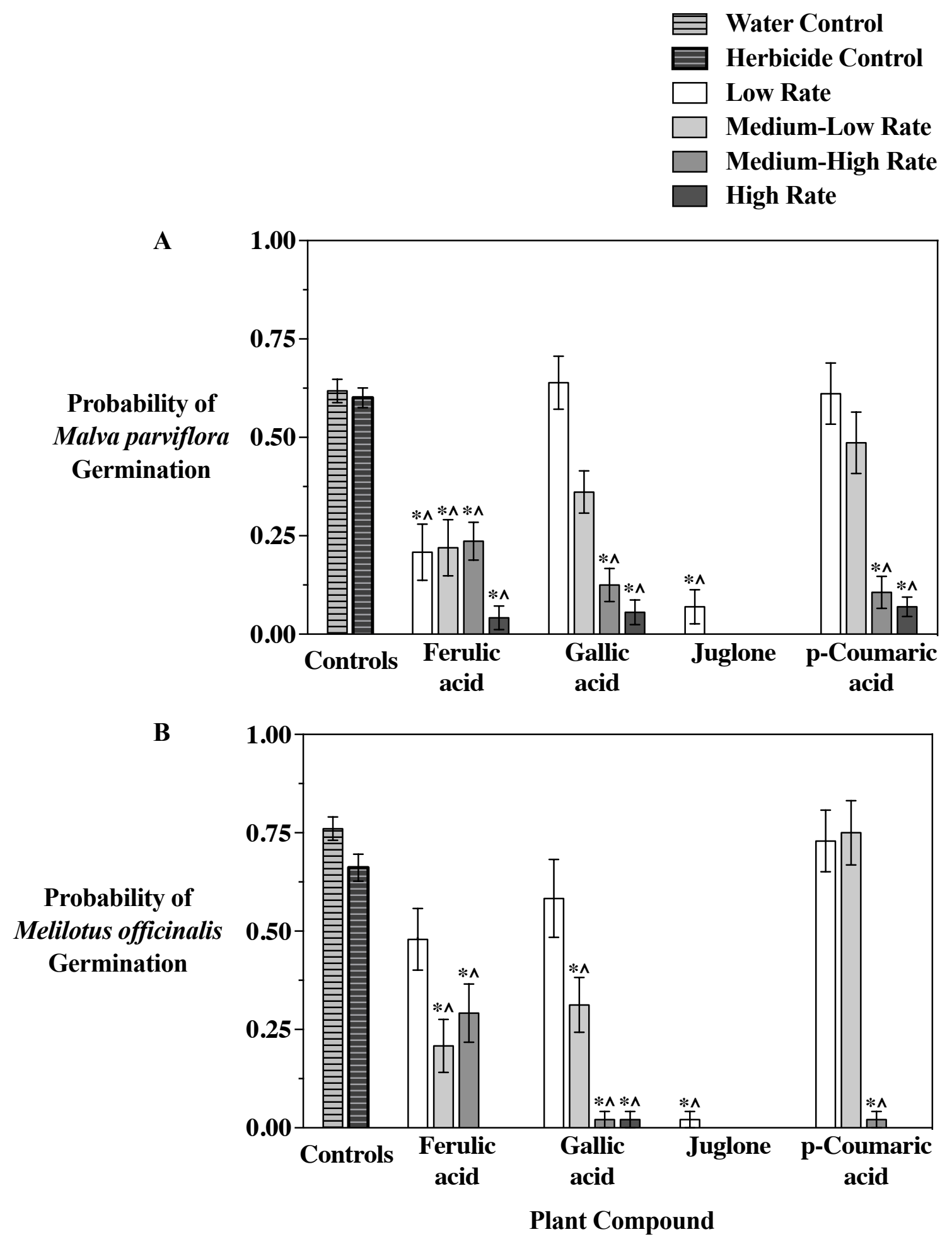

Figure 3.8. Probability of Malva parviflora (A) and Melilotus officinalis (B) germination 26 days after initial treatment. $*$ The treatment was significantly different than the water control $(\mathrm{p}<.025)$. $^{\wedge}$ The treatment was significantly different than the herbicide control $(\mathrm{p}<.025)$. The $M$. parviflora generalized linear model failed overdispersion tests $(\mathrm{p}<.05)$. Error bars are \pm 1 SEM. 
Water Control

Eerbicide Control

Low Rate

Medium-Low Rate

Medium-High Rate

High Rate
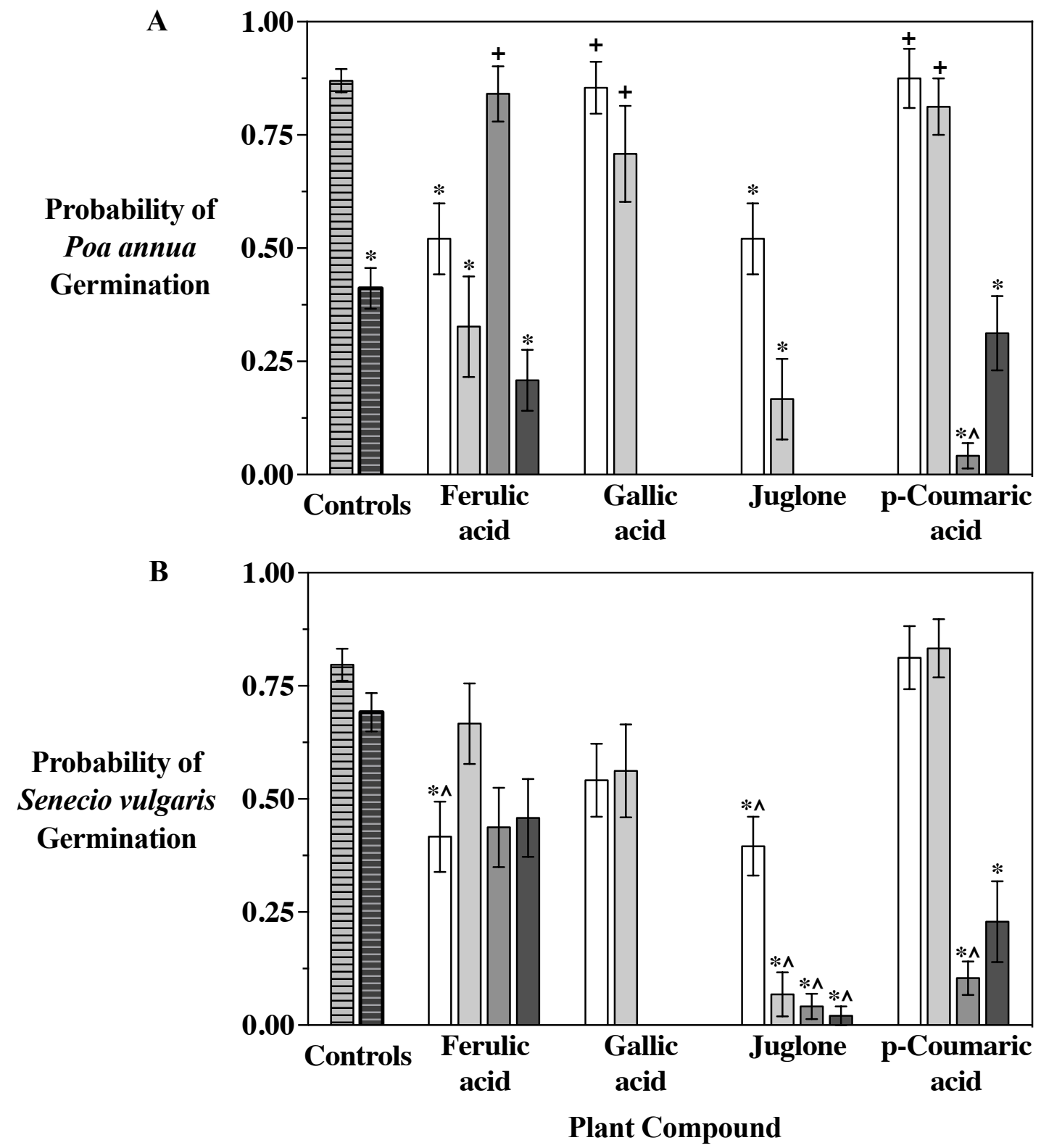

Figure 3.9. Probability of Poa annua (A) and Senecio vulgaris (B) germination 26 days after initial treatment. *The treatment was significantly different than the water control $(\mathrm{p}<.025)$. ${ }^{\wedge}$ The treatment was significantly different than the herbicide control $(\mathrm{p}<.025)$. +The treatment had significantly greater germination than the herbicide control $(\mathrm{p}<.025)$. Both analyses failed overdispersion tests $(\mathrm{p}<.05)$. Error bars are \pm 1 SEM. 
Damage Rating - A generalized linear model

with a bionomial distribution, logit link

function, and the response variable "damage

rating" was highly significant $(\mathrm{p}<.0001)$. The

factors contamination (day 11) $(\mathrm{p}=.0484)$,

compound $(\mathrm{p}<.0001)$, and concentration
Table 3.7. Generalized linear model (binomial distribution and logit link function) main effect $p$-values for the seedling damage rating in wells 11 days after initial treatment.

\begin{tabular}{lc} 
& $\mathrm{p}$-values \\
Generalized Linear Model & $<.0001$ \\
Block & 1.0000 \\
Contamination (day 11) & .0484 \\
Compound & $<.0001$ \\
Concentration[Compound] & $<.0001$ \\
\hline
\end{tabular}

nested in compound $(\mathrm{p}<.0001)$ were

also significant (Table 3.7.). Except for the low rate of $p$-Coumaric acid $(p=.135)$, all

concentrations of the plant compounds had significantly greater mean damage ratings

than the water control $(\mathrm{p}<.025)$ (Figure 3.10.). Each plant compound, except $\mathrm{p}-$

Coumaric acid, had at least one concentration that was not significantly different than the herbicide control ( $\mathrm{p}>.025)$, and therefore displayed herbicide damage symptoms and lacked germination in a similar manner to conventional herbicide-treated wells. No

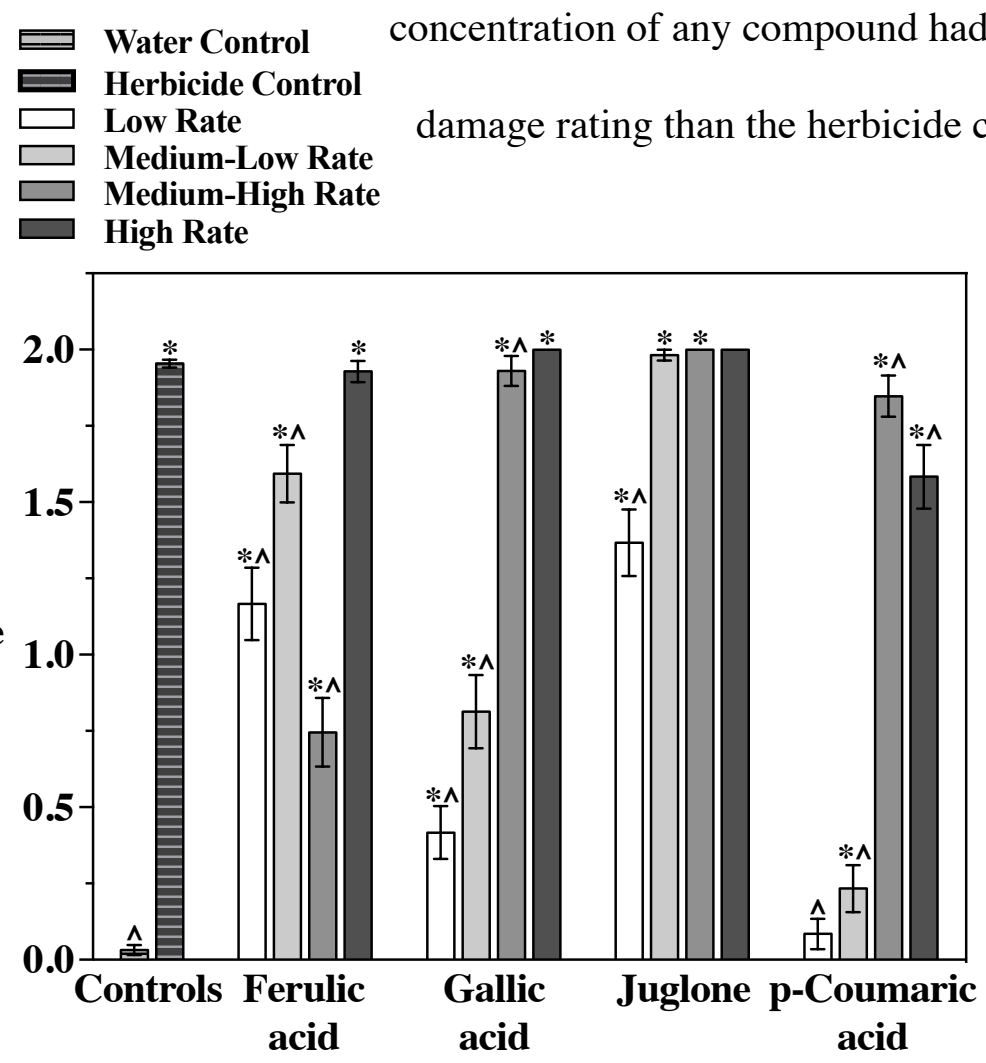

66
Figure 3.10. Mean seedling damage rating for all plant species combined (Lactuca sativa 'Inferno', Malva parviflora, Melilotus officinalis, Poa annua, and Senecio vulgaris) in plant compound treated soil. We assigned a damage rating to each well $(0,1$, or 2; see APPENDIX E.2). $\mathrm{N}=1419$. *The treatment was significantly different than the water control $(\mathrm{p}<.025) .^{\wedge}$ The treatment was significantly different than the herbicide control $(\mathrm{p}<.025)$. We could not compare the high rate of juglone to the herbicide control. Error bars are \pm 1 SEM. 
Contamination - An average contamination rating close to zero designated a treatment with little contamination (visible fungal growth) across replicate wells, and an average contamination rating between 1 and 2 designated a treatment with substantial contamination across replicates. There was minimal contamination in water control (mean: 0.004) and herbicide control (mean: 0.004) wells (Figure 3.11.). There was also minimal contamination in the low (mean: 0.033 ), medium-low (mean: 0 ), and mediumhigh (mean: 0.017) rates of p-Coumaric acid.

The highest rates of each phenolic acid plant compound were substantially contaminated (ferulic acid high rate mean: 1.61, gallic acid high rate mean: 1.93, and pCoumaric acid high rate mean: 1.92). Linear regressions found highly significant positive relationships between contamination rating and plant compound rate for each phenolic acid plant compound $(\mathrm{p}<.0001)$. The relationship between contamination rating and

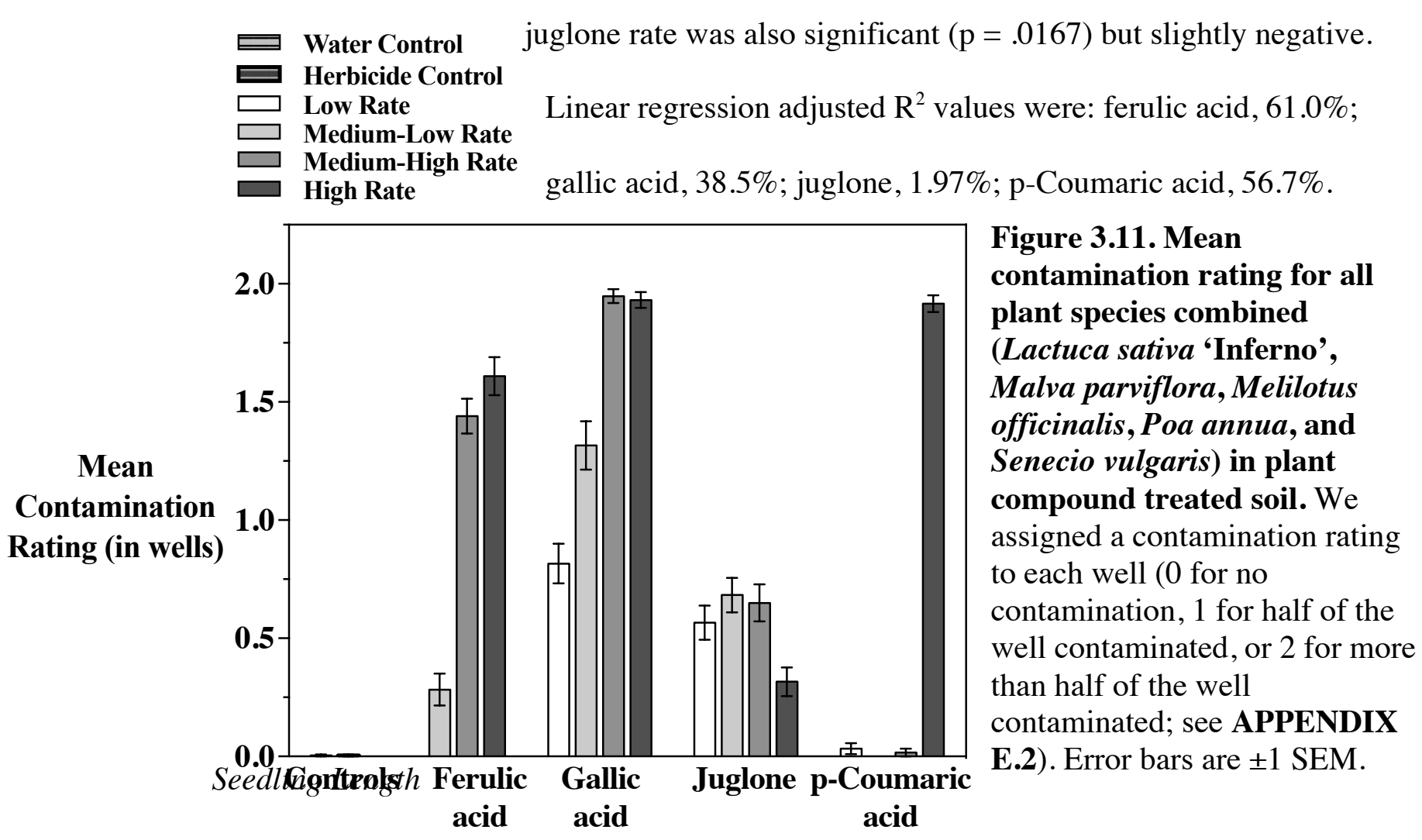


For several of the assays, dormancy and contamination (visible fungal growth) may have contributed to a non-sigmoidal relationship between seedling length and concentration. This made it difficult or impossible to fit Gompertz or logistic functions to the data (see APPENDIX F.).

Lactuca sativa 'Inferno' exhibited very little dormancy, and we were able to fit curves to all L. sativa seedling length data (Figure 3.12.). We also fit curves to $S$. vulgaris seedling length data from ferulic acid-treated soil, M. parviflora seedling length data from gallic acid-treated soil, $P$. апnиa seedling length data from juglone-treated soil,

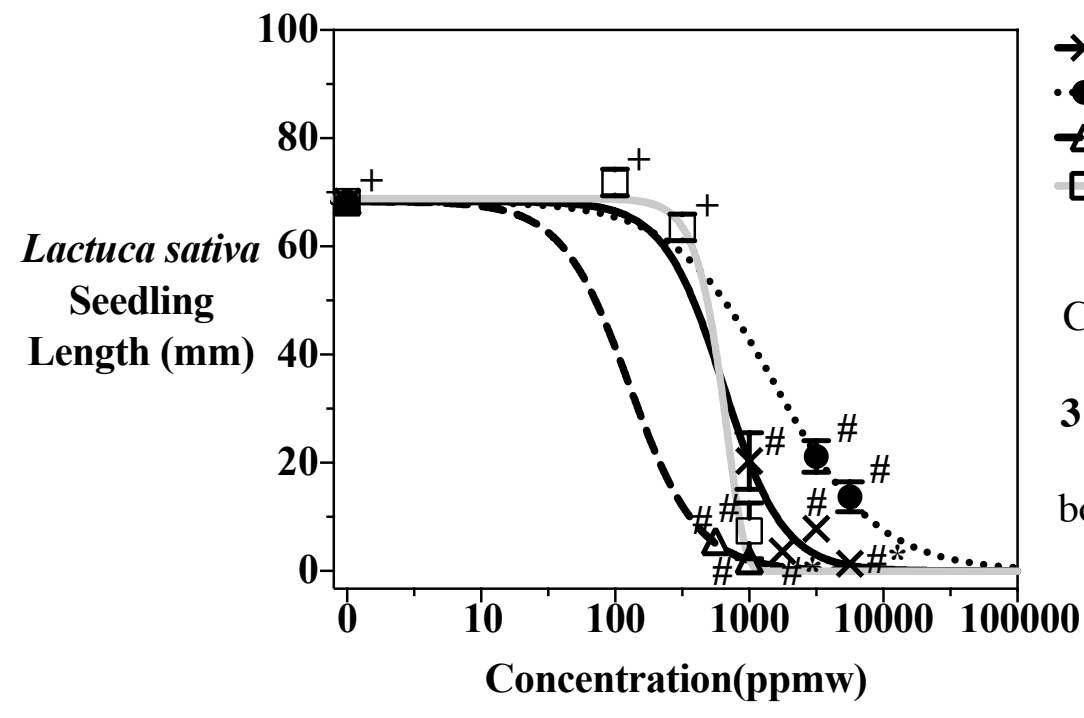

Figure 3.12. Lactuca sativa 'Inferno' seedling length 11 days after initial soil treatment in response to increasing rates of plant compounds. Concentration is on a logarithmic scale. +Treatment seedling length was significantly greater than the herbicide control $(\mathrm{p}$ $<.025)$. \#Treatment was significantly less than the water control. *Treatment seedling length was significantly less than the herbicide control $(\mathrm{p}<.025)$. The herbicide control had significantly shorter seedlings than the water control $(\mathrm{p}<.0001)$. Error bars are \pm 1 SEM.

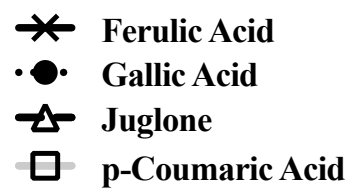

Coumaric acid-treated soil (Figure

3.13.). We fitted the juglone curves for both L. sativa and P. annua, and the gallic acid curve for L. sativa to just three plant compound rates and so they were less reliable than the other curve fits. We excluded the two highest rates of juglone in $L$. sativa, and $P$. annua assays because they completely inhibited seedling length. Gallic acid's two highest rates also 
completely inhibited L. sativa growth and so we excluded these zero seedling length results, as well. We could not fit juglone seedling length curves for M. parviflora, $M$. officinalis, or S. vulgaris due to dormancy, and/or because the compound completely inhibited seedling length on day 11 at all rates (which was the case for both $M$. parviflora and M. officinalis, see APPENDIX F.).

Curve fits, at times, violated model assumptions and/or model fit criteria so we suggest exercising some caution when interpreting model predictions. Adjusted $\mathrm{R}^{2}$ values were 0.93 or above for all fitted curves except p-Coumaric acid's $P$. annua seedling length fit (0.87) (Tables 3.9. and 3.10a.).

We considered overlapping EC confidence intervals to surround EC values that were not significantly different, and non-overlapping EC confidence intervals to surround significantly different $\mathrm{EC}$ values. The $\mathrm{EC}_{50}$ and $\mathrm{EC}_{75}$ values were significantly lower for juglone than any of the other plant compounds (Tables 3.9. and 3.10a.). Gallic acid required the greatest concentrations to achieve half-maximal and three-quarters maximal responses. Plant compounds for the L. sativa assays were in the following order of greatest to lowest phytotoxicity: juglone $>$ p-Coumaric acid $>$ ferulic acid $>$ gallic acid.

Generally, L. sativa seedling length $\mathrm{EC}_{50}$ values associated with each plant compound were lower than the weed seedling length $\mathrm{EC}_{50}$ values associated with the weed species seedling length data we were able to fit curves to. However, S. vuglaris in ferulic acid-treated wells had a significantly lower $\mathrm{EC}_{50}$ value than L. sativa in ferulic acid-treated wells. Even so, S. vulgaris and L. sativa did not have significantly different ferulic acid $\mathrm{EC}_{75}$ values. 
The cost to inhibit L. sativa seedling length in soil by $50 \%$ on a per acre basis (at a depth equivalent to that of the soil in 24-well plate wells) was in the following order of least to most expensive: gallic acid $<$ juglone $<$ p-Coumaric acid $<$ ferulic acid (Table 3.9.). The order of least to most expensive compound to inhibit L. sativa seedling length by $75 \%$ in soil on a per acre basis was nearly identical, with p-Coumaric acid being less expensive than juglone at this higher rate. Prices of individual plant compounds may decline if supply increases due to an increase in demand.

Analyses of variance followed by Dunnet's tests compared the mean seedling length of the water or herbicide controls to the mean seedling length of treatments (Table 3.8.). In L. sativa assays, all treatments had significantly shorter mean seedling lengths than the water control except for the low and medium-low rates of p-Coumaric

Table 3.8. Analysis of variance (response variable: seedling length) for Lactuca sativa 'Inferno', Malva parviflora, Poa annua, or Senecio vulgaris growing in soil amended with plant compounds. The "Treatment" factor levels were the four compounds at each rate (low, medium-low, medium-high, and high).

\begin{tabular}{lccccc} 
& $\begin{array}{c}\text { Lactuca sativa } \\
\text { 'Inferno' }\end{array}$ & $\begin{array}{c}\text { Malva } \\
\text { parviflora }\end{array}$ & $\begin{array}{c}\text { Poa } \\
\text { annua }\end{array}$ & Poa annua & $\begin{array}{c}\text { Senecio } \\
\text { vulgaris }\end{array}$ \\
Compound & $\begin{array}{c}\text { All } \\
\text { Compounds }\end{array}$ & $\begin{array}{c}\text { Gallic } \\
\text { Acid }\end{array}$ & Juglone & $\begin{array}{c}\text { p-Coumaric } \\
\text { acid }\end{array}$ & $\begin{array}{c}\text { Ferulic } \\
\text { Acid }\end{array}$ \\
\cline { 2 - 6 } \multicolumn{1}{c}{ ANOVA } & $<.0001$ & $<.0001$ & $<.0001$ & $<.0001$ & $<.0001$ \\
\cline { 2 - 6 } Block & .1966 & .0391 & .2903 & .8399 & .9447 \\
Contamination (Day 11) & .8633 & .0006 & - & - & .8317 \\
Treatment & $<.0001$ & $<.0001$ & $<.0001$ & $<.0001$ & $<.0001$ \\
\hline
\end{tabular}

acid (Figure. 3.12.). These two rates were also the only two plant compound treatments to have significantly longer L. sativa seedling lengths than the herbicide control. The medium-low and high rate ferulic acid treatments had significantly shorter L. sativa 
seedling lengths than the herbicide control. In the weed assays, at least one plant compound treatment had significantly shorter mean seedling lengths than the water control except for gallic acid (Figure 3.13.). In gallic acid M. parviflora assays the only treatment that did not have statistically greater seedling lengths than the herbicide control was the high rate. No treatment, in any of the weed assay data we fit curves to, inhibited seedling length to a statistically greater degree than the herbicide control. 
Table 3.9. Regression hillslope, adjusted $\mathbf{R}^{2}$, and $\mathrm{EC}_{50}$ and $\mathrm{EC}_{75}$ values (parts per million by weight), application rate (Kg/acre), and cost (USD) for Lactuca sativa 'Inferno' growing in soil amended with ferulic acid, gallic acid, juglone, or p-Coumaric acid.

\begin{tabular}{|c|c|c|c|c|c|c|c|c|c|c|c|c|c|}
\hline \multirow[b]{2}{*}{ Compound } & \multirow[b]{2}{*}{ Regression } & \multirow{2}{*}{$\begin{array}{c}\text { Adj. } \\
\mathbf{R}^{2}\end{array}$} & \multirow{2}{*}{$\begin{array}{l}\text { Hill- } \\
\text { slope }\end{array}$} & \multicolumn{3}{|c|}{$\mathbf{E C}_{50}$} & \multirow{2}{*}{$\begin{array}{l}\mathrm{Kg} / \\
\text { acre }\end{array}$} & \multirow{2}{*}{$\begin{array}{c}\text { Cost } \\
\text { (\$/acre })\end{array}$} & \multicolumn{3}{|c|}{$\mathbf{E C}_{75}$} & \multirow{2}{*}{$\begin{array}{l}\mathrm{Kg} / \\
\text { acre }\end{array}$} & \multirow{2}{*}{$\begin{array}{c}\text { Cost } \\
\text { (\$/acre })\end{array}$} \\
\hline & & & & UCL & Mean & LCL & & & UCL & Mean & LCL & & \\
\hline Ferulic Acid & Logistic 1P & 0.96 & -1.94 & 570 & 644 & 728 & 12.19 & 100,436 & 997 & 1136 & 1275 & 21.49 & 177,100 \\
\hline Gallic Acid & Logistic 1P & 0.95 & -1.13 & 1342 & 1584 & 1870 & 29.98 & 21,676 & 3521 & 4192 & 4914 & 79.34 & 57,360 \\
\hline Juglone & Logistic 1P & 0.99 & -1.71 & 120 & 129 & 138 & 2.43 & 48,684 & 228 & 245 & 261 & 4.63 & 92,663 \\
\hline p-Coumaric Acid & Gompertz 3P & 0.98 & -7.53 & 561 & 616 & 666 & 11.65 & 69,898 & 708 & 761 & 805 & 14.40 & 86,399 \\
\hline
\end{tabular}

Table 3.10a. Regression hillslope, and $\mathrm{EC}_{50}$ and $\mathrm{EC}_{75}$ values (parts per million by weight) for several weed species (Malva parviflora, Poa annua, and Senecio vulgaris) growing in soil amended with ferulic acid, gallic acid, juglone, or p-Coumaric acid.

\begin{tabular}{|ccccc|ccc|ccc|}
\hline & & & \multicolumn{3}{c|}{ Adj. } & \multicolumn{3}{c|}{ EC $_{\mathbf{5 0}}$} & \multicolumn{3}{c|}{ EC $_{\mathbf{7 5}}$} \\
\cline { 6 - 10 } Species & Compound & Regression & $\mathbf{R}^{\mathbf{2}}$ & Hillslope & UCL & & LCL & UCL & LCL \\
\hline Senecio vulgaris & Ferulic Acid & Logistic 1P & 0.93 & -0.90 & 252 & 316 & 397 & 844 & 1075 & 1337 \\
Malva parviflora & Gallic Acid & Logistic 3P & 0.94 & -1.55 & 5632 & 6195 & 6764 & 11406 & 12614 & 14038 \\
Poa annua & Juglone & Logistic 1P & 0.96 & -1.70 & 189 & 215 & 246 & 481 & 551 & 627 \\
Poa annua & p-Coumaric Acid & Logistic 1P & 0.87 & -2.05 & 1313 & 1663 & 2106 & 2170 & 2843 & 3523 \\
\hline
\end{tabular}

Table 3.10b. Plant compound application rates (Kg/acre) and costs (USD) to control weeds in strawberry field soil.

\begin{tabular}{|cc|cc|cc|}
\hline & \multicolumn{2}{|c|}{ EC $_{\mathbf{5 0}}$} & \multicolumn{2}{c|}{ EC $_{\mathbf{7 5}}$} \\
\cline { 3 - 7 } Species & \multicolumn{3}{c|}{$\begin{array}{c}\text { Cost } \\
\text { Comprest }\end{array}$} & \multicolumn{3}{c|}{ Kg/acre } & (\$/acre) \\
\hline Senecio vulgaris & Ferulic Acid & 5.98 & 49,296 & 20.34 & 167,620 \\
Malva parviflora & Gallic Acid & 117 & 84,773 & 239 & 172,617 \\
Poa annua & Juglone & 4.08 & 81,553 & 10.43 & 208,571 \\
Poa annua & p-Coumaric Acid & 31.48 & 188,880 & 53.80 & 322,797 \\
\hline
\end{tabular}



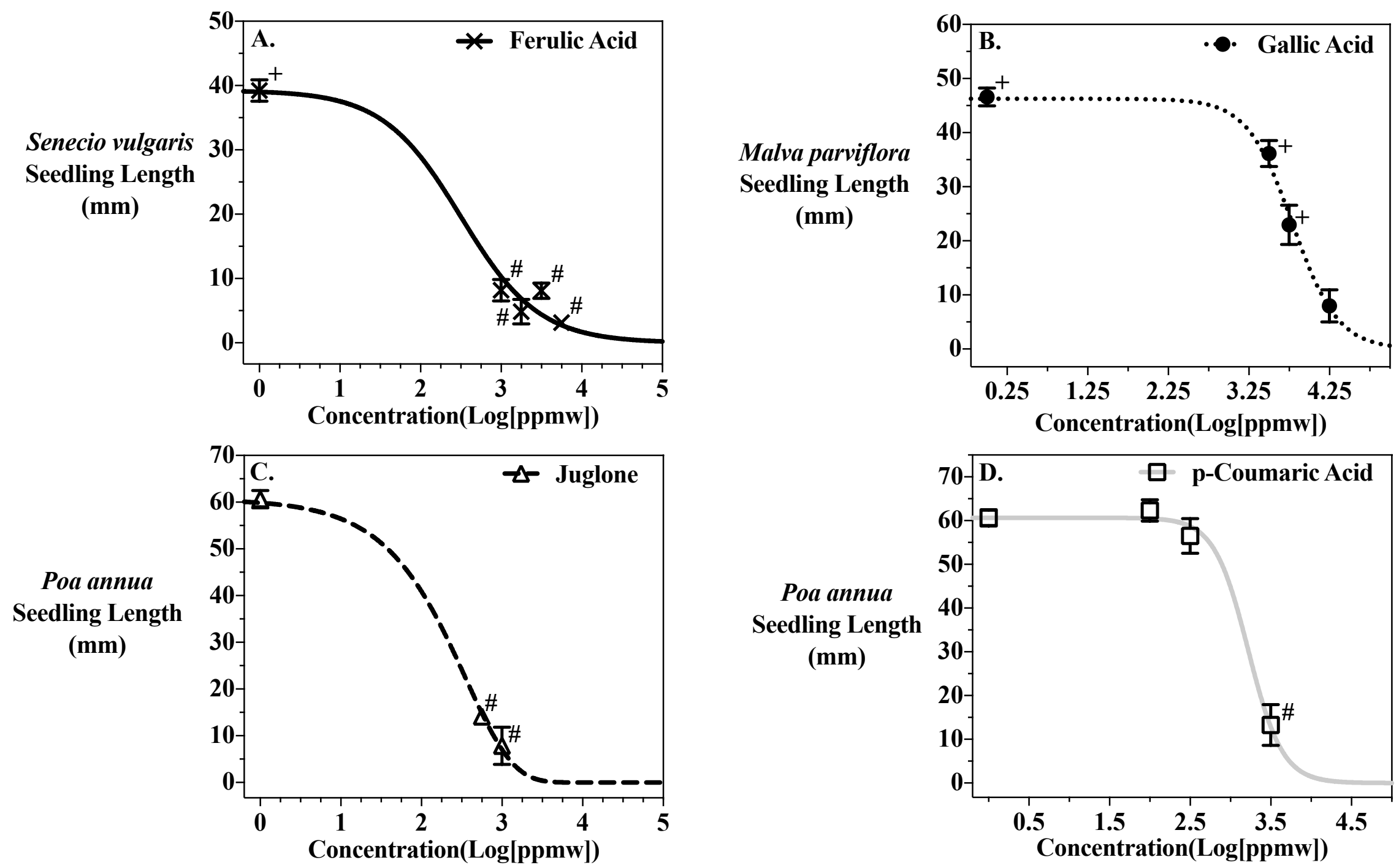

Figure 3.13. Seedling length 11 days after initial treatment of several weeds growing in plant compound treated soil in response to increasing rates of plant compounds (parts per million by weight (ppmw)). +Seedling length was significantly greater than the herbicide control $(\mathrm{p}<.025)$. \#Seedling length was significantly different than the water control. We did not observe any seedling length in Poa annua herbicide-treated wells (pendimethalin) after 11 days (although we suspect there was root growth). A. Senecio vulgaris seedling length in ferulic acid treated soil. At the $\alpha=.05$ level the medium-low rate of ferulic acid (3.25 Log[ppmw]) was significantly different than the herbicide control $(\mathrm{p}=.0391)$. B. Malva parviflora seedling length in gallic acid treated soil. The high rate of gallic acid was significantly different than the water control at $\alpha=.05$ level $(\mathrm{p}=.0301)$. C. Poa annua seedling length in juglone treated soil. D. P. annua seedling length in $\mathrm{p}$-Coumaric acid. 


\subsection{Discussion}

\subsubsection{In Vitro Assays}

Plant Compound Modes of Action - Seedling damage appeared to positively correlate with increasing plant compound rates (see APPENDIX E.1). The damage was consistent with that described in the literature and we propose was related to the modes of action of these compounds.

Booker et al. (1992) showed that ferulic acid affects net nutrient uptake and water retention in plants. Secondary metabolites, including ferulic acid, released by plants and soil microbes, stimulate secondary root growth (Blum and Rebbeck, 1989; Inderjit, 1996; Raaijmakers and Mazzola, 2012), which modifies the quantity of root exudates released (Badri and Vivanco, 2009). We observed secondary root formation in response to all plant compounds (see APPENDIX E.1). In vitro, increased root branching may have afffected water and nutrient conductivity, and then seedling growth.

Pesticidal plant compounds can promote the production of free radicals - or prevent the functioning of oxidative enzymes that protect against peroxidation (e.g. catalases and peroxidases) - resulting in tissue damage and discoloration (Weir et al., 2004). In response to gallic acid, reactive oxygen species disrupt microtubule assembly, and leads to the inhibition of root growth (Rudrappa et al., 2007). Juglone disrupts electron flow in the electron transport chain of the mitochondria's inner membrane. This prevents oxidative phosphorylation, generating reactive oxygen species that trigger apoptotic-like cell death (Babula et al., 2009).

Similar to Blum and Rebbeck (1989), who assayed cucumber with ferulic acid, we observed root necrosis - consistent with cellular damage - tan root coloration, and enlarged or deformed root tips (see APPENDIX E.1). There was minor root-tip necrosis 
in assays with $10 \mathrm{ppmw}$ juglone, however, root branching generally began at $100 \mathrm{ppmw}$ in response to all plant compounds. With few exceptions, the rate at which we observed seedling damage was also the rate in which we measured significantly shorter seedlings in plant compound treatments than in the DMSO water control.

In vitro, gallic acid inhibited the germination of $P$. апnиa but not that of any other plant species. Rudrappa et al. (2007) also found that gallic acid in vitro did not inhibit germination of Arabidopsis thaliana L. but functioned as a post-emergent inhibitor of root formation. Ferulic acid, juglone, and p-Coumaric acid significantly inhibited the germination, at one or more concentrations, of every plant species we tested (Figures 3.1-3.4). p-Coumaric acid, as well as several other phenolic acids, inhibit the glycolytic enzymes pyruvate kinase, adolase, glucosephosphate isomerase, 6-phosphate dehydrogenase, and phosphenolpyruvate carboxylase (Muscolo et al., 2001). These enzymes play a critical role in the mobilization of glucose, which promotes radicle and shoot elongation. Muscolo et al. (2001) associated reductions in their activity with the inhibition of Pinus laricio seed germination. Inhibition of germination, or delayed germination - as Williams and Hoagland (1982) observed when assaying several plant compounds with nine weed and crop species - could reduce the competitiveness of weeds in a cropping system.

Oxyfluorfen Herbicide Control - Oxyfluorfen (GoalTender ${ }^{\circledR}$ ) is approved for use in strawberry production. In the field, oxyfluorfen effectively controls $M$. parviflora, $M$. officinalis, and $S$. vulgaris. It was not a suitable conventional chemistry in vitro due to its mode of action. It significantly reduced the seedling length and germination of S. vulgaris 
but no other species. Oxyfluorfen inhibits protoporphyrinogen oxidase (PROTOX), preventing heme and chlorophyll production and forming free radicals that peroxidize lipids (Kunert and Böger, 1981; Duke et al., 1991). The compound must contact leaves or stems to reach its site of action (Fadayomi and Warren, 1979), and requires light to induce hydroxyl radical producation that bleaches tissues (Kunert and Böger, 1981).

Our in vitro assays occurred in a dark growth chamber and seeds typically germinated without aboveground seedling parts significantly contacting oxyfluorfenamended media. The herbicide control mostly failed to inhibit seedling growth because the in vitro assays did not meet oxyfluorfen's requirement for plant-part contact and light. Regardless, the plant compounds exhibited a clear dose-respone relationship in vitro, and completely inhibited seedling length compared to the water control at higher rates (Figures 3.5. and 3.6.).

The Influence of Seed Number and Mass in Seed Assays - In our in vitro assays, the total number of seeds varied slightly across plates. When we transferred seeds from conical tubes to water agar, slightly more or less than 20 seeds sometimes reached the plate. To reduce contamination, we did not attempt to remove extra or add additional seeds. Twenty-three out of twenty-four treatments (ferulic acid, gallic acid, juglone, pCoumaric acid, water control, and herbicide controls for each of four plant species) averaged 20 to 23 seeds per plate. Weidenhamer et al. (1987) found that the amount of plant compound available per seed can modify inhibitory effects. However, when Weidenhamer et al. (1987) made this conclusion, they used Whatman No. 1 filter paper. Pederson (1986) showed that Whatman filter paper assays provided less consistent results 
due to uneven moisture distribution across the filter paper, and that these assays were less sensitive than seed assays that used water agar.

The even distribution of moisture and plant compounds in our water agar-based assays should have minimized differences due to unequal seed numbers in Petri plates. One compound treatment, juglone for $P$. annua averaged 17 seeds per plate. Poa annua was the second smallest seed by mass $(0.33 \mathrm{~g} / 1000$ seeds $)$ out of the four that we assayed, and smaller seeds are usually more sensitive to plant compounds than larger seeds (Williams and Hoagland, 1982; Liebman and Sundberg, 2006). If seed number greatly affected our results in these assays we would expect to find the seedling length $\mathrm{EC}_{50}$ value for juglone to be lower in the $P$. annua assays than the other species we tested. And this is especially the case due to $P$. annua's small seed size. Yet, the seedling length $\mathrm{EC}_{50}$ for juglone in $P$. annua assays was not significantly different than that of the other plant species we tested (Table 3.4.). And so we do not believe seed number appreciably affected our results.

Seed masses in our study, in order of greatest to smallest, were: $M$. parviflora, 2.47 g/ 1000 seeds; L. sativa, 0.98 g/ 1000 seeds; P. annua, 0.33 g/ 1000 seeds; and, $S$. vulgaris, $0.22 \mathrm{~g} / 1000$ seeds. Although M. parviflora was the largest seed we assayed, it had equivalent $\mathrm{EC}_{50}$ and $\mathrm{EC}_{75}$ values to $S$. vulgaris, the smallest seed we tested, for all compounds (Table 3.4.). Lactuca sativa (the second largest seed, by mass, in our study) did require higher concentrations to reach the half-maximal and three-quarters-maximal response level for several compounds than $S$. vulgaris. Gallic acid and juglone $\mathrm{EC}_{50}$ and $\mathrm{EC}_{75}$ values were significantly lower for $S$. vulgaris than L. sativa. While this is the strongest evidence for selectivity against a weed species relative to a crop in our research, 
and may be associated with seed mass, others have found plant compounds to be highly selective.

Uddin et al. (2010) applied sorgoleone, an allelochemical produced by Sorghum spp., as a post- and pre-emergent herbicide in field conditions. Sorgoleone, like the broadleaf selective herbicide atrazine, is a photosystem II electron transport chain inhibitor. The compound inhibited corn minimally at $200 \mathrm{ppm}$ (approximately 5\%), but inhibited several weeds by between 40 and $80 \%$. Lactuca sativa was the most sensitive of the twelve crops Uddin et al. (2010) tested. Perhaps due to L. sativa's reported sensitivity, plant compounds in our assays were only slightly selective against the weeds we tested. Future research should further elucidate the selectivity of ferulic acid, pCoumaric acid, and gallic acid. For instance, soybean (Glycine max (L.)) is tolerant to several classes of plant compounds, including salicylic acid - a phenolic acid — and may tolerate the phenolic acids we used in our research (Shettel and Balke, 1983).

\section{Comparison of Phenolic Acid Results to Past Research - Weidenhamer et al. (1987)} found ferulic acid's $\mathrm{EC}_{50}$ for cucumber radicle length to be around $2 \mathrm{mM}$ (approximately $338 \mathrm{ppm}$ ) given 5 seeds per $5 \mathrm{~mL}$ (which is roughly the ratio of seeds to $\mathrm{mL}$ of solution in our assays). This value is $112-181 \mathrm{ppm}$ greater than the seedling length $\mathrm{EC}_{50 \mathrm{~s}}$ that we found in vitro. It may be that seedling length is a more sensitive response variable than root radicle length, that ferulic acid is more phytotoxic to the plant species we tested than Cucumis sativus cv. Early Green Cluster that Weidenhamer et al. (1987) assayed, plant compounds amended in agar are more bioavailable than when applying solution to filter paper, or that when Weidenhamer et al. (1987) buffered the test solution pH to 5.8 it 
reduced the phytotoxicity of ferulic acid. Blum (1996) found that a soil system with a pH of 6.9 completely prevented the phytotoxicity of phenolic compounds (the $\mathrm{pH}$ of these compounds was approximately 4.5) compared to soil systems with a pH of 5.2 and 6.0. Furthermore, the $\mathrm{pH} 6.0$ soil system--close to the $\mathrm{pH}$ of 5.8 that Weidenhamer et al. (1987) buffered the ferulic acid solution to-did not inhibit $C$. sativus leaf expansion as quickly as the $\mathrm{pH} 5.2$ soil system. Whatman filter paper seed assays are also less sensitive to inhibitory effects of plant compounds than water agar seed assays (Pederson, 1986), and so we would expect higher $\mathrm{EC}_{50}$ values in filter paper assays.

Tharayil et al. (2008) in Petri plates with Whatman filter paper, 15 surface sterilized seeds, and $6 \mathrm{~mL}$ of test solution, found the ferulic acid lettuce radicle length $\mathrm{EC}_{50}$ to be $447 \mathrm{ppm}$, and the p-Coumaric acid lettuce radicle length $\mathrm{EC}_{50}$ to be $427 \mathrm{ppm}$. Chou and Patrick (1976) assayed lettuce on Whatman 3MM chromatographic paper exposed to small sponges soaked with several phenolic acids (including ferulic and pCoumaric acids). They did not fit curves to their data or predict $\mathrm{EC}_{50 \mathrm{~s}}$ but their results show that the ferulic acid radicle length lettuce $\mathrm{EC}_{50}$ was above $400 \mathrm{ppm}$, and pCoumaric acid's lettuce radicle length $\mathrm{EC}_{50}$ was between 300 and $400 \mathrm{ppm}$. These radicle $\mathrm{EC}_{50}$ length estimates are comparable to those found by Tharayil et al. (2008). In our assays, lettuce seedling length $\mathrm{EC}_{50}$ values were $191 \mathrm{ppm}$ for ferulic acid and $129 \mathrm{ppm}$ for p-Coumaric acid, and were significantly different (their confidence intervals did not overlap). Differences between the $\mathrm{EC}_{50}$ values found by Chou and Patrick (1976) and Tharayil et al. (2008) and our research may have several sources: the particular variety of lettuce in the assay (Tharayil et al. (2008) assayed Lactuca sativa var. Buttercrunch and Chou and Patrick (1976) assayed Lactuca sativa var. Great Lakes), pH adjustment in the 
assay (Tharayil (2008) adjusted the $\mathrm{pH}$ of all solutions to 6), the manner in which the researcher exposed seed to the compounds, the organic solvent used, the response variable measured, and the growth medium. Any one of these factors or combinations of these methodological differences may have contributed to differences in assay results.

Reigosa et al. (1999) assayed six phenolic acids including ferulic acid, gallic acid, and p-Coumaric acid with six weed species. They placed 50 seeds on filter paper in $9 \mathrm{~cm}$ diameter Petri dishes and applied $3 \mathrm{~mL}$ of solution at rates from $10^{-2}$ to $10^{-5} \mathrm{M}$. At the same molarity, they saw a similar pattern to what we observed in which ferulic acid and p-Coumaric acid inhibited germination to a greater extent than gallic acid. For instance, Amaranthus retroflexus L. germination in ferulic acid was just 1.79\% (10-2 M: 1942 ppm), in p-Coumaric acid was $0 \%\left(10^{-2} \mathrm{M}: 1642 \mathrm{ppm}\right)$, and in gallic acid was $83.93 \%\left(10^{-}\right.$ $\left.{ }^{2} \mathrm{M}: 1701 \mathrm{ppm}\right)$ of the water control. Reigosa et al. (1999) also found that ferulic acid and p-Coumaric acid frequently reduced seedling length equivalently at the same molarity. Ferulic acid has a higher molecular weight, and therefore is more concentrated at the same molarity as p-Coumaric acid. And so this result is consistent with our research that found p-Coumaric acid required a significantly lower concentration to reach the seedling length three-quarters maximal response than ferulic acid for L. sativa and P. annua; although, the seedling length three-quarters maximal response was equivalent between ferulic acid and p-Coumaric acid in M.parviflora and S. vulgaris assays (Table 3.4.).

\section{Comparison of Juglone Results to Past Research - Spencer (1986), applied a 3 mM} (522 ppm) juglone solution to Whatman \#1 filter paper, and inhibited the germination of Abutilon theophrasti Medik. by 94\%. Malva parviflora and A. theophrasti are in the same 
family (Malvaceae) and possess physical dormancy due to water-impermeable seed coats (Bhagirath et al., 2006; Horowitz and Taylorson, 1983). The best logistic curve fit for juglone in our research predicted that the compound would inhibit M. parviflora seedling length by $94 \%$ at approximately $588 \mathrm{ppm}$ in vitro, a nearly identical concentration to the 522 ppm needed to inhibit $A$. theophrasti by the same amount.

In our research, juglone significantly inhibited P. аппиа germination at just 100 ppmw (approximately 97\%). Kocaçalişkan and Terzi (2001) did not see a significant difference in germination of wheat (Triticum vulgare 'Gönen'), barley (Hordeum vulgare 'Tokak'), and corn (Zea mayes 'Pan') when comparing a distilled water control to 174 ppm juglone. These crop species and P. аппиа are all Poaceae family plants, but may not be directly comparable to $P$. апnиa because of greatly different seed sizes. Kocaçalişkan and Terzi (2001) did find that $174 \mathrm{ppm}$ juglone inhibited root length of the four grass crop species previously mentioned by between 59 and $91 \%$, and shoot length by between 62 and $88 \%$. In our research, the best curve fit for the juglone assay predicted a comparable level of inhibition of $P$. аnnua seedling length at 174 ppmw (approximately 84\%) to what Kocaçalişkan and Terzi (2001) reported for root length inhibition.

\section{Lower Plant Compound Rates Were More Inhibitory Than Higher Rates - Reigosa} et al. (1999) found that several lower rates of plant compounds in vitro were more inhibitory than higher rates. In their research, gallic acid at $10^{-2} \mathrm{M} \operatorname{did}$ not inhibit $A$. retroflexus germination, but did inhibit germination at $10^{-3}, 10^{-4}$, and $10^{-5} \mathrm{M}$. We also observed this concentration/inhibition paradox. In our assays, $100 \mathrm{ppmw}$ p-Coumaric acid inhibited M.parviflora germination, but no other p-Coumaric acid rates significantly 
inhibited M. parviflora (Figure 3.2.). Juglone at $500 \mathrm{ppmw}$ also inhibited M. parviflora to a greater extent than $1000 \mathrm{ppmw}$ juglone. Both M.parviflora and A. retroflexus display physiological dormancy (Sumner and Cobb, 1967; Hayashi and Numata, 1967). The enhanced inhibition at lower rates that we observed in our research and that Reigosa et al. (1999) also found may not be the result of inhibition by plant compounds. Instead it may be due to greater dormancy in the seeds randomly assigned to the plant compound treatments than those randomly assigned to the water control. Alternatively, it may be the physical and/or physiological mechanisms of dormancy interacted with the plant compounds to produce an abnormal dose response-where higher rates inhibited germination to a lesser degree than lower rates. The three seeds in our research not requiring scarification to germinate (L. sativa, P. аппиа, and S. vulgaris, personal observation) did not display an abnormal dose-response in vitro (Figures 3.1., 3.3., and 3.4.). Future research should explore the possible interaction between plant compounds and seeds that exhibit dormancy.

Seedling Length versus Germination Inhibition - Above $1 \mathrm{mM}$ (about $174 \mathrm{ppm}$ ), juglone inhibits the development of most plant species in vitro (Williams and Hoagland, 1982; Rietveld, 1983). Seedling growth is usually more sensitive to juglone than seedling germination. Juglone at $174 \mathrm{ppm}$ significantly inhibited the germination of six of the fourteen species Rietveld (1983) tested on blotter paper, yet inhibited the radical elongation of nine out of sixteen of the same species. Kocaçalişkan and Terzi (2001), on filter paper, found this relationship to be even stronger. Juglone at $174 \mathrm{ppm}$ inhibited germination of just four of eleven crop species, but inhibited both shoot length and 
radicle length of ten of eleven of the same species. In our research, seedling growth was no more sensitive to juglone than germination. All 100 ppmw juglone treatments inhibited both the seedling length and germination of all four plant species (Figures 3.1.3.4., and 3.6.). Greater inhibition of germination in our research as compared to that of others may have been due to the sensitivity of the seeds we assayed, and the enhanced distribution of the compound in water agar assays as compared to Whatman filter paper assays.

In our research, seedling length was, however, a far more sensitive response variable than seed germination in gallic acid assays. Gallic acid inhibited P. annua germination at $1000 \mathrm{ppmw}$, but did not inhibit the germination of any other seed (Figures 3.1.-3.4.). Seedling length inhibition occurred in gallic acid treatments above $100 \mathrm{ppmw}$ for all plant species (Figure 3.6.).

Conclusions - There are numerous valid methods to assay weed and crop seeds. However, assays are difficult to compare when the surface sterilization technique, the growing medium, solvent, $\mathrm{pH}$, statistical analysis and response variable measured change from one experiment to another. Such variation highlights the need for a highly standardized, well publicized, and broadly utilized weed assay methodology when assaying plant compounds in vitro.

Despite these differences in methodologies, in vitro seed assays, replicated over time and space, consistently support that ferulic acid, gallic acid, juglone, and pCoumaric acid are herbicidal. These plant compounds inhibit the growth, and in many 
cases seed germination, of a diversity of plant species including $M$. parviflora, a difficult weed to control in strawberry production (Strand, 2008).

\subsubsection{In Soil Assays}

Comparisons to Past Research - Due to varying methodologies, and a limited number of soil assays in the literature, it is difficult to compare our results to those from previous research. However, Gerig and Blum (1991) found that cinnamic acid derivatives (such as ferulic acid and p-Coumaric acid) are more phytotoxic than benzoic acid derivatives (such as gallic acid), and our results support this notion. They also found that ferulic acid was more phytotoxic against Cucumis sativus cv. Early Green Cluster in a fine loamy soil than p-Coumaric acid, however, our research showed that p-Coumaric acid was slightly more phytototoxic to L. sativa than ferulic acid in a loamy sand (Table 3.9.). This difference could simply be due to methodological inconsistencies between experiments, or differences in the sensitivies of C. sativus cv. Early Green Cluster and L. Sativa 'Inferno' to ferulic and p-Coumaric acid.

Rietveld (1983), assaying 15 plant species in 174 ppm juglone, only saw significant germination inhibition of one species, and radicle elongation inhibition of five species relative to the water control. It was unclear if this concentration was on a $\mu \mathrm{g}$ compound/g dry soil basis or not. Fisher (1978) showed that inhibition of red pine (Pinus resinosa Ait.) radicle extension by juglone decreased over time but remained significant even 90 days after initial application in a wet-soil regime. At day 15, $50 \mu \mathrm{g}$ juglone/g dry soil inhibited $P$. resinosa radicle extension by $82 \%$ relative to the control in a fine sandy loam (Fisher, 1978). In our weed assays, in a loamy sand, $309 \mu \mathrm{g}$ juglone/g dry soil 
inhibited Lactuca sativa 'Inferno' seedling length by 82\%, 11 days after initial treatment. Neave and Dawson (1989) found that $45 \mu \mathrm{g}$ juglone/g dry in a silt loam with $4.5 \%$ organic matter inhibited black alder (Alnus glutinosa (L.) Gaertn.) radicle elongation by approximately $30 \%$ until 22 days after initial treatment but not beyond. In our weed seed assays, $78 \mu \mathrm{g}$ juglone/g soil inhibited L. sativa seedling length by $30 \% 11$ days after the initial treatment. The higher rates required in our research to achieve the same level of inhibition as Fisher (1978) and Neave and Dawson (1989) could be due to differences in soil texture, organic matter content, juglone selectivity, compounds already present in the soil, the response variable measured, or microbial degradation or transformation of juglone.

Source of Contamination - Blum et al. (2000) found that soil rich in individual phenolic acids stimulated growth of bacteria that utilize the phenolic acids as a carbon source, and that this led to less inhibition by the compounds. In our soil assays, visible fungal growth (contamination covariate) did not significantly affect germination of any plant species or the seedling length of L. sativa (Tables 3.6. and 3.8.), but did significantly affect the damage rating for all plant species combined (Table 3.7.), and the seedling length of $M$. parviflora in gallic acid $(\mathrm{p}=.0006)$.

There were several potential sources of contamination: the plant seed, the acetone solvent, the plant compounds, and/or the soil itself. It is unlikely that the compounds introduced contaminants to the assay wells, because they are not only fungicidal but - in some cases - bactericidal (Clark et al., 1990; McKeehen et al., 1999; Curreli et al., 2001; Sarma and Singh, 2003; Bingwu et al., 2007; Fischer et al., 2012; Céspedes et al., 2014). 
Moreover, we prepared the compounds in high concentrations of acetone solvent. The lowest acetone concentration in treatment vials was $88.5 \%(\mathrm{w} / \mathrm{w})$, and in stock solutions was $86 \%(w / w)$. Drews (1977) found that acetone dilutions above $85 \%$ had no Staphylococcus aureus growth regardless of exposure time to the acetone. Therefore, there is a low probability that the acetone or the compounds, which remained in acetone stock solutions for several days, were significant contamination sources.

Only one well out of 237 herbicide control wells, and one well out of 238 water control wells had any contamination on day 11 . And so, the combination of acetone, soil, seed, and sterile deionized water or herbicide rarely led to contamination 11 days after the initial treatment. The addition of plant compounds, however, consistently led to contaminated wells. All phenolic acid treatments were more contaminated in wells with higher concentrations of compound (Figure 3.11.). Unlike in phenolic acid assays, in the juglone assay wells we did not see greater contamination with increasing rates, eventhough all juglone treatments had some contaminated wells. The high-rate of juglone had the least contamination of all juglone treatments and $32 \%$ of high-rate juglone replicate wells were contaminated. Adding phenolic acid plant compounds, but not the naphthoquinone (juglone), stimulated microbial growth in the non-sterile soil environment, which reflects more field-realistic conditions than in vitro Petri plate assays.

Plant compounds support microbial biomass in soil, and modify the population ratio of bacteria:fungi (Turner and Rice, 1975; Schmidt, 1988; Kong et al., 2008). Lou et al. (2016) uncovered a "dynamic" relationship between soil microbiota and phenolic plant compounds in red clover (Trifolium pratense L.) tissue. Regardless of whether the 
assay soil was sterile or not, they found that allelochemicals inhibited the germination of Sinapis alba L. after the integration of fresh clover or dried clover residue. In non-sterile soil, microorganisms degraded the clover residue and its associated allelochemicals, reducing the inhibitory effect of plant compounds on S. alba. Yet, microorganisms also inhibited germination and radical elongation themselves. Thus, there was an early plant compound "inhibitory phase" followed by a microbial "inhibitory phase".

The rates we chose for each compound (Table 3.5.) appeared to traverse the plant compound and microbial inhibitory phases that Lou et al. (2016) described. In juglone soil treatments, the compound was the primary determinant of inhibitory effects: the three lowest juglone rates inhibited seedling length and germination while displaying similarly low levels of contamination. Although 53-63\% of wells from the three lowest juglone rate treatments were contaminated, the mean contamination rating in these wells was only 0.58 to 0.65 and so, on average, they were were less than half contaminated. The similar contamination levels across juglone rates were despite the low rate of juglone being less inhibitory of germination and seedling length, and having a lower damage rating than the higher rates (Figures 3.7-3.10, 3.12., and 3.13.). Consistent with the in vitro and in soil results presented in this paper and others, the highest rate of juglone may have been antimicrobial (only $32 \%$ of wells were contaminated, and the average contamination rating was 0.32$)$.

At its two lowest rates, p-Coumaric acid did not significantly inhibit seedling length or germination, and did not have a greater seedling damage rating than the water control. The low rate of p-Coumaric acid had only two contaminated wells, and the medium-low rate had no contaminated wells. So contamination did not affect the two 
lowest rates of p-Coumaric acid (which were non-inhibitory). On the other hand, the medium-high rate of p-Coumaric acid had only 1 contaminated well out of 59 replicate wells, yet inhibited the germination of every plant species, and the seedling length of $L$. sativa. Thus, we attribute inhibition at the medium-high rate of $\mathrm{p}$-Coumaric acid to the phytotoxicity of the compound. All wells at the highest rate of p-Coumaric acid were contaminated, and so inhibitory effects may be due to a combination of the phytotoxicity of the compound and mircoorganismal growth.

In several treatments, we saw greater inhibition at lower plant compound rates than at higher rates of the same compound (Figures 3.9., 3.10., 3.12., and 3.13.). This made it difficult to fit Gompertz and logistic functions to each dataset, as there were, in fact, two dose-response relationships occurring simultaneously: one related to the phytotoxicity of the plant compounds, and one related to the stimulation of microbial growth. As plant compound rates increased, contamination modified inhibitory effects. For instance, there was less inhibition of L. sativa seedling length by ferulic acid at the medium-high rate (1778 ppmw) than the medium-low rate (562 ppmw), despite a larger than 3-fold increase in concentration. Similarly, $P$. annua and S. vulgaris germinated less in the medium-high rate of $\mathrm{p}$-Coumaric acid (1000 ppmw) than the high rate of $\mathrm{p}$ Coumaric acid (3162 ppmw). Both of these less inhibitory higher rates had far more contaminated treatment wells than the more inhibitory lower rates. In p-Coumaric acid assays, we applied a high enough concentration to promote microbial growth that then reduced the phytotoxicity of the compound. In ferulic acid wells, the high rate did not display a reduction in compound phytotoxicity despite being the most contaminated rate of ferulic acid (Figure 3.11.)). The ferulic acid high rate may have been sufficient to 
reach the microbial inhibitory phase that Lou et al. (2016) described. These results provide further evidence that there is a complex relationship between plant compound phytotoxicity and soil microorganisms.

Our findings are also compatible with research suggesting that an alteration of soil microbial communities by plants and their root exudates may play a role in forming weed and pathogen suppressive soils (Mazzola, 2002; Bais et al., 2006; Mouhamadou et al., 2013). Ferulic acid, gallic acid, juglone, and p-Coumaric acid exist in root exudates of a variety of plants (Narasimhan et al., 2003; Rudrappa et al., 2007; Yang et al., 2010; Wu et al., 2000). As described in Trognitz et al. (2016), past research has shown that plant compounds modify the weed suppressiveness of soils by inhibiting or promoting pathogenic (Eppinga et al., 2006; Nijjer et al., 2007) or mutualistic (Richardson et al., 2000; Weir, 2007) microbial symbionts of plants. Researchers have also attributed the success of invasive species at least partially to the effects of plant compounds on soil microbiota that enhances the competitiveness of the invading plant (Stinson et al., 2006; Callaway et al., 2008).

\section{Conclusions -}

1. The growth of microbial populations in soil assays and seed dormancy substantially complicates the fitting of dose-response curves. When this occurs, a greater number of plant compound rates and replicates are needed.

2. Despite the first conclusion, the microbial growth we observed corresponded to research suggesting that microbes both metabolize 
plant compounds and are a part of the inhibitory process. It appears that microbes simultaneously reduce the phytotoxic effects of plant compounds while also acting phytotoxically themselves.

3. Oxyfluorfen (GoalTender ${ }^{\circledR}$ ) and plant compounds - at sufficient rates — inhibited seedling length, and substantially damaged germinated seedlings. However, plant compounds, unlike oxyfluorfen (GoalTender ${ }^{\circledR}$ ), also inhibited weed seed germination in soil.

4. Juglone was the most herbicidal plant compound we tested in soil (it had much lower $\mathrm{EC}_{50}$ and $\mathrm{EC}_{75}$ values than the phenolic acids).

5. Juglone's cost may make it less viable than the phenolic acids, and especially gallic acid, which was the least herbicidal, but also the least expensive of the plant compounds to apply on a per acre basis. 


\section{CHAPTER 4.}

\section{PLANT COMPOUNDS IN STRAWBERRY PRODUCTION}

Since 1991, no chemical company has introduced a new mode of action to the herbicide market. Rüegg et al. (2007) attributes this to a reduction in the number of agrochemical companies from 35 in 1985, to just 11 in 2006 (Shulte, 2004 (as cited in Rüegg et al., 2007)), and a simultaneous increase in the cost of developing new herbicides. The total cost to register a single herbicidal product increased exponentially from $\$ 50$ million in the late 1970s to $\$ 250$ million in the early 1990s (Phillips McDougall, 2003 (as cited in Rüegg et al., 2007)). Toxicology, residue analysis, metabolite analysis and behavior in the environment make up a majority of development expenses. Rüegg et al. (2007) mentioned that new herbicides need to seek a balance between high mobility and long persistence-characteristics of more bioactive chemistries - and low water solubility, strong binding to soil colloids, and short-residual toxicity - which reduce leaching and non-target impacts. The results presented in this thesis and past research suggest that plant compounds might achieve this balance. Yet, the substantial cost of screening, formulation, field trials, and environmental-impact studies will remain an obstacle to registering naturally-sourced pesticidal compounds.

Despite the potential registration expense, there are additional reasons to favor assaying plant compounds and other secondary metabolites before screening combinatorially-produced synthetic compounds. For instance, low concentrations of the compounds we tested may also stimulate or be a part of pathogen resistance in strawberry plants. Hukkanen et al. (2007) applied benzothiadiazole, a functional analog of salicylic acid, to strawberry leaves and saw increased phenolic acid production, including gallic and p-Coumaric acid, in strawberry plant cell walls. The increased production of 
phenolics may play a role in the powdery mildew resistance associated with benzothiodiazole treatments.

Gallic acid treatments upregulate chitanse and peroxidase production (pathogenesis-related proteins) in cucumber (Cucumis sativus L.) plants (Nguyen et al., 2013). Similarly, gallic acid, at just $20 \mathrm{ppm}$ in culture solution increased production of cytochrome p450 and glutathione S-transferase (important proteins in the conjugation and removal of toxic substances from the cells of plants), and pathogenesis-related proteins that upregulate during abiotic or biotic stress (Golisz et al., 2008).

Al-Wakeel et al. (2013) dipped Helianthus annus L. seed in coumarin or salicylic acid solutions and both compounds reduced $M$. phaseolina disease severity once the seed had germinated and grown into a mature plant. They attributed this reduction to increased chitinase and $\beta$-1,3-glucanase activity in H. annus leaves (Al-Wakeel et al., 2013), enzymes that breakdown fungal cell wall components (Ebrahim et al., 2011). Ferulic acid, as well as other phenolics, also increased in concentration in response to salicylic acid and coumarin seed treatments. The upregulation of pathogensis-related proteins and phenolics in H. annus, in response to coumarin and salicylic acid, occurred in a dosedependent manner. A phenolic acid dip for strawberry plants, at a low-enough rate to prevent phytotoxicity, might induce systemic resistance to $M$. phaseolina and reduce strawberry fruit yield loss due to the pathogen. Future research should address if the induction of systemic resistance in strawberry plants, and the simultaneous inhibition of crop pathogens by plant compounds could also lower the cost of field applications.

Plant compounds may be a sustainable solution for organic strawberry growers who have few means of controlling soilborne pathogens and weeds. They could also 
encourage field conversions to organic production. Alternatives to fumigants, including fungicides, solarization, anaerobic soil disinfestation, steaming, raised bed trough planting in soilless media, and crop rotations, are either not economical, inconvenient, ineffective, or unsustainable. In a greenhouse study, The Strawberry Center at Cal Poly (San Luis Obispo) found that eight different fungicides with four modes of action did not adequately control M. phaseolina and F. oxysporum f.sp.fragariae (Carter, 2016). On the other hand, fungicide treatments after stimulating $M p$ microsclerotia germination with strawberry plant extract reduced the number of germinated microsclerotia with intact mycelium. Interestingly, the strawberry plant extract itself also reduced intact mycelium counts - a possible allelopathic effect. Our research suggests that individual plant compounds may similarly stimulate the germination of overwintering spores, and harm mycelial growth. Plant extracts and formulated plant compound mixtures could be one component of an organic strawberry grower's pest control toolkit.

Rotating strawberries with allelochemical-producing cover crops is a promising alternative to fumigation. Additionaly, M. phaseolina does not infect common cover crops that are potential alternative hosts (Koike et al., 2016). Strawberry growers currently integrate mustard seed meal or broccoli residue into fields to benefit from the pesticidal activity of glucosinolates, flavonoids, and phenolic acids released by Brassicaceae family species (Al-Sherif et al., 2013; Cartea et al., 2011). Muramoto et al . (2014) planted host resistant cultivars, bio-fumigated with broccoli, and incorporated mustard cover crop residues to achieve, in just one to three years, a statistically identical yield to seven-year rotation fields. 
Following the growth and incorporation of a cover crop, growers might add phenolic acid-containing allelochemical solutions to enhance pest control. Of the plant compounds we tested, p-Coumaric acid was, overall, the most phytotoxic and fungicidal phenolic acid. Adding a low rate of p-Coumaric acid (which Rasmussen and Einhellig (1977) found was synergistic with ferulic acid) could promote the pesticidal effects of decaying Brassicaceae species residues (Blum, 1996; Reigosa et al., 1999; Muscolo et al., 2001). Not only is p-Coumaric acid potentially more pesticidal than ferulic acid, but ferulic acid sorbs more competitively to negatively charged binding sites than pCoumaric acid, and this could release p-Coumaric acid into the soil solution (Dalton et al., 1989; Tharayil et al., 2006). On the other hand, any p-Coumaric acid additions may be ineffective in clay soils with high organic matter content due to a preponderance of negatively charged sites in this soil type. Strategically adding allelochemicals may only be effective under certain edaphic conditions. The loss of phenolic acids in single solute and multisolute solutions from the soil solution is two to four times faster in silt loam than in sandy loam soils (Tharayil et al., 2008). Sandy, low-organic matter soils, ideal for strawberry production (Strand, 2008), are more likely to benefit from phenolic acid applications than soils in other cropping systems.

Blum (1996), Blum et al. (1993) Tharayil et al. (2008), William and Hoagland (1982), McKeehen et al. (1999), Rasmussen and Einhellig (1977) and Muscolo et al. (2001) combined plant compounds and, depending on the mixture, observed decreased or enhanced phytotoxicity. Future research should further explore including organic adjuvants, surfactants, and other compounds (e.g. glucose and methionine (Blum, 1996)) while also mixing compounds known to function additively or synergistically. Such 
solutions could reduce the amount of active ingredient(s) required, lowering the cost of a plant-compound based pesticide.

Producing site-specific compound solutions, and then applying these solutions to problem areas in a field, might also lower plant compound costs and minimize environmental impacts. The iChip - a device that allows for culturing of approximately $50 \%$ of all soilborne bacteria-(Ling et al., 2015) - followed by sequencing of the hypervariable region of bacterial 16sRNA, will allow for better qualification and quantification of a field's microbial makeup. Alongside a consideration of soil type, and other abiotic factors, an advanced understanding of a soil's microbiome could lead to production of tailor-made plant compound mixtures; solutions that will achieve pest control objectives including shortening persistence, and minimizing non-target impacts.

Beginning with the evolution of plants 700 million years ago, a complex and dynamic relationship formed based on chemical communication between plants and microbes. As scientists continue to describe the language of this interaction, the addition of plant compounds to agricultural fields may eventually serve to modify the ongoing conversations between organisms, and help to make strawberry and other agricultural production systems more sustainable. To this day, the cryptic phenomenon known as allelopathy, and first described long ago in the works of Theophrastus, remains highly relevant. In fact, allelochemicals could bring forth a new era of pest control in agricultural fields. 


\section{BIBLIOGRAPHY}

Achatz, M., E.K. Morris, F. Müller, M. Hilker, and M.C. Rillig. 2014. Soil hyphamediated movement of allelochemicals: arbuscular mycorrhizae extend the bioactive zone of juglone. Functional Ecology 28:1020-1029.

Al-Sherif, E., A.K. Hegazy, N.H. Gomaa, and M.O. Hassan. 2013. Allelopathic effect of black mustard tissues and root exudates on some crops and weeds. Planta Daninha, Viçosa-MG 31(1):11-19.

Al-Wakeel, S.M., M.M.A. Gabr, W.M. Abu-el-soud, and A.M. Saleh. 2013. Coumarin and salicylic acid activate resistance to Macrophomina phaseolina In Helianthus annus. Acta Agronomica Hungarica 61(1):23-35.

Asao T., H. Kitazawa, T. Ban, M. Habibur, R. Pramanik, and K. Tokumasa. 2008. Electrodegradation of root exudates to mitigate autotoxicity in hydroponically grown strawberry (Fragaria x ananassa Duch.) plants. Hortscience 43(7):20342038.

Babula, P., V. Adam, R. Kizek, Z. Sladky, and L. Havel. 2009. Naphthoquinones as allelochemical triggers of programmed cell death. Environmental and Experimental Biology 65:330-337.

Badri, D.V . and J.M. Vivanco. 2009. Regulation and function of root exudates. Plant, Cell and Environment 32:666-681.

Bais, H.P., T.L. Weir, L.G. Perry, S. Gilroy, and J.M. Vivanco. 2006. The role of root exudates in rhizosphere interactions with plants and other organisms. The Annual Review of Plant Biology 57:233-266.

Bandeira, M., R. Cavalcanti, L. Maria, P. Albuquerque, R.J.M. De Custodio, C.A. Gomez, and A. De Rezende. 2011. Allelopathy, an alternative tool to improve cropping systems. A review. Agronomy for Sustainable Development 31:379395.

Bhagirath, S.C., G. Gill, and C. Preston. 2006. Factors affecting seed germination of little mallow (Malva parviflora) in Southern Australia. Weed Science 54(6):10451050 .

Belz, R.G., K. Hurle, and S.O. Duke. 2005. Dose-response - a challenge for allelopathy? Nonlinearity in Biology, Toxicology, and Medicine 3:173-211.

Bingwu, Q., L. Xianqquo, X. Wei, L. Haifeng, T. Guanrong, and P. HoYong. 2007. Antifungal activity of juglone and its derivative 5,8-dihydroxy-1,4naphthoquinone. Plant Protection 33(2):81-84.

Blum, U., and S.R. Shafer. 1988. Microbial populations and phenolic acids in soil. Soil Biology and Biochemistry 20(6):793-800.

Blum, U., and J. Rebbeck. 1989. Inhibition and recovery of cucumber roots given multiple treatments of ferulic acid in nutrient culture. Journal of Chemical Ecology 15(3):917-928.

Blum, U. 1996. Allelopathic interactions involving phenolic acids. Journal of Nematology 28(3):259-267.

Blum, U., K.L. Staman, L.J. Flint, and S.R. Shafer. 2000. Induction and/or selection of phenolic acid-utilizing bulk-soil and rhizosphere bacteria and their influence on phenolic acid phytotoxicity. Journal of Chemical Ecology 26(9):2059-2078. 
Blum, U. 2011. Plant-Plant allelopathic interactions: phenolic acids, cover crops and weed emergence. New York City, NY: Springer. pg. 175. eBook.

Bolda, M.P., L. Tourte, K.M. Klonsky, and R.L. De Moura. 2011. Sample costs to produce second year strawberries. UC Cooperative Extension. PDF file.

Booker, F.L., U. Blum, and E.L. Fiscus. 1992. Short-term effects of ferulic acid on ion uptake and water relations in cucumber seedlings. Journal of Experimental Botany 43:649-655.

California Department of Pesticide Regulation. Pounds of pesticide active ingredients, 1998-2013, by general use categories. September 15, 2016 from http://www.cdpr.ca.gov/docs/pur/pur13rep/tables/table2.pdf.

California Department of Pesticide Regulation. Total reported pounds of all active ingredients (AI), acres treated, acres planted, and prices for strawberry each year from 2009 to 2013. September 15, 2016 from http://www.cdpr.ca.gov/docs/pur/pur13rep/tables/table29.pdf.

Callaway, R.M., D. Cipollini, K. Barto, G.C. Thelen, S.G. Hallett, D. Prati, K. Stinson, and J. Klironomos. 2008. Novel weapons: invasive plant suppresses fungal mutualists in America but not in its native Europe. Ecology 89(4):1043-1055.

Cartea, M.E., M. Francisco, P. Soengas, and P. Velasco. 2011. Phenolic compounds in Brassica vegetables. Molecules 16:251-280.

Carter, M. 2016. Investigating novel approaches for the integrated control of the soilborne strawberry pathogens Macrophomina phaseolina and Fusarium oxysporum f.sp. fragariae (Unpublished master's thesis). California Polytechnic State University, San Luis Obispo, California, USA.

Céspedes, C.L., J.R. Salazar, A. Ariza-Castolo, L. Yamaguchi, J.G. Ávila, P. Aqueveque, I. Kubo, and J.A. Larcón. 2014. Biopesticides from plants: Calceolaria integrifolia s.1.. Environmental Research 132:391-406.

Chapuis-lardy, L.D. Contour-Ansel, and F. Bernhard-Reversat. 2002. High-performance liquid chromatography of water-soluble phenolics in leaf litter of three Eucalyptus hybrids (Congo). Plant Sciences 163:217-222.

Chou, C-H., and Z.A. Patrick. 1976. Identification and phytotoxic activity of compounds produced during decomposition of corn and rye residues in soil. Journal of Chemical Ecology 2(3):369-387.

Clark, A.M., T.M. Jurgens, and C.D. Hufford. 1990. Antimicrobial activity of juglone. Phytotherapy Research 4(1):11-14.

Cloud, G. L. and Rupe, J.C. 1991. Comparison of three media for enumeration of sclerotia of Macrophomina phaseolina. Plant Disease 75:771-772.

Coley-Smith, J.R., and J.E. King. 1969. The production by species of Allium of alkyl sulphides and their effect on germination of sclerotia of Sclerotium cepivorum Berk.. Annals of Applied Biology 64:289-301.

Curreli, N., F. Sollai, L. Massa, O. Comandini, A. Rufo, E. Sanjust, A. Rinaldi, and A.C. Rinaldi. 2001. Effects of plant-derived naphthoquinones on the growth of Pleurotus sajor-caju and degradation of the compounds by fungal cultures. Journal of Basic Microbiology 41(5):253-259.

Dalton, B.R., U. Blum, and S.B. Weed. 1989. Differential sorption of exogenously applied ferulic, p-Coumaric, p-Hydroxybenzoic, and vanillic acids in soil. Soil Science Society of America Journal 53:757-762. 
Dayan, F.E. 2002. Octan-1-ol / water partition coefficients of p-benzo- and pnaphthoquinones corrected for $\mathrm{pH}$ effect. Journal of Chemical Research 2:2-3.

Dhaouadi, K., W. Meliti, S. Dallai, M. Belkhir, S. Ouerghemmi, H. Sebei, and S. Fattouch. 2015. Commercial Lawsonia inermis L. dried leaves and processed powder: phytochemical composition, antioxidant, antibacterial, and allelopathic activities. Industrial Crops and Products 77:544-552.

Duhamel, M., R. Pel, A. Ooms, H. Bücking, J. Jansa, J. Ellers, N.M. van Straalen, T. Wouda, P. Vandenkoornhuyse, and E.T. Kiers. 2013. Do fungivores trigger the transfer of protective metabolites from host plants to arbuscular mycorrhizal hyphae? Ecology 94:2019-2029.

Duke, S.O., and J. Lydon. 1987. Herbicides from natural compounds. Weed Technology $1(2): 122-128$.

Duke, S.O., J. Lydon, J.M. Becerril, T.D. Sherman, L.P. Lehnen Jr., and H. Matsumoto. 1991. Protoporphyrinogen oxidase-inhibiting herbicides. Weed Science 39:465-473.

Duke, S.O. 2015. Proving allelopathy in crop-weed interactions. Weed Science Special Issue:121-132.

Duroux, L., F.M. Delmotte, J-M. Lancelin, G. Kéravis, and C. Jay-Allemand. 1998. Insight into naphthoquinone metabolism: $\beta$-glucosidase-catalysed hydrolysis of hydrojuglone $\beta$-D-glucopyranoside. Biochemical Journal 333:275-283.

Drews, R.C. 1977. Acetone sterilization in ophthalmic surgery. Annals of Ophthalmology 9(6):781-784.

Ebrahim, S., K. Usha, and B. Singh. 2011. Pathogenesis related (PR) proteins in plant defense mechanism in Science against microbial pathogens: communicating current research and technological advances. Badajoz, Spain: Formatex. pp. 1043-1054. PDF.

Eppinga, M.B., M. Rietkerk, S.C. Dekker, P.C. De Ruiter, and W.H. Van der Putten. 2006. Accumulation of local pathogens: a new hypothesis to explain exotic plant invasions. Oikos 114(1):168-176.

Ercisli, S., A. Esitken, C. Turkkal, and E. Orhan. 2005. The allelopathic effects of juglone and walnut leaf extracts on yield, growth, chemical and PNE compositions of strawberry cv. Fern. Plant Soil and Environment 51(6):283-287.

Ferreira, M. I., and C.F. Reinhardt. 2010. Field assessment of crop residues for allelopathic effects on both crops and weeds. Agronomy Journal 102(6):15931600 .

Fischer, T.C., C. Gosch, B. Mirbeth, M. Gselmann, V. Thallmair, and K. Stich. 2012. Potent and specific bactericidal effect of juglone (5-Hydroxy-1,4naphthoquinone) on the fire blight pathogen Erwinia amylovora. Journal of Agricultural and Food Chemistry 60:12074-12081.

Fisher, R.F. 1978. Juglone inhibits pine growth under certain moisture regimes. Soil Science Society of America Journal 42:801-803.

Fadayomi, O., and G.F. Warren. 1977. Uptake and translocation of nitrogen and oxyfluorfen. Weed Science 25(2):111-114.

Galati, G., O. Sabzevari, J.X. Wilson, and P.J. O'Brien. 2002. Prooxidant activity and cellular effects of the phenoxyl radicals of dietary flavonoids and other polyphenolics. Toxicology 177:91-104. 
Gerig, T.M. and U. Blum. 1991. Effects of mixtures of four phenolic acids on leaf area expansion of cucumber seedlings grown in Portsmouth $\mathrm{B}_{1}$ soil materials. Journal of Chemical Ecology 17(1):29-40.

Golisz, A., B. Lata, S.W. Gawronski, and Y. Fujii. 2007. Specific and total activities of the allelochemicals identified in buckwheat. Weed Biology and Management 7:164-171.

Golisz, A., M. Sugano, and Y. Fujii. 2008. Microarray expression profiling of Arabidopsis thaliana L. in response to allelochemicals identified in buckwheat. Journal of Experimental Botany 59(11):3099-3109.

Haifa: Pioneering the Future. Strawberry crop guide: growing strawberries. September 15, 2016 from http://www.haifagroup.com/knowledge_center/crop_guides/strawberry/growing_strawberries/.

Hayashi, I., and M. Numata. 1967. Ecology of pioneer species of early stages in secondary succession. The Botanical Magazine Tokyo 80:11-22.

Heisey, R.M. 1990. Allelopathic herbicidal effects of extracts from tree of heaven (Ailanthus altissima). American Journal of Botany 77(5):662-670.

Heisey, R.M., and T.K. Heisey. 2003. Herbicidal effects under field conditions of Ailanthus altissima bark extract, which contains ailanthone. Plant and Soil 256:85-99.

Hejl, A.M., F.A. Einhellig, and J.A. Rasmussen. 1993. Effects of juglone on growth, photosynthesis, and respiration. Journal of Chemical Ecology 19(3):559-568.

Heleno, S.A., A. Martins, M. João, R.P. Queiroz, and I.C.F.R. Ferreira. 2015. Bioactivity of phenolic acids: metabolites versus parent compounds: a review. Food Chemistry 173:501-513.

Horowitz, M., and R.B. Taylorson. 1983. Effect of high temperatures on imbibition, germination, and thermal death of velvetleaf (Abutilon theophrasti) seeds. Canadian Journal of Botany 61:2269-2276.

Hukkanen, A.T., H.I. Kokko, A.J. Buchala, G.J. McDougall, D. Stewart, S.O. Kärenlampi, and R.O. Karjalainen. 2007. Benzothiadiazole induces the accumulation of phenolics and improves resistance to powdery mildew in strawberries. Journal of Agricultural and Food Chemistry 55(5):1862-1870.

Inderjit. 1996. Plant phenolics in allelopathy. The Botanical Review 62(2):186-202.

Iqbal, Z., S. Hiradate, A. Noda, S. Isojima, and Y. Fujii. 2003. Allelopathic activity of buckwheat: isolation and characterization of phenolics. Weed Science 51:657662.

Ito, I., K. Kobayashi, and T. Yoneyama. 1998. Fate of dehydromatricaria ester added to soil and its implications for the allelopathic effect of Solidago altissima L.. Annals of Botany 82:625-630.

Johnson, R., and B.A. Cody. 2015. California agricultural production and irrigated water use. Congressional Research Service. PDF file.

Kaur, S., G.S. Dhillon, S.K. Brar, G.E. Vallad, R. Chand, and V.B. Chauhan. 2012. Emerging phytopathogen Macrophomina phaseolina: biology, economic importance and current diagnostic trends. Critical Reviews in Microbiology 38(2):136-151. 
Kocaçalişkan, I., and I. Terzi. 2001. Allelopathic effects of walnut leaf extracts and juglone on seed germination and seedling growth. Journal of Horticultural Science \& Biotechnology 76(4):436-440.

Koike, S. T. 2008. Crown rot of strawberry caused by Macrophomina phaseolina in California. Plant Disease 92:1253.

Koike, S. T., S. C. Kirkpatrick, and T. R. Gordon. 2009. Fusarium wilt of strawberry caused by Fusarium oxysporum in California. Plant Disease 93:1077.

Koike, S.T., R.G. Thomas, D. Oleg, A. Husein, and M. Frank. 2013. Charcoal Rot of Strawberry. California Strawberry Commission Production Guideline 10:1-6.

Koike, S.T., R.S. Arias, C.S. Hogan, F.N. Martin, and T.R. Gordon. 2016. Status of Macrophomina phaseolina on strawberry in California and preliminary characterization of the pathogen. International Journal of Fruit Science. Retrieved from http://dx.doi.org/10.1080/15538362.2016.1195313

Komada, H. 1975. Development of a selective medium for quantitative isolation of Fusarium oxysporum from natural soil. Review of plant protection research 8: 114-124.

Kunert, K.J., and P. Böger. 1981. The bleaching effect of the diphenyl ether oxyfluorfen. Weed Science 29(2):169-173.

Lam, T.B.T., K. Kadoya, and K. Iiyama. 2001. Bonding of hydroxycinnamic acids to lignin: ferulic and p-coumaric acids are predominantly linked at the benzyl position of lignin, not the $\beta$-position, in grass cell walls. Phytochemistry 57:987992.

Lehmann, R.G., H.H. Cheng, and J.B. Harsh. 1987. Oxidation of phenolic acids by soil iron and manganese oxides. Soil Science Society of America Journal 51:352-356.

Liebman, M., and D.N. Sundberg. 2006. Seed mass affects the susceptibility of weed and crop species to phytotoxins extracted from red clover shoots. Weed Science 54:340-345.

Ling, L.L., T. Schneider, A.J. Peoples, A.L. Spoering, I. Engels, B.P. Conlon, A. Mueller, T.F. Schäberle, D.E. Hughes, S. Epstein, M. Jones, L. Lazarides, V.A. Steadman, D.R. Cohen, C.R. Felix, K.A. Fetterman, W.P. Millett, A.G. Nitti, A.M. Zullo, C. Chen, and K. Lewis. 2015. A new antibiotic kills pathogens without detectable resistance. Nature 517:455-459.

Loffredo, E., and A. Traversa. 2014. Soil and compost humic fractions regulate the response of Sclerotinia sclerotiorum to exogenously added allelochemical compounds. Biology and Fertility of Soils 50:1281-1290.

Lou, Y., A.S. Davis, and A.C. Yannarell. 2016. Interactions between allelochemicals and the microbial community affect weed suppression following cover crop residue incorporation into soil. Plant Soil 399:357-371.

Macias, F.A. 1995. Allelopathy in the search for natural herbicide models. Allelopathy 582:310-329.

Macias, F.A., J.M.G. Molinillo, R.M. Varela, and J.C.G. Galindo. 2007. Allelopathy-a natural alternative for weed control. Pest Management Science 63:327-348.

Mazzola, M. 2002. Mechanisms of natural soil suppressiveness to soilborne diseases. Antonie van Leeuwenhoek 81:557-564. 
McKeehen, J.D., R.H. Busch, and R.G. Fulcher. 1999. Evaluation of wheat (Triticum aestivum $\mathrm{L}$.) phenolic acids during grain development and their contribution to Fusarium resistance. Journal of Agricultural and Food Chemistry 47:1476-1482. Mendes, R., M. Kruijt, I. de Bruijn, E. Dekkers, M. van der Voort, J.H.M. Schneider, Y.M. Piceno, T.Z. DeSantis, G.L. Andersen, P.A.H.M. Bakker, J.M. Raaijmakers. 2011. Deciphering the rhizosphere microbiome for disease-suppressive bacteria. Science 332:1097-1100.

Motulsky, H.J., and A. Christopoulos. 2003. Fitting models to biological data using linear and nonlinear regression. A practical guide to curve fitting. San Diego, CA: GraphPad Software Inc., www.graphpad.com.

Mouhamadou, B., J. Puissant, E. Personeni, M. Desclos-Theveniau, E.M. Kastl, M. Schloter, L. Zinger, J. Roy, R.A. Geremia, and S. Lavorel. 2013. Effects of two grass species on the composition of soil fungal communities. Biology and Fertility of Soils 49:1131-1139.

Muramoto, J., S.R. Gliessman, S.T. Koike, C. Shennan, C.T. Bull, K. Klonsky, and S. Swezey. 2014. Integrated biological and cultural practices can reduce crop rotation period of organic strawberries. Agroecology and Sutainable Food Systems 38:603-631.

Muscolo, A., M.R. Panuccio, and M. Sidari. 2001. The effect of phenols on respiratory enzymes in seed germination Respiratory enzyme activities during germination of Pinus laricio seeds treated with phenols extracted from different forest soils. Plant Growth Regulation 35:31-35.

Narasimhan, K., C. Basheer, V.B. Bajic, and S. Swarup. 2003. Enhancement of plantmicrobe interactions using a rhizosphere metabolomics-driven approach and its application in the removal of polychlorinated biphenyls. Plant Physiology 132(1):146-153.

Neave, I.A. and J.O. Dawson. 1989. Juglone reduces growth, nitrogenase activity, and root respiration of actinorhizal black alder seedlings. Journal of Chemical Ecology 15(6): 1823-1836.

Nguyen, D-M-C., D-J. Seo, H-B. Lee, L-S. Kim, and K-Y. Kim. 2013. Antifungal activity of gallic acid purified from Terminalia nigrovenulosa bark against Fusarium solani. Microbial Pathogenesis 56:8-15.

Nijjer, S., W.E. Rogers, and E. Siemann. 2007. Negative plant-soil feedbacks may limit persistence of an invasive tree due to rapid accumulation of soil pathogens. Proceedings of the Royal Society B 274:2621-2627.

Pederson, G.A. 1986. White clover seed germination in agar containing tall fescue leaf extracts. Crop Science 26:1248-1249.

Pimentel, D. 2005. Environmental and economic costs of the application of pesticides primarily in the United States. Environment, Development and Sustainability 7(2):229-252.

Ponts, N., L. Pinson-Gadais, A-L. Boutigny, C. Barreau, and F. Richard-Forget. 2011. Cinnamic-derived acids significantly affect Fusarium graminearum growth and in vitro synthesis of type $b$ trichothecenes. Postharvest pathology and mycotoxins 101(8):929-934.

Putnam, A.R. 1985. Weed allelopathy in Weed physiology volume 1: reproduction and ecophysiology. Boca Rotan, FL: CRC Press. p.131-155. 
Raaijmakers, J.M., and M. Mazzola. 2012. Diversity and natural functions of antibiotics produced by beneficial and plant pathogenic bacteria. Annual Review of Phytopathology 50:403-424.

Radosevich, S. R., J.S. Holt, and C.M. Ghersa. 2007. Ecology of weeds and invasive plants: relationship to agriculture and natural resource management $\left(3^{\text {rd }} \mathrm{ed}\right.$.). New Jersey: John Wiley \& Sons, Inc. Print.

Reigosa, M.J., X.C. Souto, and L. Gonzalez. 1999. Effect of phenolic compounds on the germination of six weeds species. Plant Growth Regulation 28:83-88.

Rice, E.L. 1984. Allelopathy ( $2^{\text {nd }}$ ed.). Academic Press: Orlando, Florida.

Rietveld, W.J. 1983. Allelopathic effects of juglone on germination and growth of several herbaceous and woody species. Journal of Chemical Ecology 9(2):295-308.

Ruan, Y. V. Kotraiah, and D.C. Straney. 1995. Flavanoids stimulate spore germination in Fusarium solani pathogenic on legumes in a manner sensitive to inhibitors of cAMP-dependent protein kinase. The American Phytopathological Society 8(6):929-938.

Rüegg, W.T., M. Quadranti, and A. Zoschke. 2007. Herbicide research and development: challenges and opportunities. Weed Research 47:271-275.

Richardson, D.M., N. Allsopp, C.M. D’Antonio, S.J. Milton, and M. Rejmánek. 2000. Plant invasions - the role of mutualisms. Biological Reviews 75:65-93.

Rudrappa, T., J. Bonsall, J.L. Gallagher, D.M. Seliskar, and H.P. Bais. 2007. Rootsecreted allelochemical in the noxious weed Phragmites australis deploys a reactive oxygen species response and microtubule assembly disruption to execute rhizotoxicity. Journal of Chemical Ecology 33:1898-1918.

Sarma, B.K., and U.P. Singh. 2003. Ferulic acid may prevent infection of Cicer arietinum by Sclerotium rolfsii. World Journal of Microbiology \& Biotechnology 19:123127.

Schmidt, S.K. 1988. Degradation of juglone by soil bacteria. Journal of Chemical Ecology 14(7):1561-1571.

Seefeldt, S.S., J.E. Jensen, and E.P. Fuerst. 1995. Log-logistic analysis of herbicide doseresponse relationships. Weed Technology 9(2):218-227.

Shettel, N.L., and N.E. Balke. 1983. Plant growth response to several allelopathic chemicals. Weed Science 31(3):293-298.

Shrestha, A. 2009. Potential of black walnut (Juglans nigra) extract product (NatureCur®) as a pre- and post-emergence bioherbicide. Journal of Sustainable Agriculture 33:810-822.

Singleton, L., D.J. Mihail, and C.M. Rush. 1992. Macrophomina in Methods for Research on Soilborne Phytophathogenic Fungi. St. Paul, Minnesota: APS Press. Print.

Stinson, K.A., S.A. Campbell, J.R. Powell, B.E. Wolfe, R.M. Callaway, G.C. Thelen, S.G. Hallett, D. Prati, and J.N. Klironomos. 2006. Invasive plant suppresses the growth of native tree seedlings by disrupting belowground mutualisms. PloS Biology 4(5):e140.

Strand, L. 2008. Integrated Pest Management for Strawberries ( $2^{\text {nd }}$ Ed.). Berkeley, CA: University of California Agriculture and Natural Resources. Print.

Sumner, D.C., and R.D. Cobb. 1967. Germination characteristics of cheeseweed (Malva parviflora L.) seeds. Agronomy Journal 59:207-208. 
Tarawali, S.A., G. Tarawali, A. Larbi, and J. Hanson. 1995. Methods for the evaluation of forage legumes, grasses and fodder trees for use as livestock feed. Nairobi, Kenya: International Livestock Research Institute. eBook.

Tharayil, N., P.C. Bhowmik, and B. Xing. 2006. Preferential sorption of phenolic phytotoxins to soil: implications for altering the availability of allelochemicals. Journal of Agricultural and Food Chemistry 54:3033-3040.

Tharayil, N., P.C. Bhowmik, and B. Xing. 2008. Bioavailability of allelochemicals as affected by companion compounds in soil matrices. Journal of Agricultural Food Chemistry 56:3706-3713.

Trognitz, F., E. Hackl, S. Widhalm, and A. Sessitsch. 2016. The role of plant-microbiome interactions in weed establishment and control. FEMS Microbiology Ecology 92(10):fiw138.

Turner, J.A. and E.L. Rice. 1975. Microbial decomposition of ferulic acid in soil. Journal of Chemical Ecology 1(1):41-58.

Uddin, M.R., O.J. Won, and J.Y. Pyon. 2010. Herbicidal effects and crop selectivity of sogoleone, a sorghum root exudate under greenhouse and field conditions. Korean Journal of Weed Science 30(4):412-420.

United States Department of Agriculture. California Agricultural Statistics 2013 Crop Year. January 10, 2017 from https://www.nass.usda.gov/Statistics_by_State/California/Publications/California Ag_Statistics/Reports/2013cas-all.pdf.

United States Environmental Protection Agency. Methyl Bromide. January 10, 2017 from https://www.epa.gov/ods-phaseout/methyl-bromide.

Vogel, C.S., and J.O. Dawson. 1985. Effect of juglone on growth in vitro of Frankia isolates and nodulation of Alnus glutinosa in soil. Plant and Soil 87:79-89.

Vyvyan, J.R. 2001. Allelochemicals as leads for new herbicides and agrochemicals. Tetrahedron 58:1631-1646.

Wacker, T.L., G.R. Safir, and C.T. Stephens. 1990. Effects of ferulic acid on Glomus fasciculatum and associated effects on phosphorus uptake and growth of asparagus (Asparagus officinalis L.). Journal of Chemical Ecology 16(3):901-909.

Weidenhamer, J.D., T.C. Morton, and J.T. Romeo. 1987. Solution volume and seed number: often overlooked factors in allelopathic bioassays. Journal of Chemical Ecology 13(6):1481-1491.

Weir, T.L. 2007. The role of allelopathy and mycorrhizal associations in biological invasions. Allelopathy Journal 20(1):43-50.

Weir, T.L., S-W. Park, and J.M. Vivanco. 2004. Biochemical and physiological mechanisms mediated by allelochemicals. Current Opinion in Plant Biology 7:472-479.

Weston, L.A. 1996. Utilization of allelopathy for weed management in agroecosystems. Agronomy Journal 88:860-866.

Williams, R.D., and R.E. Hoagland. 1982. The effects of naturally occurring phenolic compounds on seed germination. Weed Science 30:206-212.

Willis, R.J. 2007. The History of Allelopathy. Dordrecht, The Netherlands: Springer. Print.

Wofsy, S.C., M.B. McElroy, and Y.L. Yung. 1975. The chemistry of atmospheric bromine. Geophysical Research Letters 2(6):215-218. 
Wu, H., T. Haig, J. Pratley, D. Lemerle, and M. An. 2000. Distribution and exudation of allelochmicals in wheat Triticum aestivum. Journal of Chemical Ecology 26(9):2141-2154.

Wu, F., Z. Guan, and A. Whidden. 2012. Strawberry Industry Overview and Outlook. PDF file.

Yang, L., P. Wang, and C. Kong. 2010. Effect of larch (Larix gmelini Rupr.) root exudates on Manchurian walnut (Juglans mandshurica Maxim.) growth and soil juglone in a mixed-species plantation. Plant and Soil 329:249-258. 


\section{APPENDICES}

\section{A. Fungus Assay Photographs}

\section{A.1 In Vitro Fungus Assays}

Photos are of isolates growing on $1 / 2$ PDA with plant compound rates arranged, from left to right: 10, 100, 500, and 1000 parts per million by weight. Different colored lines were drawn on different days. We took photographs four days after center inoculating $M p$ plugs, and eight days after center inoculating Fof plugs.

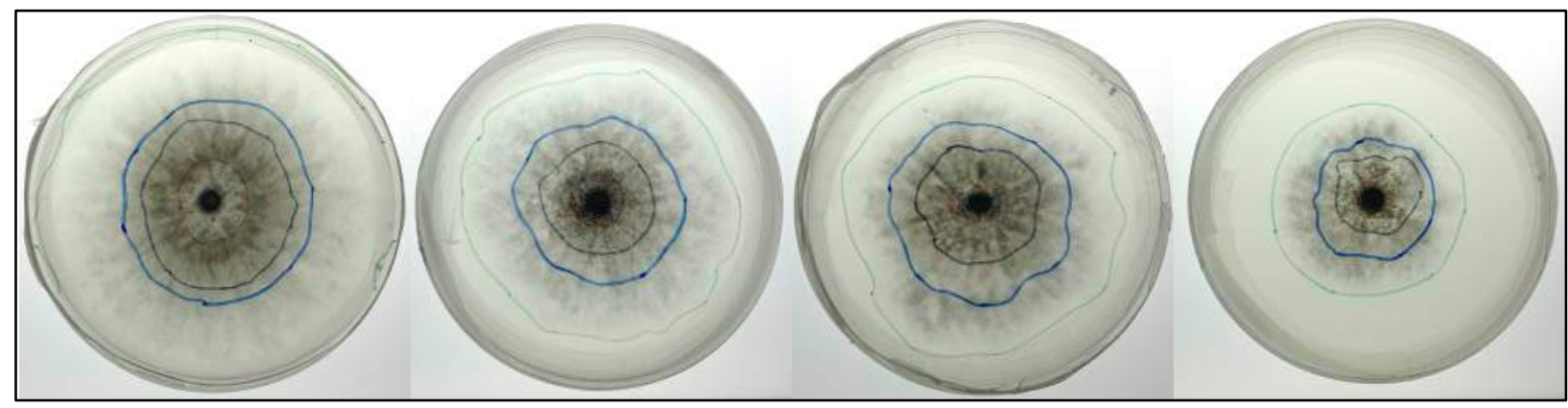

Photo 1. Macrophomina phaseolina 13 growing on ferulic acid amended plates.

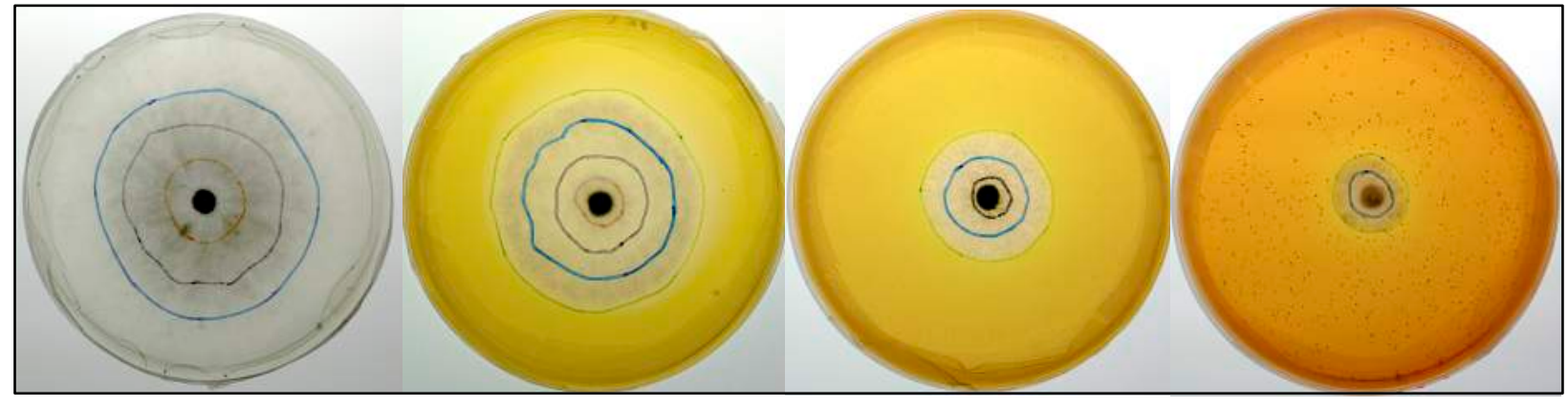

Photo 2. Macrophomina phaseolina 13 growing on juglone amended plates.

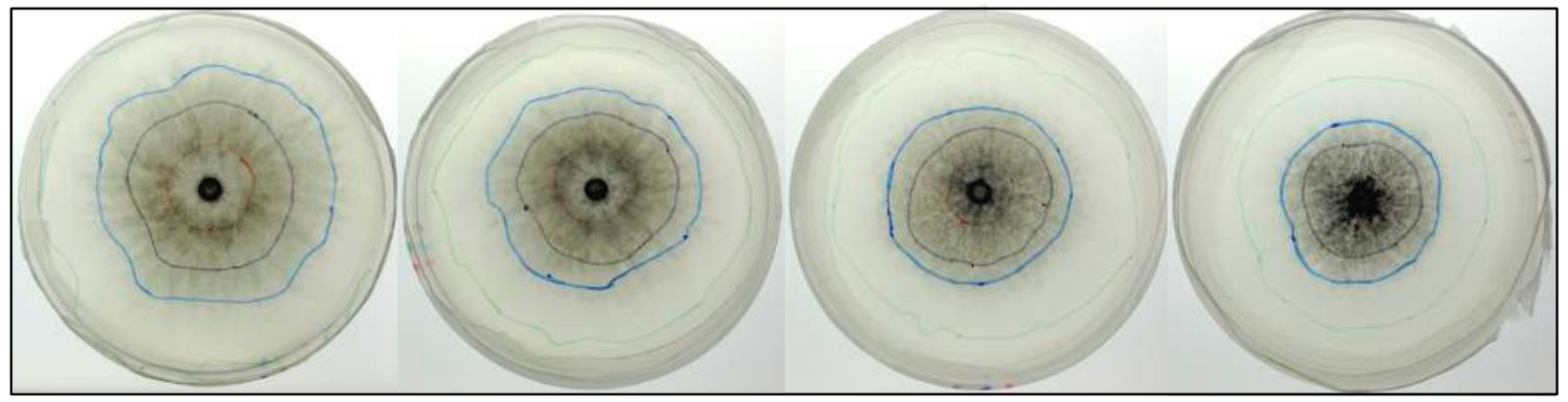

Photo 3. Macrophomina phaseolina 13 growing on p-Coumaric acid amended plates.

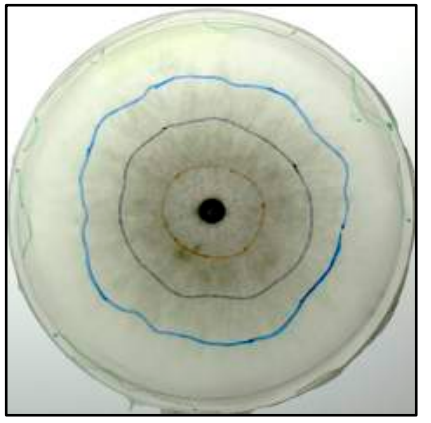

Photos 4 and 5.

Macrophomina phaseolina 13.

Water control with DMSO

(left), and fungicide control with DMSO (right).

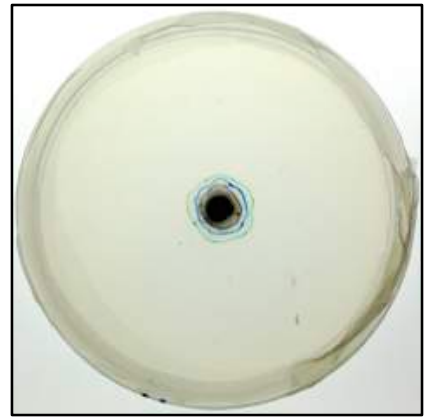




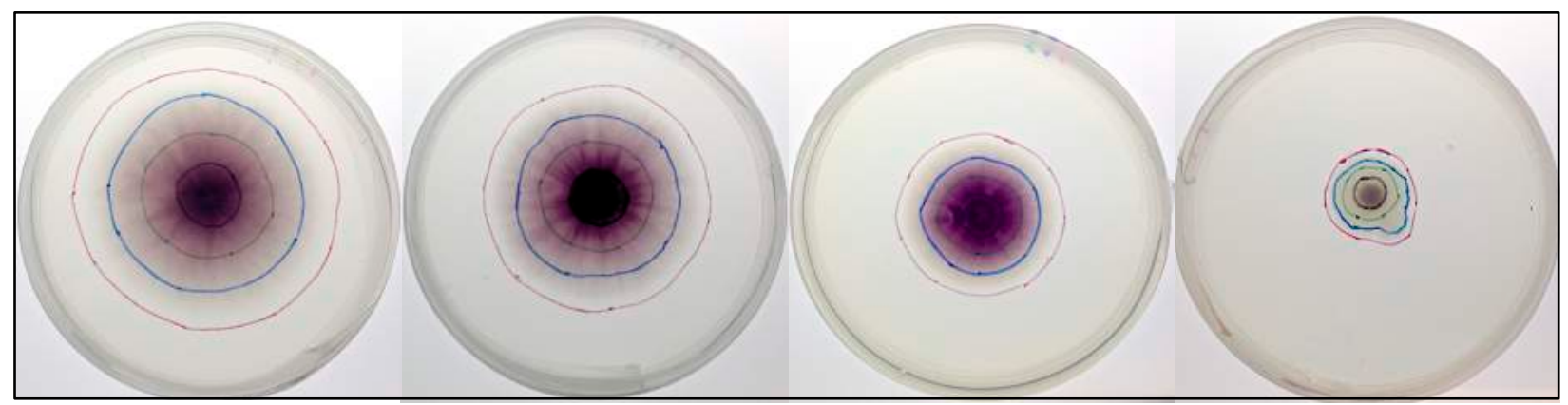

Photo 6. F usarium oxysporum f.sp. fragariae 19 growing on ferulic acid amended plates.

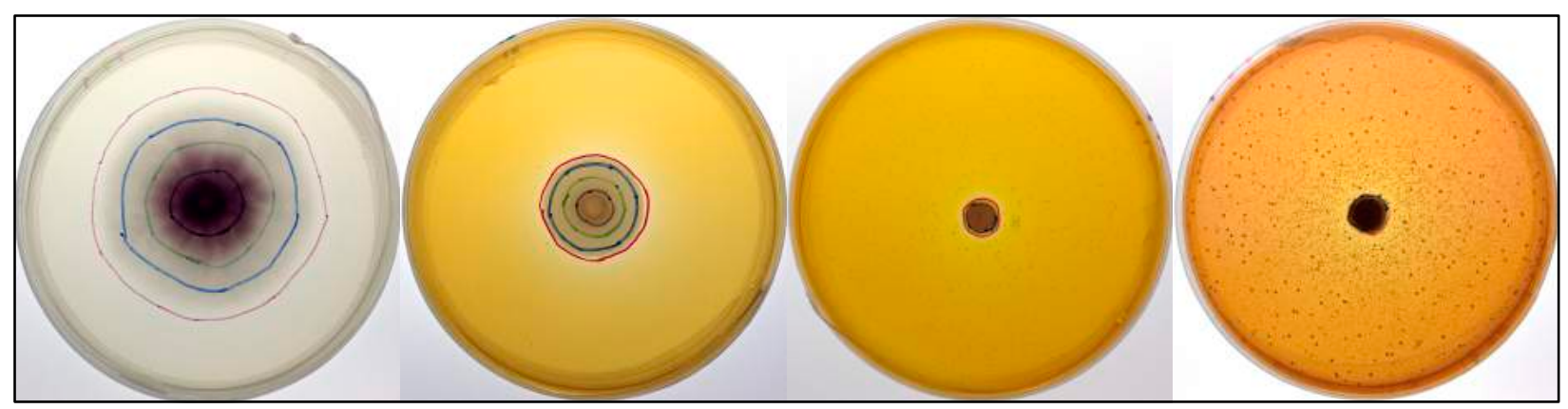

Photo 7. Fusarium oxysporum f.sp. fragariae 19 growing on juglone amended plates.

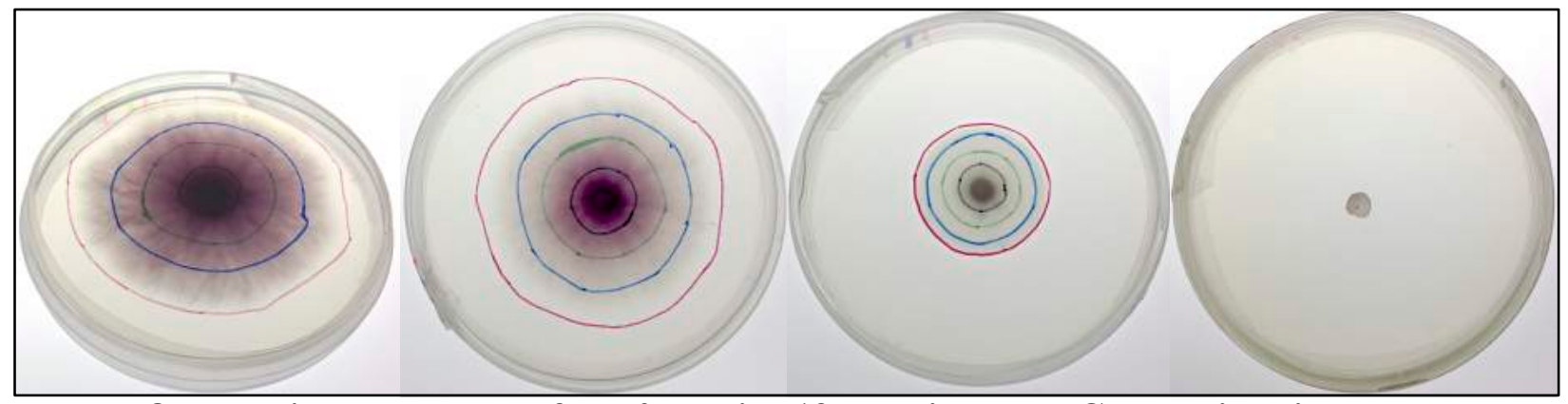

Photo 8. Fusarium oxysporum f.sp. fragariae 19 growing on p-Coumaric acid amended plates.
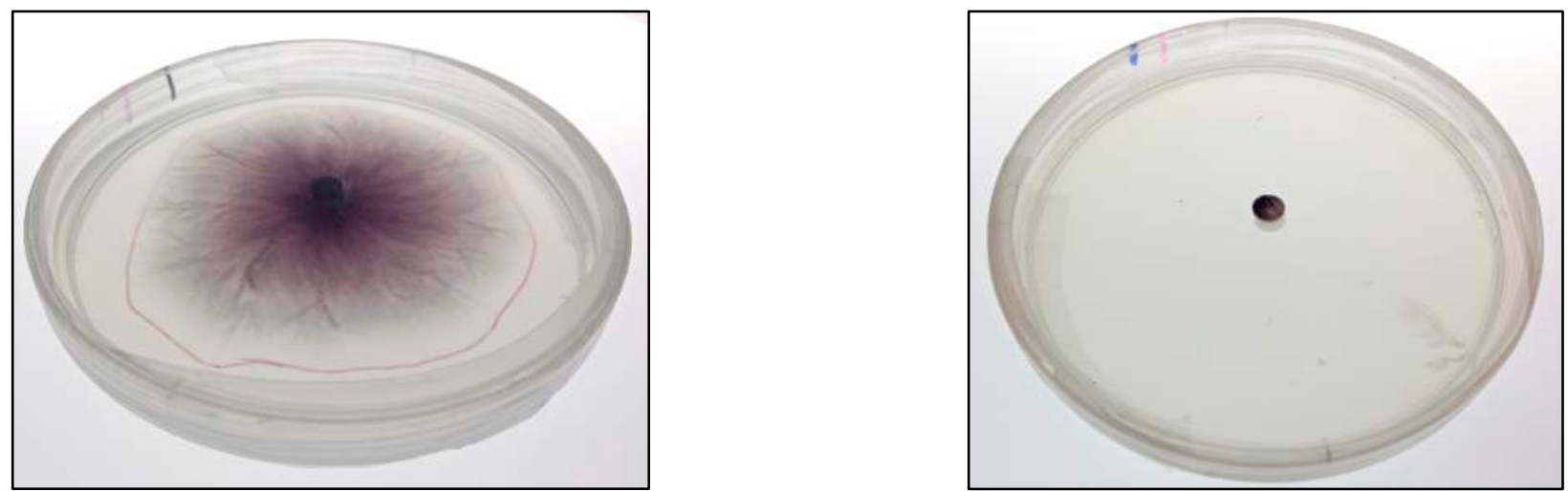

Photos 9 and 10. Fusarium oxysporum f.sp. fragariae 19. Water control with DMSO (left) and fungicide control with DMSO (right). 


\section{A.2 In Soil Fungus Assays}

Macrophomina phaseolina colony forming units (CFUs) in RB selective media. We plated treated soil with inoculum using an Andersen Cascade Impactor. Left to right: low, medium-low, mediumhigh, and high rates of plant compounds. Red dots are above $M p$ colonies. Some colonies are not Mp.

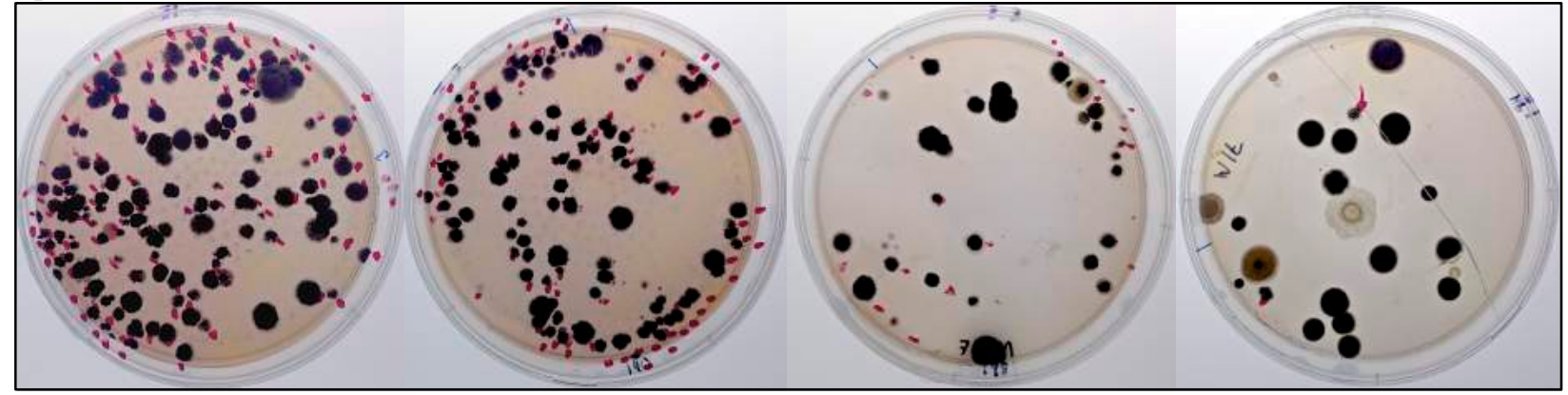

Photo 1. Macrophomina phaseolina 8 and 13 CFUs after treatment with ferulic acid in soil.

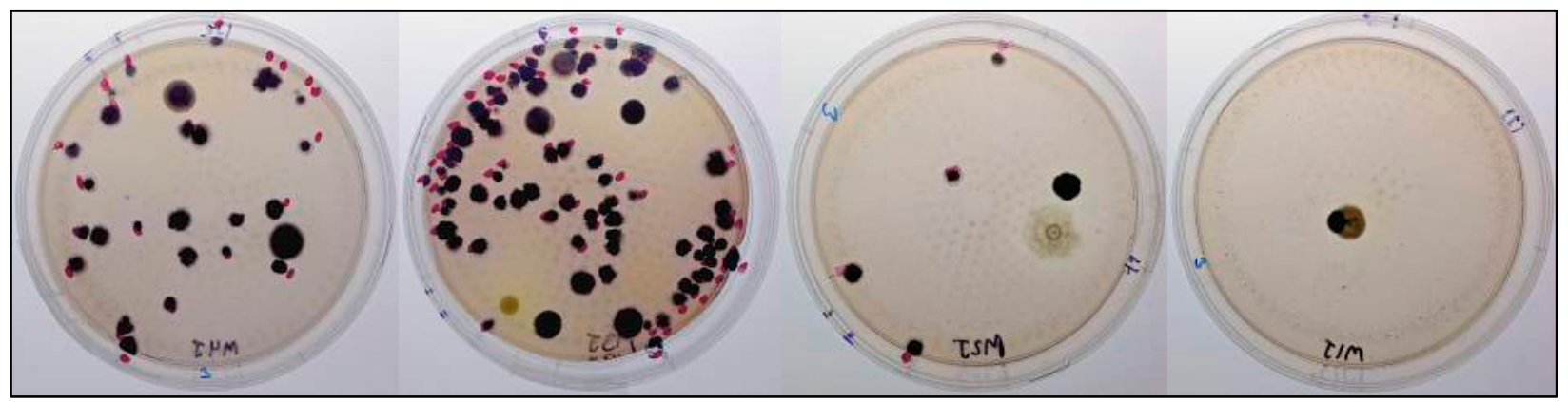

Photo 2. Macrophomina phaseolina 8 and 13 CFUs after treatment with juglone in soil.

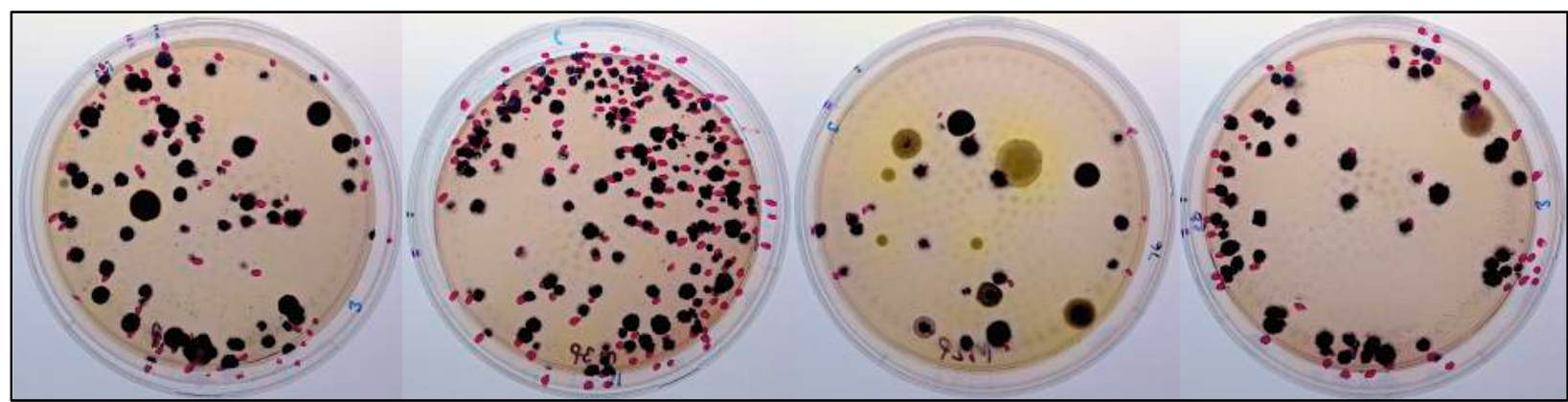

Photo 3. Macrophomina phaseolina 8 and 13 CFUs after treatment with p-Coumaric acid in soil.
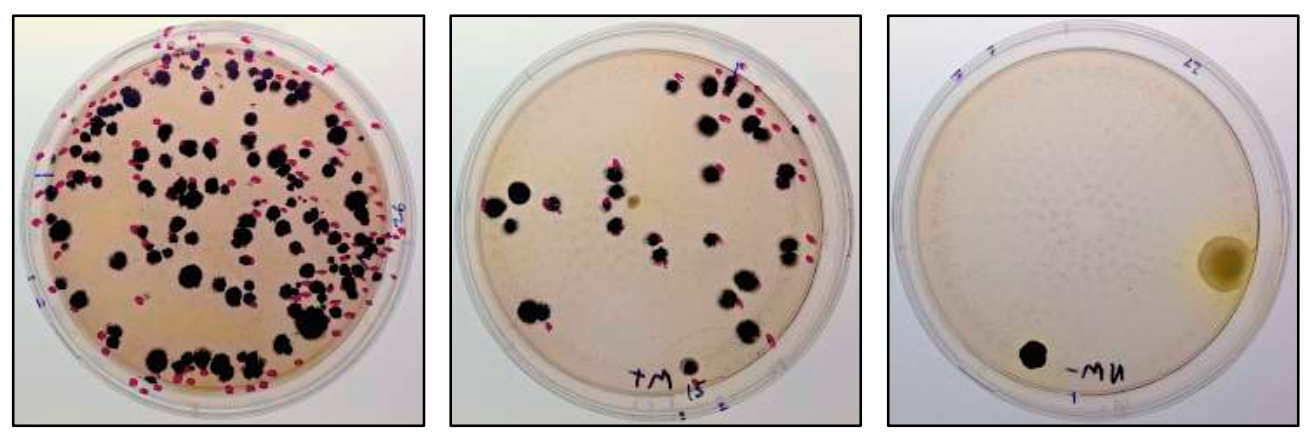

Photos 4-6. In soil water control with pathogen (left), fungicide control with pathogen (center), and water control without pathogen (right). 
Photos are of Fusarium oxysporum f.sp. fragariae colony forming units in Komada selective media. We direct plated plant compound treated soil with inoculum in a sodium hexametaphosphate/water agar solution. Left to right: low, medium-low, medium-high, and high rates of plant compounds. Komada media is highly selective, and all colonies are Fof.

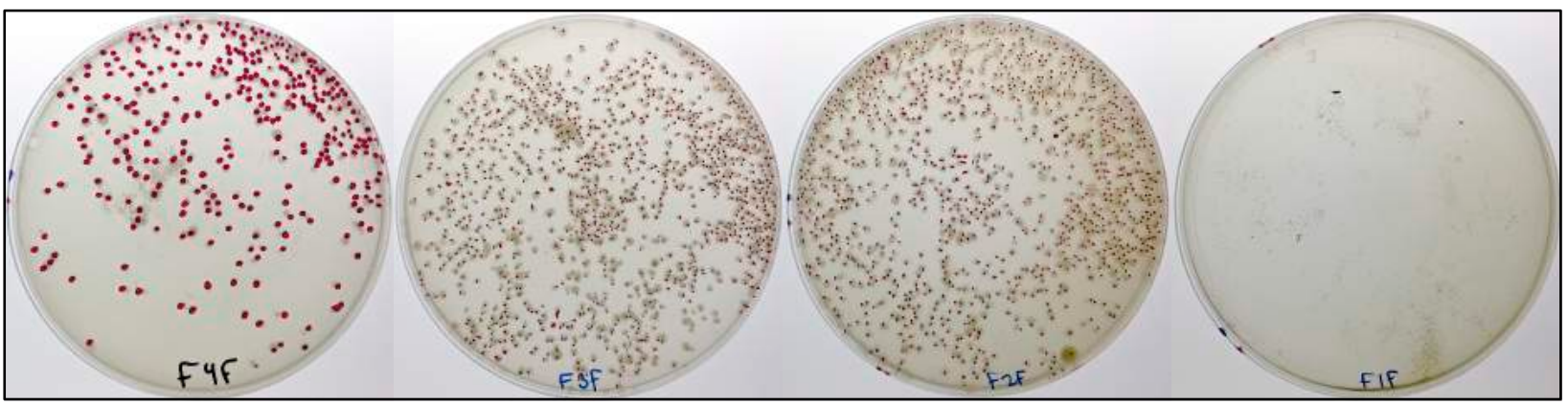

Photo 7. Fusarium oxysporum f.sp. fragariae CFUs after treatment with ferulic acid in soil.

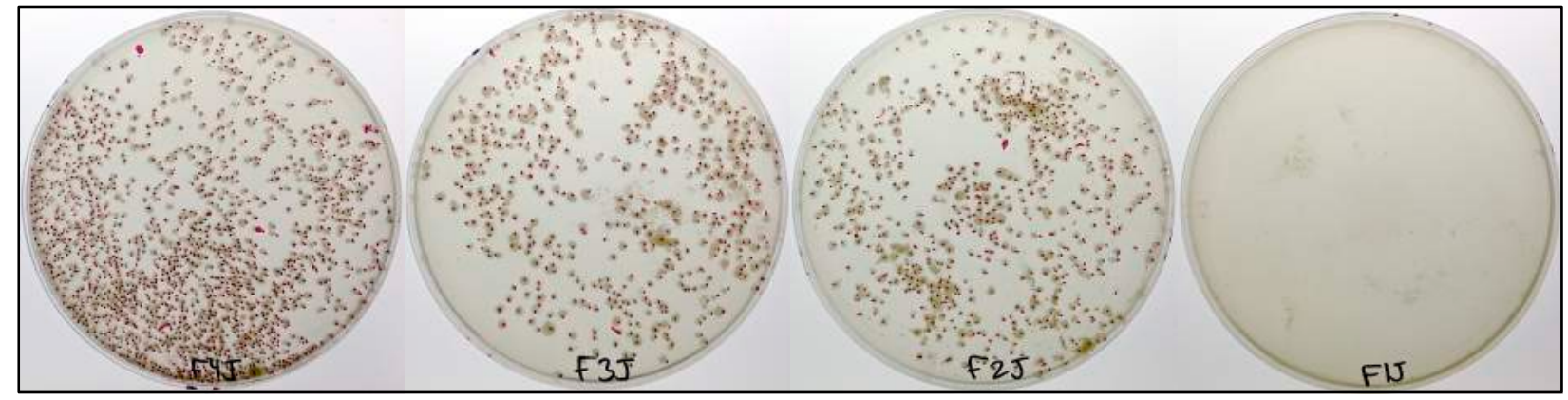

Photo 8. F usarium oxysporum f.sp. fragariae CFUs after treatment with juglone in soil.

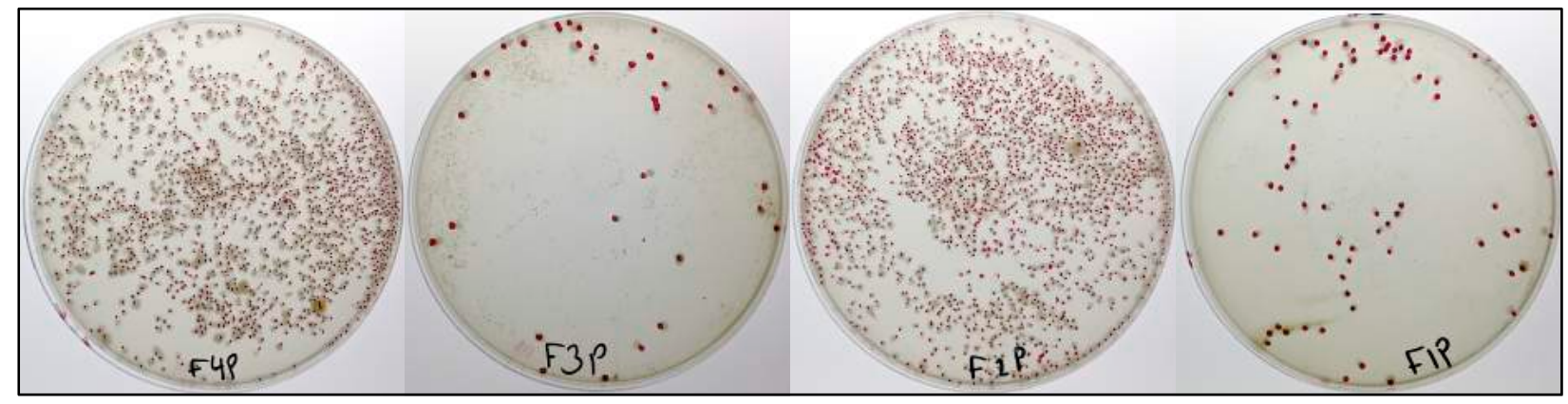

Photo 8. Fusarium oxysporum f.sp. fragariae CFUs after treatment with juglone in soil.
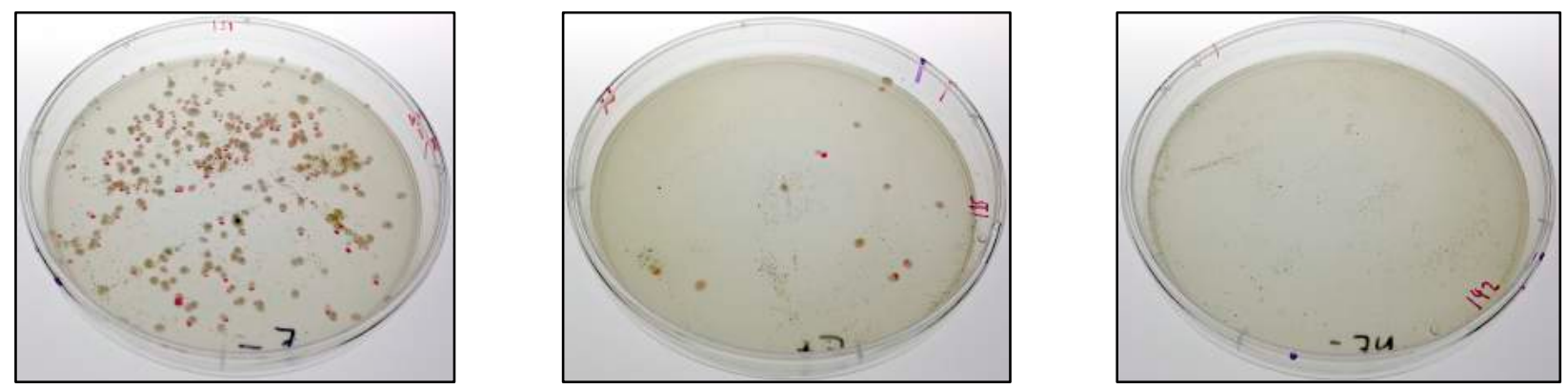

Photos 9-11. In soil water control with pathogen (left), fungicide control with pathogen (center), and water control without pathogen (right). 


\section{B. Macrophomina Phaseolina Andersen Cascade Impactor Pilot Study}

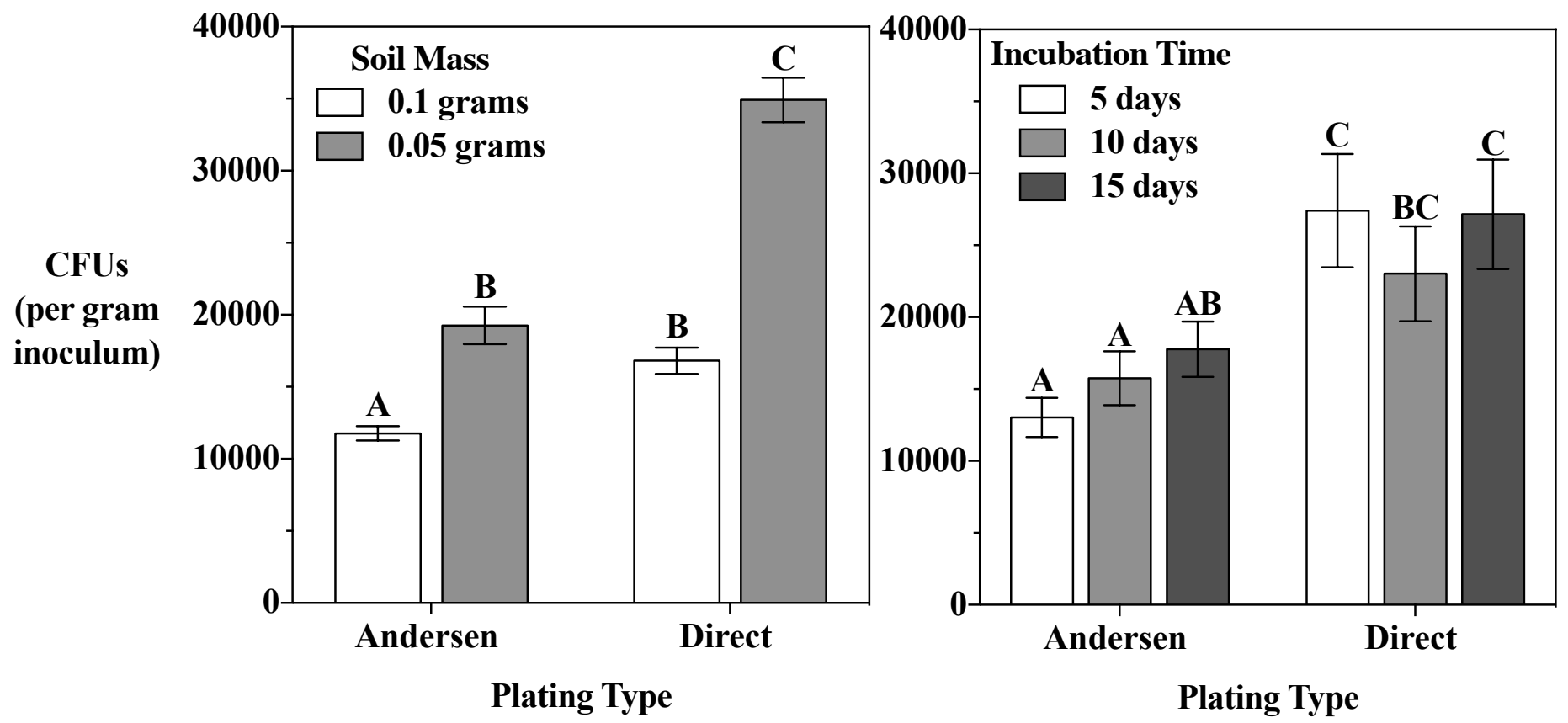

Figure 1. Comparison of colony forming unit (CFU) detection between Andersen sampling and direct plating techniques using different masses of soil $(0.1 \mathrm{~g}$, and $0.05 \mathrm{~g}$ with $10 \%(\mathrm{w} / \mathrm{w})$ inoculum) and counting colonies after $\mathbf{5 , 1 0}$, or 15 days of incubation. $\mathrm{F}(11,36)=27.53, \mathrm{p}<.0001, \mathrm{~N}=4$. Bars with different letters are significantly different $(\mathrm{p}<.05)$. Error bars are \pm 1 SEM.

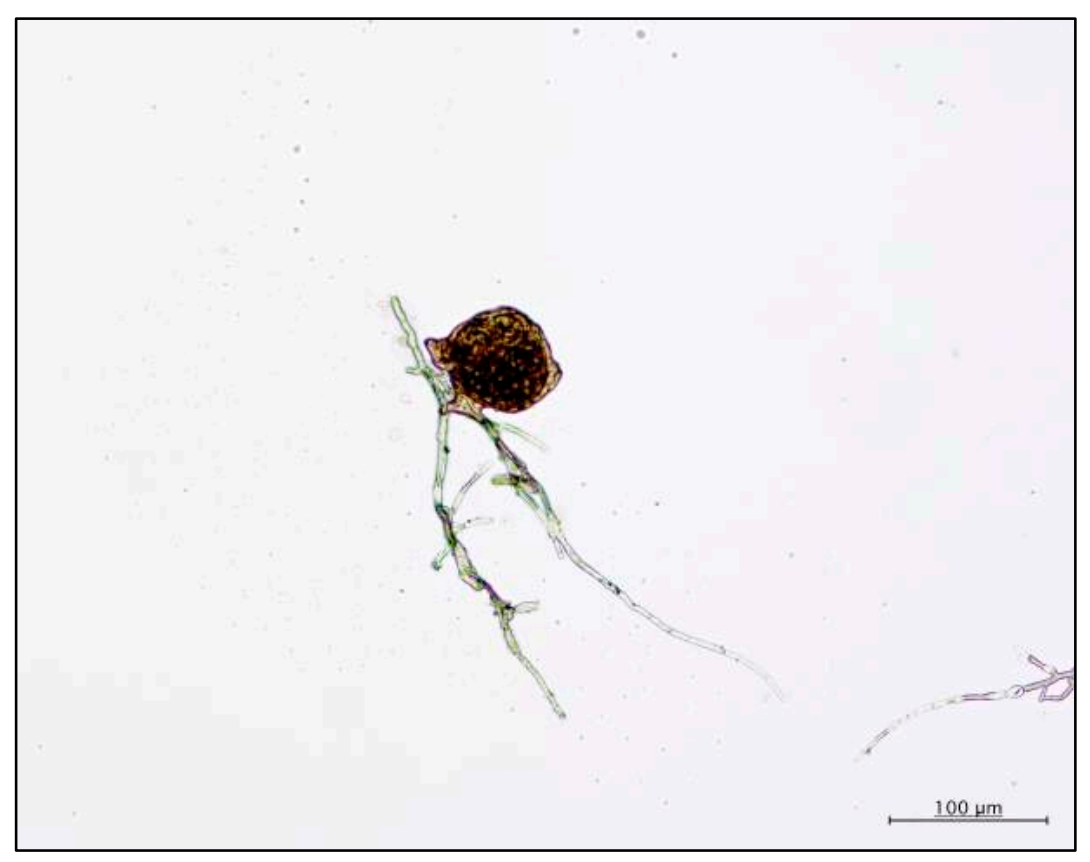

Photo 1. Condensed melanized hyphae forming a microsclerotium (left).

Photo 2. Soil distribution on selective agar after using an Andersen Cascade Impactor (below).

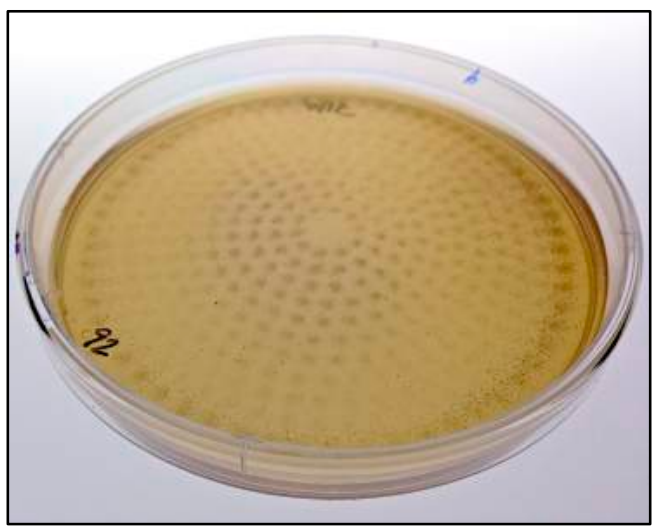




\section{Strawberry Farm Locations and Weed Species Collected}

\begin{tabular}{|c|c|c|}
\hline Strawberry Farm or Grower & Location & Species Collected (Seed) \\
\hline Agua Linda & $\begin{array}{l}34^{\circ} 59^{\prime} 24.48^{\prime \prime} \mathrm{N} \\
120^{\circ} 30^{\prime} 1.39^{\prime \prime} \mathrm{W}\end{array}$ & $\begin{array}{l}\text { Malva parviflora } \mathrm{L} \text {. } \\
\text { Poa annua } \mathrm{L} .\end{array}$ \\
\hline Black Jack Farms & $\begin{array}{c}34^{\circ} 45^{\prime} 25.6^{\prime \prime} \mathrm{N} \\
120^{\circ} 24^{\prime} 04.0^{\prime \prime} \mathrm{W}\end{array}$ & $\begin{array}{l}\text { Malva parviflora } \mathrm{L} \text {. } \\
\text { Poa annua } \mathrm{L} . \\
\text { Senecio vulgaris } \mathrm{L} \text {. }\end{array}$ \\
\hline $\begin{array}{c}\text { Cal Poly, San Luis Obispo } \\
\text { Campus }\end{array}$ & $\begin{array}{c}35^{\circ} 18^{\prime} 18.1 ” \mathrm{~N} \\
120^{\circ} 40^{\prime} 27.0 ” \mathrm{~W}\end{array}$ & Malva parviflora $\mathrm{L}$. \\
\hline Jesus Chavez & $\begin{array}{c}34^{\circ} 53^{\prime} 16.0^{\prime \prime} \mathrm{N} \\
120^{\circ} 21^{\prime} 14.6^{\prime} \mathrm{W}\end{array}$ & $\begin{array}{l}\text { Malva parviflora } \mathrm{L} . \\
\text { Poa annua } \mathrm{L} . \\
\text { Senecio vulgaris } \mathrm{L} .\end{array}$ \\
\hline Jose Iniguez (organic) & $\begin{array}{c}35^{\circ} 03^{\prime} 40.8^{\prime \prime} \mathrm{N} \\
120^{\circ} 35^{\prime} 18.7^{\prime \prime} \mathrm{W}\end{array}$ & $\begin{array}{l}\text { Malva parviflora } \mathrm{L} \text {. } \\
\text { Poa annua } \mathrm{L} . \\
\text { Senecio vulgaris } \mathrm{L} .\end{array}$ \\
\hline Luis Torres (organic) & $\begin{array}{c}34^{\circ} 54^{\prime} 57.2^{\prime \prime} \mathrm{N} \\
120^{\circ} 22^{\prime} 30.7^{\prime \prime} \mathrm{W}\end{array}$ & $\begin{array}{l}\text { Malva parviflora } \mathrm{L} . \\
\text { Poa annua } \mathrm{L} . \\
\text { Senecio vulgaris } \mathrm{L} .\end{array}$ \\
\hline Main Street Farm & $\begin{array}{c}34^{\circ} 52^{\prime} 23.5^{\prime \prime} \mathrm{N} \\
120^{\circ} 23^{\prime} 24.2^{\prime \prime} \mathrm{W}\end{array}$ & $\begin{array}{l}\text { Malva parviflora } \mathrm{L} \text {. } \\
\text { Poa annua } \mathrm{L} . \\
\text { Senecio vulgaris } \mathrm{L} \text {. }\end{array}$ \\
\hline Ramiro Chavez & $\begin{array}{c}34^{\circ} 54^{\prime} 54.0^{\prime \prime} \mathrm{N} \\
120^{\circ} 24^{\prime} 02.0^{\prime \prime} \mathrm{W}\end{array}$ & $\begin{array}{l}\text { Malva parviflora } \mathrm{L} \text {. } \\
\text { Poa annua } \mathrm{L} . \\
\text { Senecio vulgaris } \mathrm{L} \text {. }\end{array}$ \\
\hline Rigoberto Chavez & $\begin{array}{c}35^{\circ} 2^{\prime} 43.5^{\prime \prime} \mathrm{N} \\
120^{\circ} 34^{\prime} 05.4^{\prime \prime} \mathrm{W}\end{array}$ & Malva parviflora $\mathrm{L}$. \\
\hline Royal Oaks Farms & $\begin{array}{c}36^{\circ} 54^{\prime} 14.7^{\prime \prime} \mathrm{N} \\
121^{\circ} 43^{\prime} 57.1{ }^{\prime \prime} \mathrm{W}\end{array}$ & Senecio vulgaris L. \\
\hline Royal Oaks Farms (organic) & $\begin{array}{c}36^{\circ} 53^{\prime} 38.8 ” \mathrm{~N} \\
121^{\circ} 41^{\prime} 29.0 \text { '” }\end{array}$ & $\begin{array}{l}\text { Malva parviflora } \mathrm{L} \text {. } \\
\text { Senecio vulgaris } \mathrm{L} \text {. }\end{array}$ \\
\hline Sunberry Farm & $\begin{array}{c}34^{\circ} 55^{\prime} 06.8^{\prime \prime} \mathrm{N} \\
120^{\circ} 28^{\prime} 23.5^{\prime} \mathrm{W}\end{array}$ & $\begin{array}{c}\text { Poа annua } \mathrm{L} . \\
\text { Senecio vulgaris } \mathrm{L} \text {. }\end{array}$ \\
\hline
\end{tabular}




\section{Seed Surface Sterilization Study}

We ran an experiment to assess the effects of drying plates (no drying, 30 mins of drying, or overnight drying) and the amount of time seeds are soaked in a sodium hypochlorite/Triton ${ }^{\mathrm{TM}} \mathrm{X}-100$ solution, on the probabilty of agar contamination (visible fungal hyphae or bacterial colonies) and the probability of seed germination. We used two sodium hypochlorite concentrations depending on the plant species (3\% for Lactuca sativa 'Inferno', Malva parviflora, Melilotus officinalis, and Poa annua; and $6 \%$ for Senecio vulgaris) and $1 \%$ Triton $^{\mathrm{TM}} \mathrm{X}-100$. We also used two different soaking regime times: Senecio vulgaris soaked in sterilization solution for 0 mins, 10 mins (normal), or 20 mins (double). All other seeds soaked for 0 mins, 7 mins (normal), or 14 mins (double).

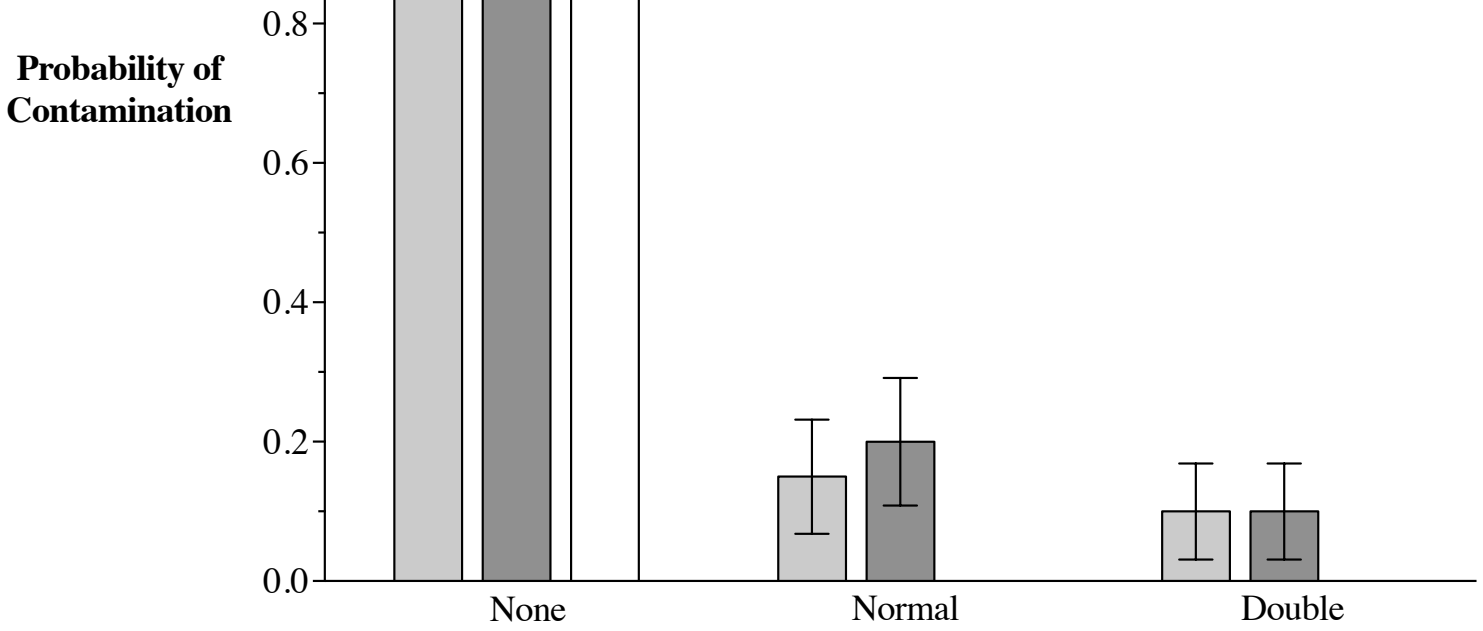

Sterilization Time

Figure 1. Probability of contamination due to Petri plate dry time (no dry time, 30 mins of dry time, and overnight dry time) and surface sterilization time (none, normal, and double). All plant species grouped together. We excluded treatments from analysis that had limited or no variability in the probability of contamination response variable (these treatments were: all no surface sterilization treatments, and overnight plate dry time for normal and double surface sterilization treatments). There was no contamination in normal and double sterilization time treatments with overnight plate dry times (bars not visible). A nominal logistic regression did not find a significant difference between normal sterilization and double sterilization treatments $\left(\mathrm{X}^{2}(6, \mathrm{~N}=80)=2.28, \mathrm{p}=.8919\right)$. Error bars are \pm 1 SEM. 

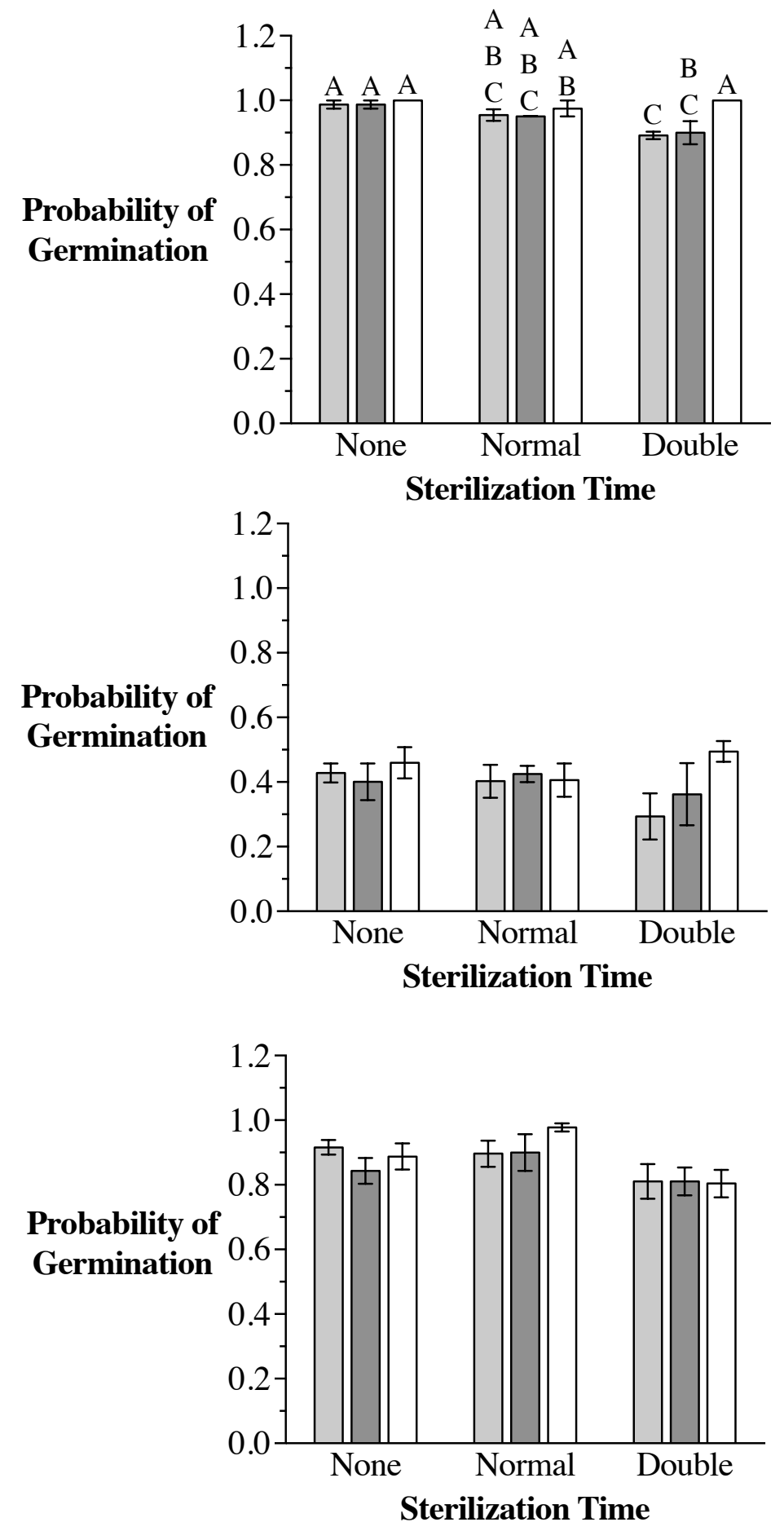
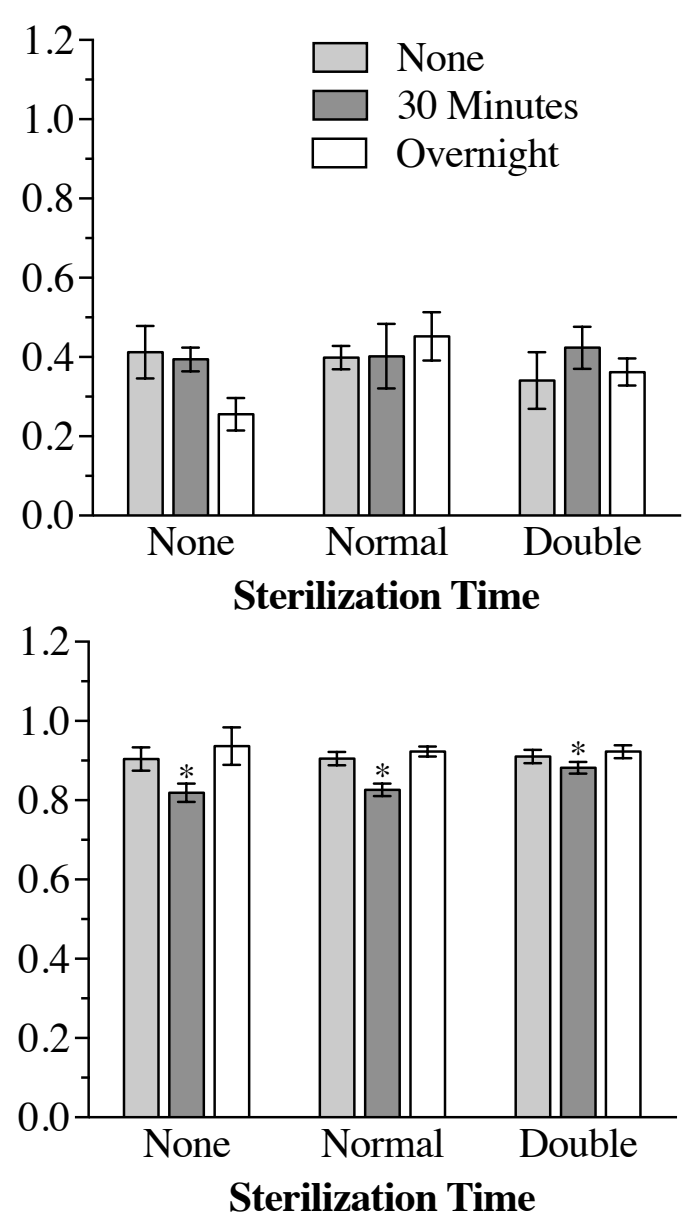

Figure 2. Germination rates of five plant species exposed to three different petri plate dry times and three different surface sterilization times. Clockwise from upper left: Lactuca sativa 'Inferno', Malva parviflora, Poa аппиа, Senecio vulgaris, and Melilotus officinalis. Treatments with different letters are significantly different $(\mathrm{p}<.05)$. *Drying plates for 30 mins significantly decreased Poa annua germination. Error bars are \pm 1 SEM.

Table 1. The effects of petri plate dry time and surface sterilization time on the germination rate of five plant species.

\begin{tabular}{c|ccccc}
\hline \multirow{2}{*}{ Species } & $\begin{array}{c}\text { Lactuca } \\
\text { sativa }\end{array}$ & $\begin{array}{c}\text { Malva } \\
\text { parviflora }\end{array}$ & $\begin{array}{c}\text { Melilotus } \\
\text { officinalis }\end{array}$ & $\begin{array}{c}\text { Poa } \\
\text { annua }\end{array}$ & $\begin{array}{c}\text { Senecio } \\
\text { vulgaris }\end{array}$ \\
\hline \multirow{2}{*}{ ANOVA } & $F(11,24)=4.78$, & $F(11,24)=.78$, & $F(11,24)=.85$, & $F(11,24)=2.42$, & $F(11,24)=1.57$, \\
& $\mathrm{p}=.0007$ & $\mathrm{p}=.6553$ & $\mathrm{p}=.7201$ & $\mathrm{p}=.0338$ & $\mathrm{p}=.1709$ \\
\hline
\end{tabular}




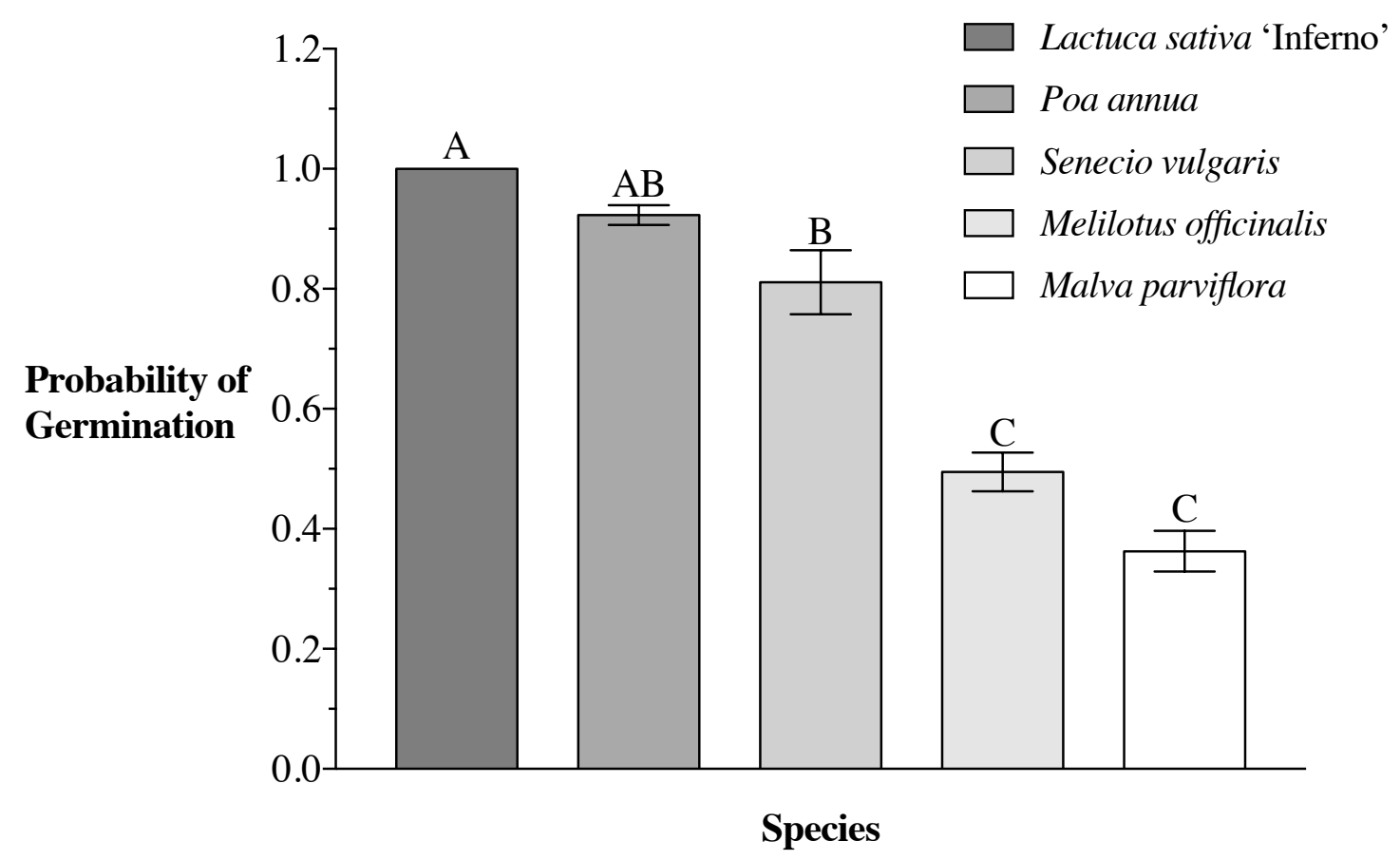

Figure 3. Comparison of seed germination rates of five plant species after surface sterilization. We dried all plates overnight and surface sterilized seeds with 3\% sodium hypochlorite and $1 \%$ Triton $^{\mathrm{TM}} \mathrm{X}-100$ for 14 mins (Lactuca sativa 'Inferno', Mavla parviflora, Melilotus officinalis, and Poa апnиa), or 6\% sodium hypochlorite and $1 \%$ Triton $^{\mathrm{TM}} \mathrm{X}-100$ for 20 mins (Senecio vulgaris only). $F(7,12)$ $=40.2777, \mathrm{p}<.0001$. Error bars are \pm 1 SEM.

\section{Conclusion: Surface Sterilization Study-}

Across seed of all plant species, there was no contamination (fungal hyphae or bacterial colonies) over the course of the surface sterilization experiment when Petri plates dried overnight and seeds soaked in surface sterilization solution for either 14 or 20 mins (depending on the species). In the plant compound weed assays, we dried plates overnight and soaked seeds in solutions similar or equivalent to the "double sterilization" treatment in this surface sterilization study. We concluded that the surface sterilization procedure successfully reduced or eliminated contamination in Petri plates.

In most cases, surface sterilization did not inhibit germination. However, the 30 min plate dry time for $P$. апnи , and the interaction of no dry time or 30 min dry time with double sterilization for $L$. sativa did reduce germination relative to other treatments. These treatments were not a part of the plant compound weed assays, and so we are confident that surface sterilization did not inhibit germination in the experiments we presented in this thesis. 


\section{E. Weed Seed Assay Photographs}

\section{E.1 In vitro weed seed assays}

Photos 1 and 2. Lactuca sativa 'Inferno' growing on water agar amended with plant compounds. Ferulic acid (left) and gallic acid (right). Top to bottom: 10, 100, 500, and 1000 parts per million by weight treatments.
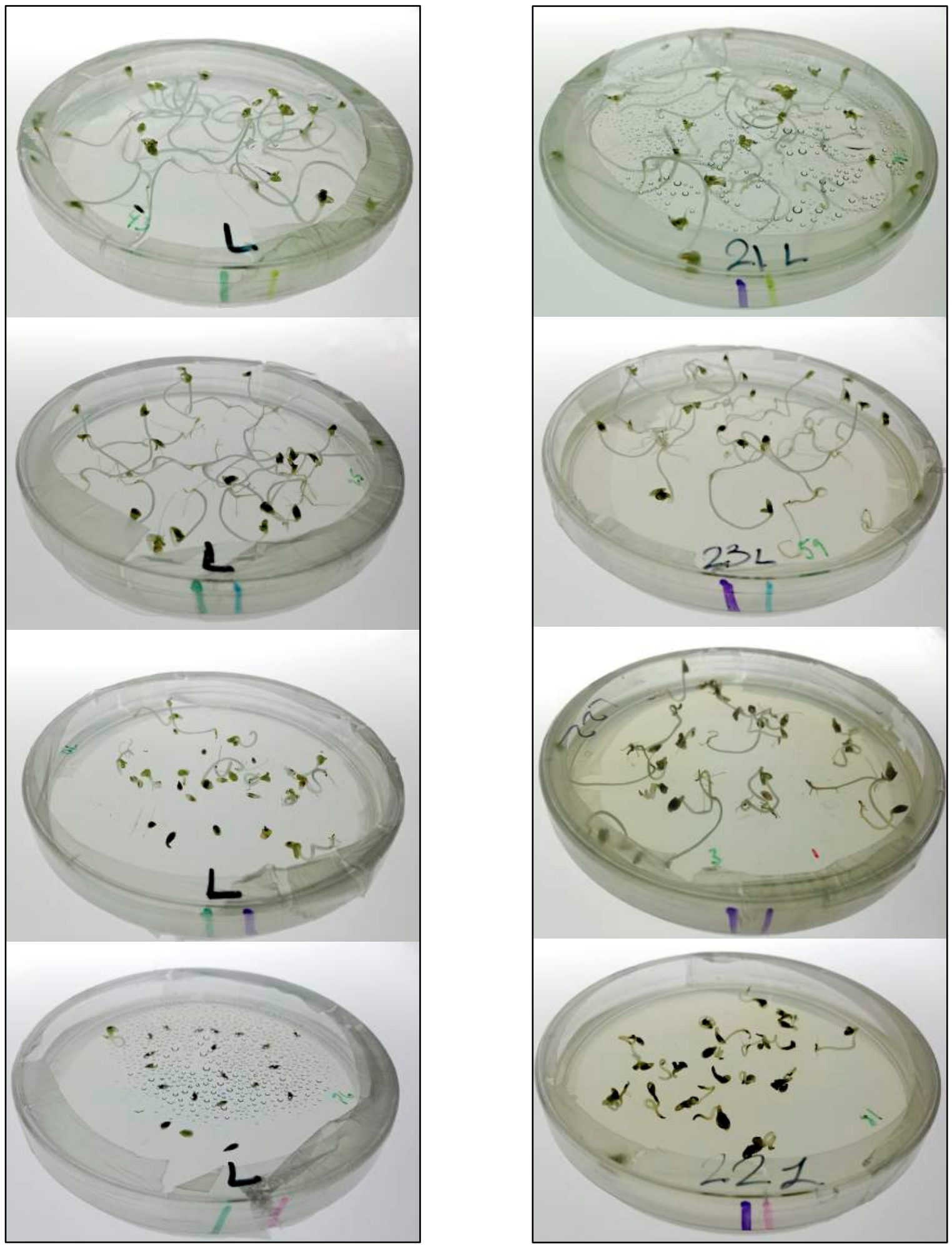
Photos 3. and 4. Lactuca sativa 'Inferno' growing in water agar amended with plant compounds. Juglone (left) and p-Coumaric acid (right). Top to bottom: 10, 100, 500, and 1000 parts per million by weight.
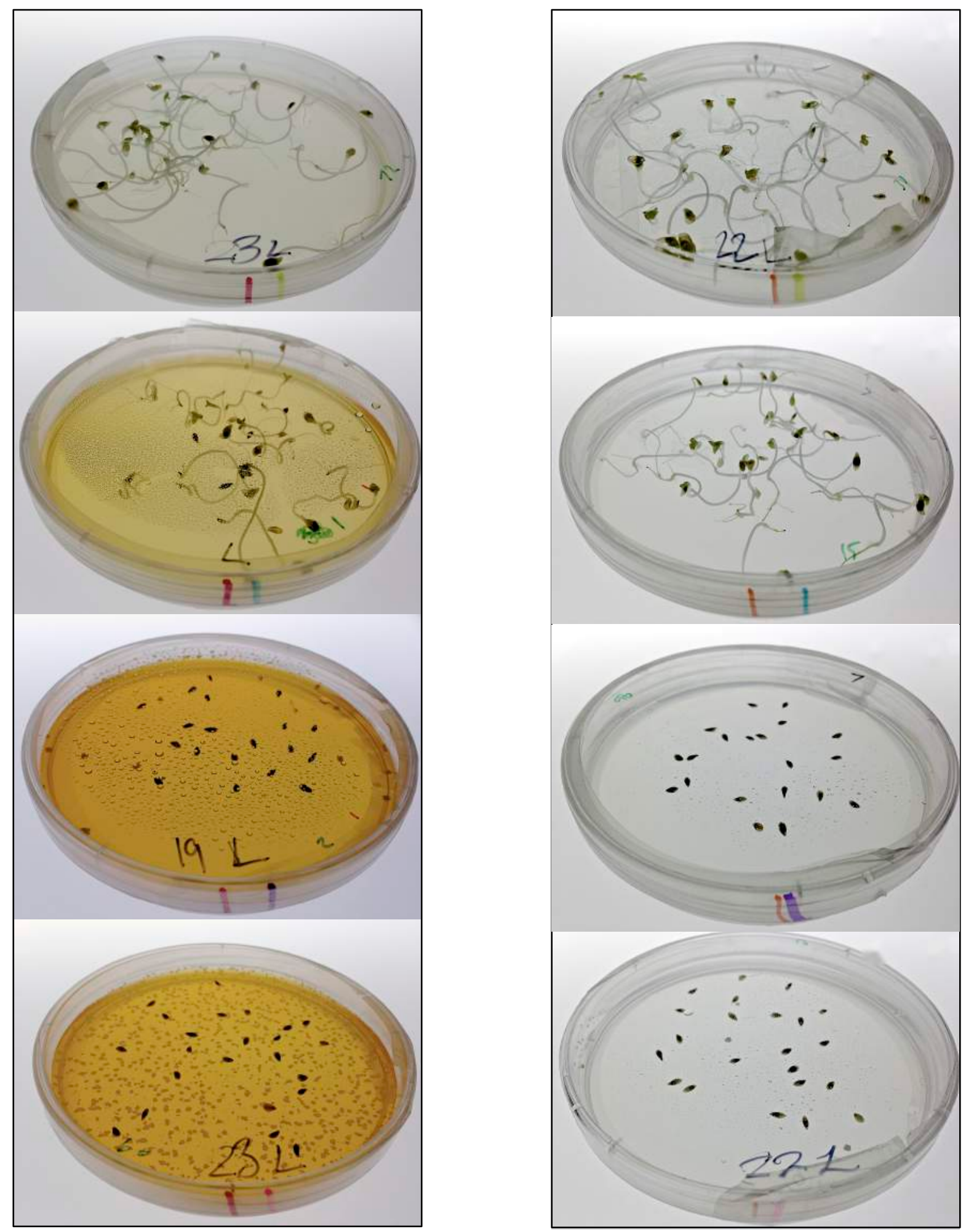

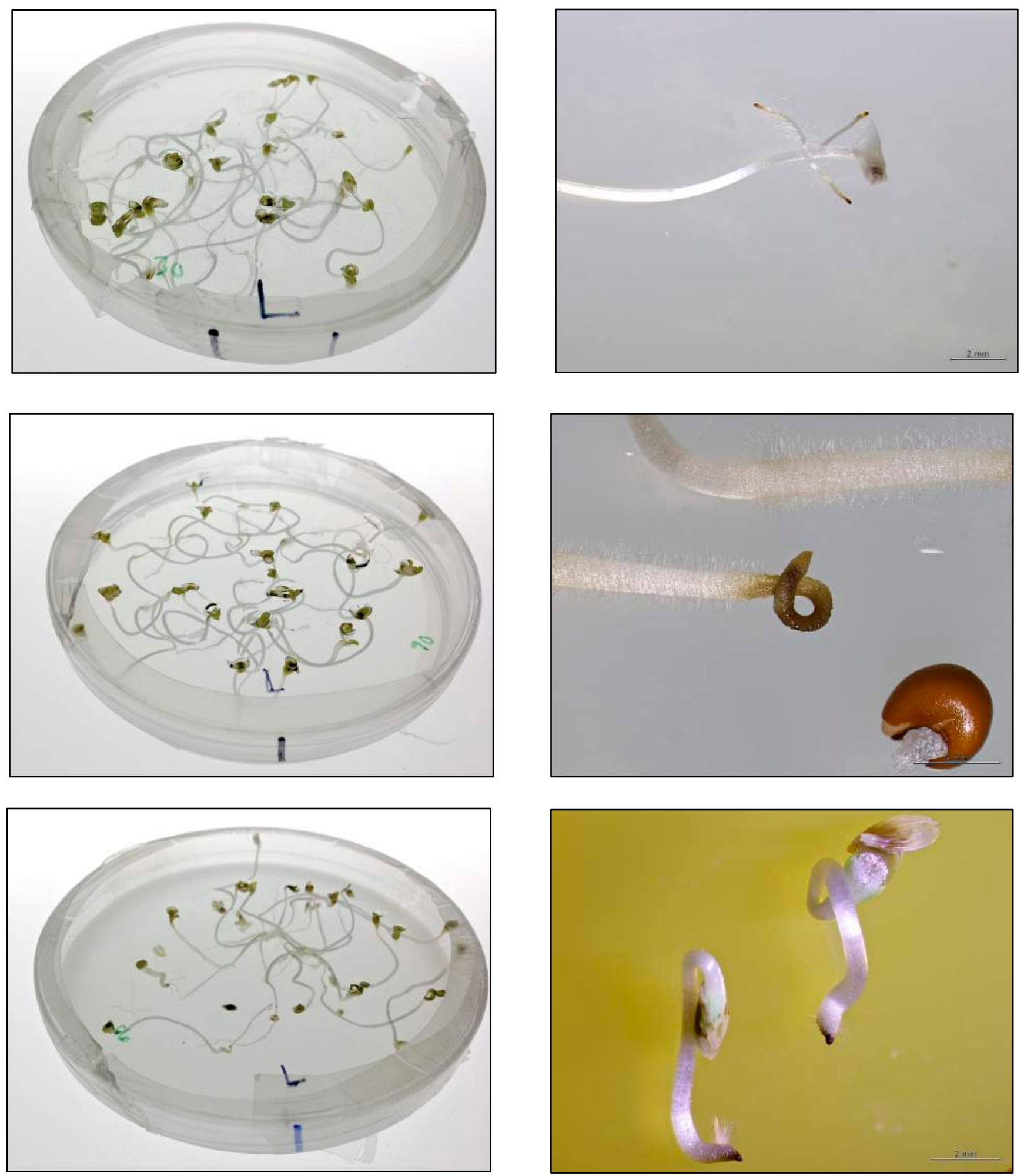

Photos 5-10. Left column, top to bottom; Lactuca sativa 'Inferno' growing in water agar amended with DMSO, without DMSO, and with oxyfluorfen (GoalTender ${ }^{\circledR}$ ). Right column, top to bottom: a seedling in 500 parts per million by weight (ppmw) gallic acid with lateral root branching, Malva parviflora root with a necrotic lesion at the root tip in 1000 ppmw gallic acid, and L. sativa in 100 ppmw juglone with root tip dieback. 


\section{E.2 In Soil Weed Seed Assays}

\section{Damage Rating System-}

The damage rating system had three levels. We assigned a " 0 " damage rating to wells containing seedlings with no discernible damage, a " 1 " damage rating to wells containing seedlings with slight damage, and a " 2 " damage rating to wells containing seedlings with severe damage.

\section{“0” Damage Examples}

No obvious symptoms of herbicide damage existed on leaves, stems, or shoots.
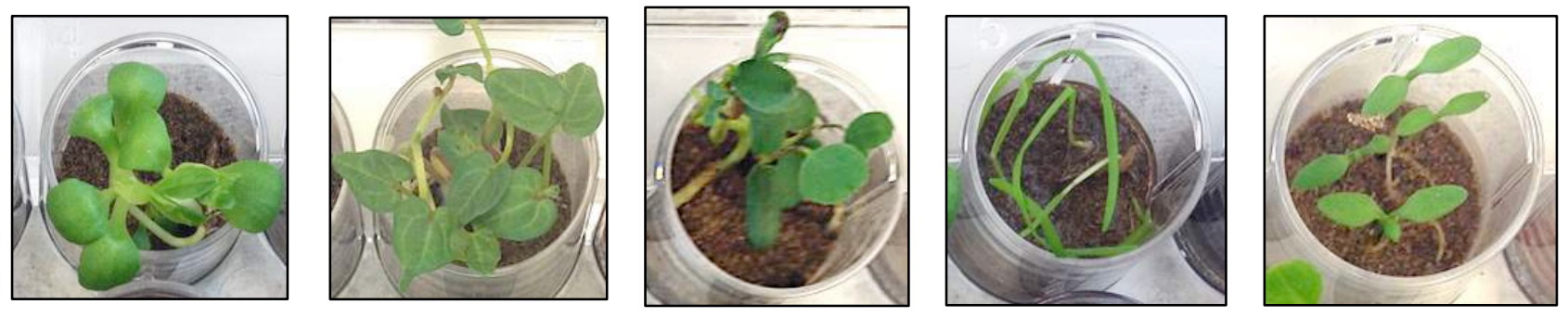

“1” (Slight) Damage Examples

Seedlings showed at least one symptom of herbicide damage: necrosis, chlorosis, epinasty, bleaching, stunted shoot or root growth, burned roots, necrotic speckling, collapsed stem, etc.
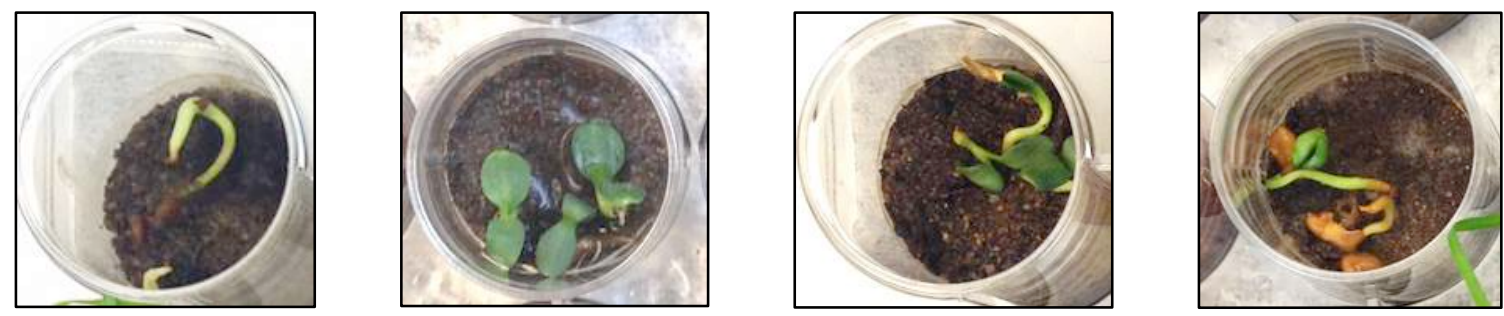

"2" (Severe) Damage Examples

Seedlings showed multiple signs of herbicide damage (necrosis, chlorosis, epinasty, etc.). Stems or leaves were discolored and there was stunted growth. A damaged cotyledon or root radical may be all that emerged, or there was no germination.
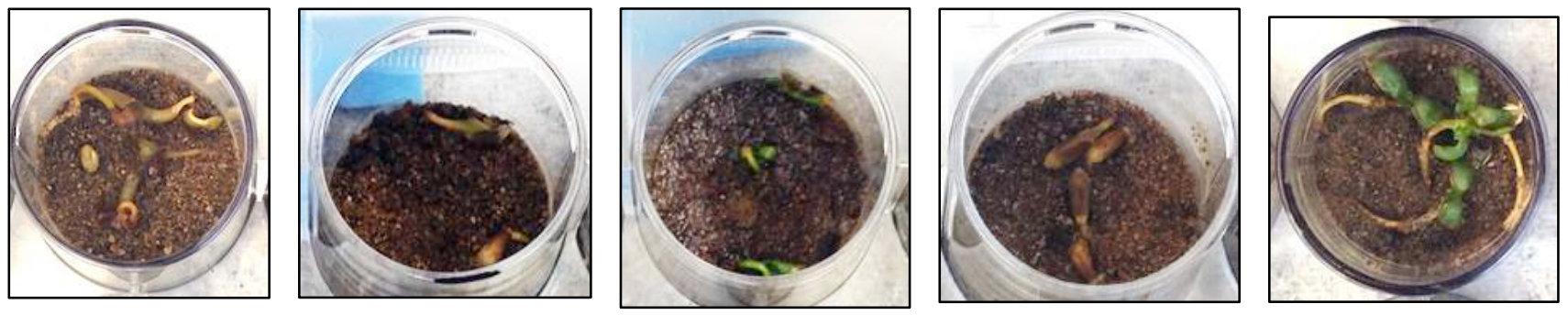


\section{Contamination Rating System-}

We rated wells according to their level of contamination (visible microbial growth), and determined that contamination was usually fungal due to the presence of mycelium, aerial hyphae, and/or spore-producing structures.

“0” (None) Examples (no contamination occurred in the well)

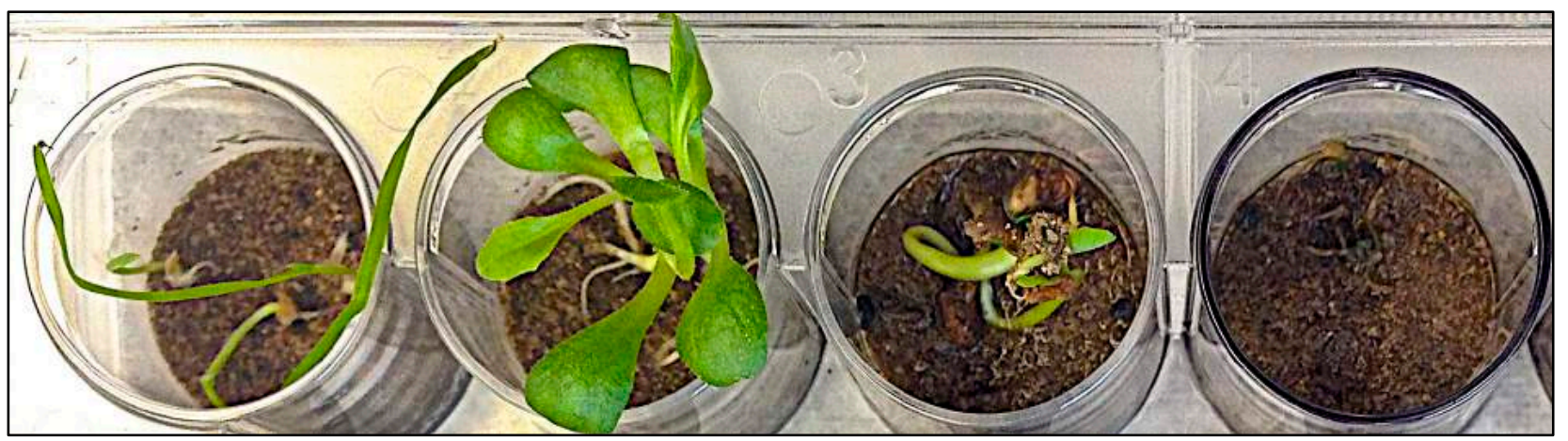

"1" (Slight) Examples (contamination occurred in half of the well or less)

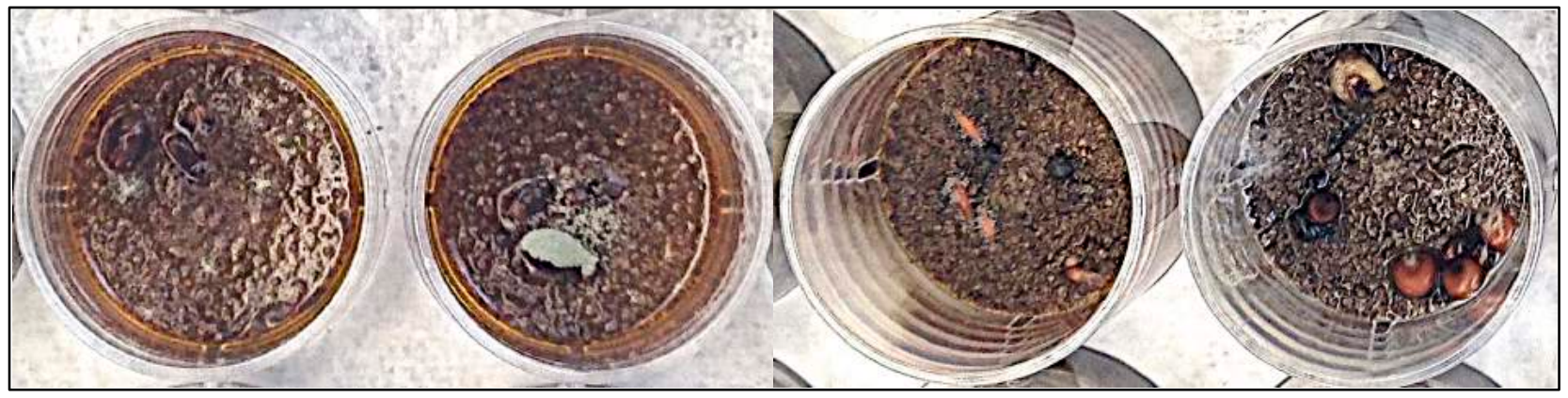

"2" (Major) Examples (contamination occurred in more than half of the well)

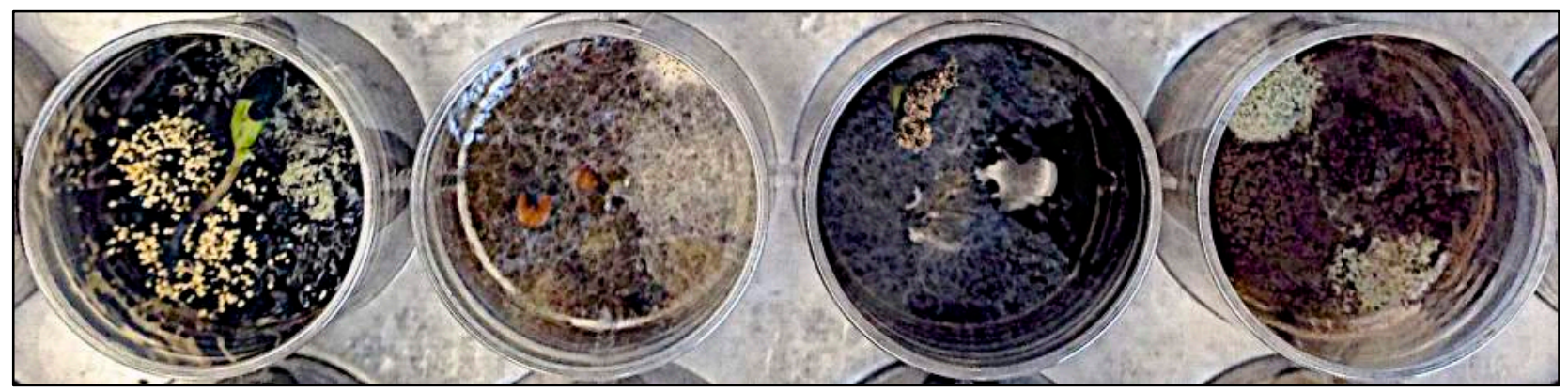


Photos 1 and 2. Top, one of the sixty weed assay 24-well plates with treatments randomly assigned to wells after 11 days of seedling growth. Bottom, treatments corresponding to each well in the top photograph (see treatment keys on the following page).
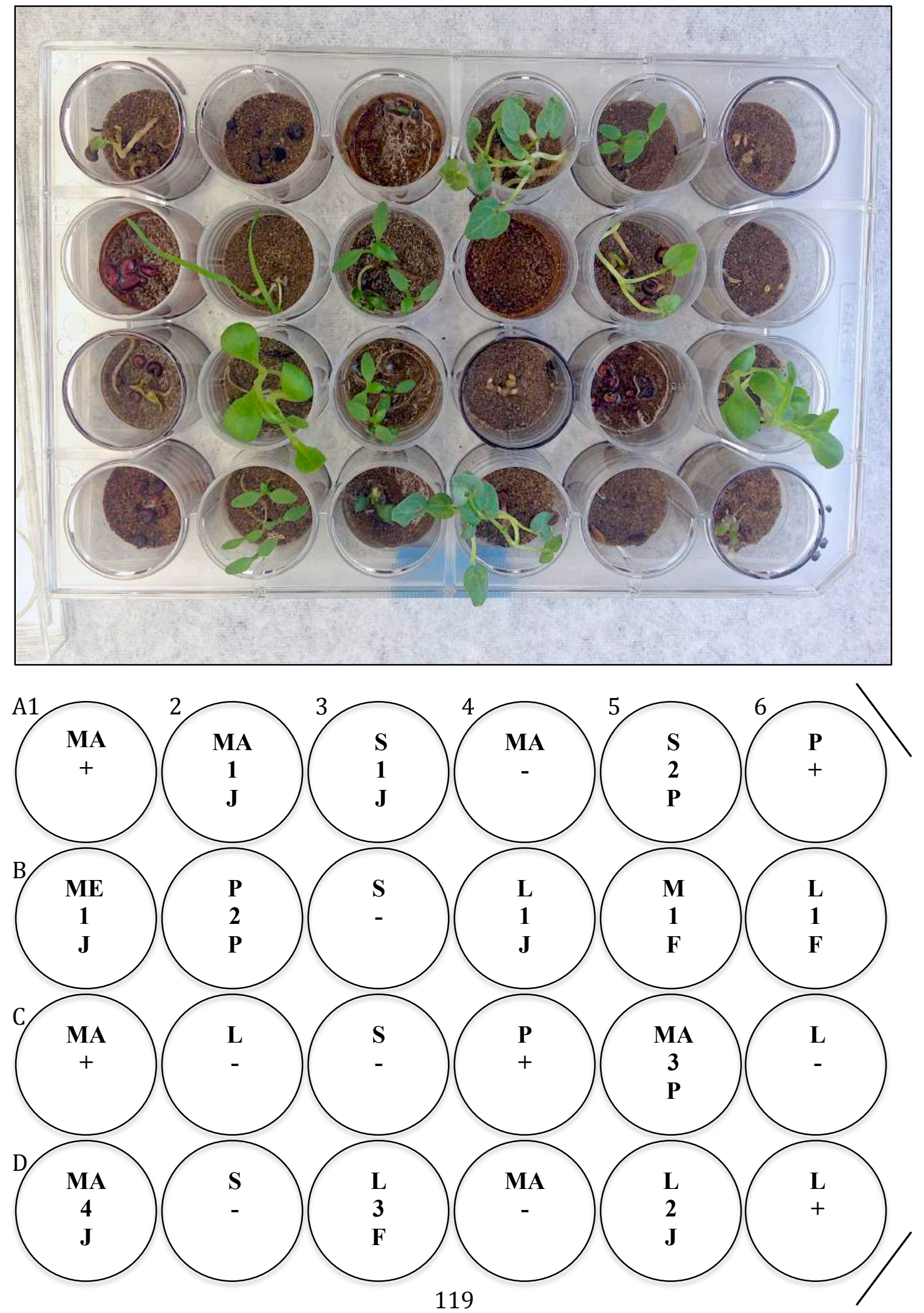
Tables 1-3. 24-well plate treatment keys. We used templates (like that shown on the bottom of the previous page) with these codes to randomly assign 1440 treatments to 60, 24-well plates.

\begin{tabular}{|l|c|}
\hline Species & Letter Code \\
\hline Lactuca sativa 'Inferno' & $\mathrm{L}$ \\
\hline Malva parviflora & $\mathrm{MA}$ \\
\hline Melilotus officinalis & $\mathrm{ME}$ \\
\hline Poa annua & $\mathrm{P}$ \\
\hline Senecio vulgaris & $\mathrm{S}$ \\
\hline
\end{tabular}

\begin{tabular}{|l|c|}
\hline Rate & Number Code \\
\hline Low & 1 \\
\hline Medium-low & 2 \\
\hline Medium-high & 3 \\
\hline High & 4 \\
\hline
\end{tabular}

\begin{tabular}{|l|c|}
\hline Compound & Letter Code \\
\hline Ferulic acid & F \\
\hline Gallic acid & G \\
\hline Juglone & J \\
\hline p-Coumaric acid & P \\
\hline Water Control & - \\
\hline Herbicide Control & + \\
\hline
\end{tabular}


F. In soil 11 Day seedling length results for all plant species. There were four rates for each plant compound (parts per million by weight (ppmw). The averages (below) include zero seedling length values.

\begin{tabular}{|c|c|c|c|c|c|c|}
\hline Compound & $\begin{array}{c}\text { Rate } \\
(\mathbf{p p m w})\end{array}$ & $\begin{array}{l}\text { Lactuca sativa } \\
\text { 'Inferno' }\end{array}$ & $\begin{array}{c}\text { Malva } \\
\text { parviflora }\end{array}$ & $\begin{array}{l}\text { Melilotus } \\
\text { officinalis }\end{array}$ & Роа аппиа & $\begin{array}{l}\text { Senecio } \\
\text { vulgaris }\end{array}$ \\
\hline Herbicide Control & $\mathrm{n} / \mathrm{a}$ & 14.85 & 16.58 & 11.74 & 0 & 5.12 \\
\hline Water Control & $\mathrm{n} / \mathrm{a}$ & 66.89 & 46.59 & 44.50 & 60.66 & 37.61 \\
\hline \multirow{4}{*}{ Ferulic Acid } & 1000 & 18.65 & 7.08 & 11.81 & 20.92 & 6.13 \\
\hline & 1778 & 3.35 & 4.64 & 0.97 & 7.06 & 4.39 \\
\hline & 3162 & 7.17 & 7.77 & 6.92 & 15.70 & 6.75 \\
\hline & 5623 & 0.73 & 0.71 & 0 & 0.75 & 1.83 \\
\hline \multirow{4}{*}{ Gallic Acid } & 3162 & 21.22 & 33.14 & 14.71 & 27.52 & 9.63 \\
\hline & 5623 & 12.47 & 21.05 & 4.54 & 3.94 & 4.65 \\
\hline & 10000 & 0 & 10.92 & 0 & 0 & 0.08 \\
\hline & 17783 & 0 & 1.33 & 1.08 & 0 & 0 \\
\hline \multirow{4}{*}{ Juglone } & 562 & 3.21 & 0 & 0 & 12.85 & 3.77 \\
\hline & 1000 & 0.33 & 0 & 0 & 1.96 & 0.67 \\
\hline & 1778 & 0 & 0 & 0 & 0 & 0.42 \\
\hline & 3162 & 0 & 0 & 0 & 0 & 0.25 \\
\hline \multirow{4}{*}{ p-Coumaric Acid } & 100 & 65.86 & 38.04 & 45.56 & 62.36 & 36.97 \\
\hline & 316 & 63.50 & 35.83 & 36.77 & 51.77 & 38.46 \\
\hline & 1000 & 3.17 & 7.18 & 0 & 1.00 & 0.36 \\
\hline & 3162 & 0 & 13.92 & 0 & 4.42 & 4.71 \\
\hline
\end{tabular}




\section{G. Description of Nonlinear Regression Parameters}

To determine $\mathrm{EC}_{50}$ values (the half-maximal response) for each combination of pest species and compound we fit either logistic, or Gompertz functions to the data. Both functions are biologically relevant (Seefeldt et al., 1995). The upper asymptote of a sigmoidal curve models the fact that a small enough dose of a growth-limiting substance has or no inhibitory little effect. As dose increases, a compound with antagonistic activity reaches an inhibitory concentration. From this dose onward, increasing concentrations reduce the organism's growth or function to a greater and greater extent (the sloped part of the sigmoidal shape) until reaching a lower asymptote (often complete inhibition or death). The two equations take the following forms:

Logistic 4P: $y=d+\frac{c-d}{1+\operatorname{Exp}[-a *(x-b)]}$

Gompertz 4P: $y=d+(c-d) * \operatorname{Exp}[-\operatorname{Exp}(-a *(x-b))]$

The "a" parameter is the slope of the curve at the inflection point, the "b" parameter is the inflection point, the "c" parameter is the upper asymptote, and the " $\mathrm{d}$ " parameter is the lower asymptote. The Gompertz curve is sigmoidal, like the logistic curve, but is asymmetric around the inflection point. We can simplify the logistic or Gompertz curves by constraining parameters. For instance, frequently the growth rate (Hillslope) is 1 if the response variable is inhibition, or -1 if the response variable is growth (Motulsky and Christopoulos, 2003). It is also often appropriate to constrain the upper asymptote to the negative control average and the lower asymptote to zero for a growth response variable, and visa versa for an inhibition response variable (Motulsky and Christopoulos, 2003). 